\title{
Catálogo de los especímenes tipo de la Colección Herpetológica de la Fundación Miguel Lillo, Tucumán, Argentina
}

\author{
Catalog of Type Specimens of the Herpetological Collection of the \\ Fundación Miguel Lillo, Tucumán, Argentina
}

\author{
Gustavo J. Scrocchi ${ }^{1,2}$; Sonia Kretzschmar ${ }^{1}$ \\ 1 Instituto de Herpetología. Fundación Miguel Lillo (FML), Miguel Lillo 251, (T4000JFE) San Miguel de \\ Tucumán, Tucumán, Argentina. Correspondencia: gustavo.scrocchi@gmail.com \\ 2 Unidad Ejecutora Lillo (UEL-FML-CONICET), Fundación Miguel Lillo (FML) y Consejo Nacional de Inves- \\ tigaciones Científicas y Técnicas (CONICET), Miguel Lillo 251, (T4000JFE) San Miguel de Tucumán,
}

> Resumen - Se proveen los datos de todos los ejemplares depositados en la Colección Herpetológica de la Fundación Miguel Lillo, que revisten alguna categoría de "Tipo" de acuerdo al Código Internacional de Nomenclatura Zoológica (International Trust for Zoological Nomenclature, 1999). Se brindan todos los datos de los ejemplares en forma exhaustiva y se mencionan las discrepancias entre los datos que presentan en colección y los que fueron publicados en la descripción original. También se aclara el estatus actual del taxón.

Palabras clave: Anfibios, reptiles.

> Abstract - "Catalog of Type Specimens of the Herpetological Collection of the Fundación Miguel Lillo, Tucumán, Argentina". Full registration data for all type series which have a category of "Type" according to the International Code of Zoological Nomenclature (International Trust for Zoological Nomenclature, 1999), deposited in the Fundación Miguel Lillo Herpetological Collection are presented. The data of these specimens are given in exhaustive form and the discrepancies between the registration data and those published in the original description are mentioned. The current status of the taxa are also clarified.

Keywords: Amphibians, reptiles.

\section{INTRODUCCIÓN}

Nuestra colección herpetológica comenzó con los ejemplares que pertenecían a la colección personal de Miguel Lillo, cuya donación dio origen a la Fundación que lleva su nombre en 1931. Actualmente alberga aproximadamente 100.000 ejemplares, constituyéndose cuantitativamente en la segunda colección herpetológica de importancia en el país.

El primer investigador en trabajar en la colección (1943-1948), fue Jean Vellard, médico y biólogo de origen francés, especializado en etnobiología, quien estudió principalmente anfibios andinos y se interesó por venenos de arácnidos y serpientes, siendo el

Recibido: 23/10/17 - Aceptado: 12/11/17 primero en mencionar el efecto de la crotoxina sobre las células cancerígenas.

En 1947 arribó a Tucumán, y permaneció hasta 1955, José Miguel Cei, biólogo italiano naturalizado argentino y uno de los más conocidos herpetólogos del país, que escribió cientos de trabajos sobre la herpetofauna de Argentina y Chile. Desde su partida y hasta 1964, la colección permaneció prácticamente cerrada, debido a que no había herpetólogos en la Fundación Miguel Lillo. Durante esos años se perdieron algunos especímenes de la colección y, entre ellos, el tipo de Leptodactylus chaquensis descrito por Cei (1950).

En 1964 llegó a Tucumán Raymond F. Laurent, herpetólogo belga que fue Director del Instituto de Herpetología de la Fundación Miguel Lillo hasta su jubilación en 
1996. A su llegada a nuestro país, añadió a sus investigaciones sobre herpetofauna africana, el estudio de anfibios y reptiles sudamericanos, trabajando especialmente con Telmatobius, Gastrotheca y Liolaemus. Laurent impulsó la herpetología argentina e influenció en varias generaciones de estudiantes. Bajo su dirección el Instituto de Herpetología creció y desde ese momento y hasta hoy, decenas de investigadores y becarios trabajaron y trabajan en él. Debido al trabajo de todas estas personas, la colección mantiene un crecimiento constante hasta nuestros días. Esteban Lavilla, especialista en anfibios y uno de los primeros estudiantes argentinos de Laurent, es actualmente el Director del Instituto.

El primer catálogo de especímenes tipo de las colecciones de vertebrados de la Fundación Miguel Lillo fue publicado por el entomólogo K. Hayward (1963) y en él se listan nueve tipos herpetológicos. Posteriormente fueron publicados catálogos de otros grupos taxonómicos (Aranda et al. 2016; Colomo y Berta 2005 a,b; Hayward, 1964); pero sobre herpetología, el de Hayward (1963) continúa siendo el único. Creemos necesario actualizar la información sobre los cientos de tipos depositados en la colección durante los 54 años pasados desde aquel trabajo y cumplir de este modo con la Recomendación $72 \mathrm{~F}$ del Código Internacional de Nomenclatura Zoológica (International Trust for Zoological Nomenclature, 1999) que en su apartado 72F.4., encomienda publicar listas de los tipos portadores de nombre en posesión o custodia de las Instituciones.

\section{MÉTODOS}

Los datos que se incluyen son los que efectivamente se encuentran en la colección y en los registros de la misma. Se presentan de la siguiente forma:

- Designación binominal original Autor, año.

- Cita completa del trabajo donde se realizó la descripción original.

- Tipo: se mencionan los siguientes tipos, de acuerdo al Código
- Holotipo: ejemplar único sobre el que se basa un nuevo taxón nominal de nivel especie en la publicación original.

- Sintipos: cada ejemplar de una serie tipo de la cual no se ha designado ni holotipo ni lectotipo [Arts. 72.1.2, 73.2, 74]. Se utilizaba antiguamente el término cotipo, que no es aceptado por el Código actualmente; aclaramos esta situación en los pocos casos que esto ocurre.

- Neotipo: ejemplar único designado como tipo portanombre de una especie o subespecie nominal cuando hay necesidad de definir el taxón nominal objetivamente y no se cree que exista tipo portanombre.

- Paratipo: cada ejemplar de una serie tipo que no sea el holotipo.

- Alotipo: término no regulado por el Código, es un ejemplar designado del sexo opuesto al del holotipo. Sólo se mencionan como tales los pocos ejemplares así nombrados en los trabajos originales y que deben considerarse paratipos.

- Número de colección.

- Cantidad de ejemplares presentes en la colección.

- Acrónimo y número original, cuando los ejemplares fueron obtenidos por canje o donación de otros Museos.

- Número de campo cuando existe.

- Localidad, presentada en el orden: Localidad. Departamento. Provincia. País. Coordenadas geográficas y altitud, cuando fueron mencionadas en la publicación original.

- Coleccionistas. Se mencionan a continuación de los datos anteriores.

- Fecha de colección.

- Comentarios. Incluimos el nombre actualmente en uso y, en caso necesario, el sinónimo válido. Se discuten las discrepancias entre los datos publicados y los datos de la colección. En los casos que se donaron o intercambiaron paratipos con otras colecciones, incluimos el acrónimo y número actual de los ejemplares, siempre que pudimos localizarlos.

Los acrónimos de las colecciones mencionadas en el texto son:

- AC: Colección herpetológica. Cátedra 
de Anatomía Comparada. Facultad de Ciencias Exactas, Físicas y Naturales, Universidad Nacional de Córdoba. Córdoba. Argentina.

- CBF: Colección Boliviana de Fauna. Museo Nacional de Historia Natural. La Paz. Bolivia.

- CEUCH: Coleção Zoológica de Referência. Seção de Herpetologia. Universidade Federal do Mato Grosso do Sul, Campus de Corumbá. Corumbá. Mato Grosso do Sul. Brasil.

- CWW: Colección de Wolfgang K. Weyrauch, malacólogo alemán que trabajó en Tucumán desde 1962 hasta su fallecimiento en 1970.

- IBA: Instituto de Biología Animal, Facultad de Ciencias Agrarias, Universidad Nacional de Cuyo, Mendoza, Argentina.

- ICN: Colección Batracológica del Instituto de Ciencias Naturales. Museo de Historia Natural. Universidad Nacional de Colombia. Bogotá. Colombia.

- IMCN-UNSJ: Colección Herpetológica del Instituto y Museo de Ciencias Naturales de la Universidad Nacional de San Juan, San Juan, Argentina.

- KUH: Kansas University Museum of Natural History. Lawrence. Kansas. USA

- LACM: Natural History Museum of Los Angeles County, Section of Herpetology, Los Angeles, California, USA.

- LSUMZ: Louisiana State University Museum of Zoology. Baton Rouge, Louisiana, USA. Actualmente Louisiana State University Museum of Natural Science y el nuevo acrónimo: LSU.

- MACN: Museo Argentino de Ciencias Naturales «Bernardino Rivadavia». Buenos Aires. Argentina.

- MCN: Museo de Ciencias Naturales, Universidad Nacional de Salta. Salta. Argentina.

- MCZ: Museum of Comparative Zoology. Harvard University. Cambridge, Massachusetts. USA.

- MFA: Museo Provincial de Ciencias Naturales Florentino Ameghino. Santa Fe. Argentina.

- MHNG: Muséum d'Histoire naturelle. Ginebra. Suiza.
- MNHN: Museo Nacional de Historia Natural. Montevideo. Uruguay

- MNRJ: Museu Nacional do Rio de Janeiro. Rio de Janeiro. Brasil.

- MZUC: Museo de Zoologia, Universidad de Concepción, Chile.

- MZUSP: Museu de Zoologia, Universidade de São Paulo, São Paulo, Brasil.

- REB: Colección Herpetológica de la Reserva Ecológica El Bagual. Departamento Laishí. Formosa. Argentina.

- UNMdP: Laboratorio Vertebrados. Instituto de Investigaciones Marinas y Costeras. Facultad de ciencias Exactas y Naturales. CONICET-Universidad Nacional de Mar del Plata. Argentina.

- UNNEC: Colección Herpetológica de la Universidad Nacional del Nordeste. Corrientes. Argentina.

- UNRC-DCN-ZV: Cátedra de Zoología de Vertebrados. Departamento de Ciencias Naturales. Universidad Nacional de Río Cuarto. Río Cuarto. Córdoba. Argentina.

\section{RESULTADOS}

\section{AmPHibia. BATRACHIA. ANURA FAMILIA ARTHROLEPTIDAE Arthroleptis pyrrhoscelis Laurent, 1952}

Laurent R. F. 1952. Reptiles et batraciens nouveaux du massif du mont Kabobo et du plateau des Marungu. Revue de Zoologie et de Botanique Africaines 46: 18-34.

Paratipos FML 03149 (6 machos, 9 hembras). Alto Lubitshako, Terr. de Fizi, Kivu, República Democrática del Congo. 1.9002.000 msnm. R. F. Laurent. 26-30 octubre 1950.

Comentarios. - Coleccionados originalmente en «Belgian Congo», actual República Democrática del Congo. Los especímenes depositados en nuestra colección formaban parte de una serie de 18 machos y 185 hembras no etiquetados separadamente en la descripción original y recibidos en canje posteriormente. 


\section{Schoutedenella globosa pasteelsi} Laurent, 1954

Laurent R. F. 1954. Remarques sur le genre Schoutedenella. Annales du Musée Royal du Congo Belge. Nouvelle Série in $4^{\circ}$ Sciences Zoologiques. Tervuren 1: 34-40.

Paratipo FML 03091 (hembra). Kipoyo, Terr. de Fizi. Kivu. República Democrática del Congo. 700 msnm. R. F. Laurent. 9-11 octubre 1950.

Comentarios. - Actualmente considerado sinónimo junior de Arthroleptis xenochirus Boulenger, 1905, según Poynton y Broadley (1985). Coleccionados originalmente en «Belgian Congo», actual República Democrática del Congo. Los especímenes depositados en nuestra colección formaban parte de una serie de 1 macho y 6 hembras no etiquetados separadamente en la descripción original y recibidos en canje posteriormente.

\section{FAMILIA BATRACHYLIDAE \\ Atelognathus salai Cei, 1984}

Cei J. M. 1984. A new leptodactylid frog, genus Atelognathus, from southern Patagonia, Argentina. Herpetologica 40: 47-51.

Paratipos FML 03257 (hembra) y FML 03258-03260 (juveniles). Andean slopes facing Mount Ap Iwan. $16 \mathrm{~km}$ South of Portezuelo, Northern border of Lago Buenos Aires. Departamento Lago Buenos Aires. San-

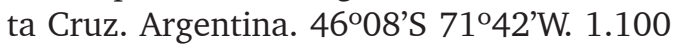
msnm. J. M. Cei, S. S. de Cei, y J. Olazábal. 19 marzo 1982.

\section{FAMILIA BUFONIDAE \\ Atelopus moreirae \\ Miranda-Ribeiro, 1920}

Miranda-Ribeiro A. de. 1920. Os Brachycephalideos do Museu Paulista (com tres especes novas). Revista do Museu Paulista 12: 307-316.
Paratipo FML 02369. No original 501. Retiro. Itatiaia. Rio de Janeiro. Brasil. C. Moreira. 04 julio 1902.

Comentarios. - Actualmente Melanophryniscus moreirae (Miranda-Ribeiro, 1920), según Gallardo (1961). Ejemplar obtenido por intercambio con Dr. Antenor Leitão de Carvalho.

\section{Atelopus rubriventris Vellard, 1947}

Vellard J. 1947. Un nuevo batracio del Norte Argentino. Acta zoologica lilloana 4: 115-119.

Holotipo FML 00173. San Andrés. Departamento Orán. Salta. Argentina. 1800-2.000 msnm. S. Pierotti. Febrero 1945.

Comentarios. - Actualmente Melanophryniscus rubriventris (Vellard, 1947) según McDiamid (1972). El holotipo fue mencionado con el número 173/1 en la descripción original y también por Hayward (1963), y Lavilla (1993). Los «cotipos» mencionados como 173/2 y 173/3 en la descripción original, no pudieron localizarse.

\section{Bufo gallardoi Carrizo, 1992}

Carrizo G. R. 1992. Cuatro especies nuevas de anuros (Bufonidae: Bufo e Hylidae: Hyla) del norte de la Argentina. Cuadernos de Herpetología 7: 14-23.

Paratipo FML 01732. Abra Colorada, a 1,5 km de Abra de Cañas. Departamento Valle Grande. Jujuy. Argentina. J. M. Gómez. 10 mayo 1971.

Paratipos FML 02118/1-20 (20 ejemplares). Abra de Cañas. Departamento Valle Grande. Jujuy. Argentina. 1.707 msnm. O.Budin y T. Fasola. 08-17 diciembre 1972.

Comentarios. - Actualmente Rhinella gallardoi (Carrizo, 1992), según Chaparro et al. (2007). Los datos presentados acá son los originales y difieren de los publicados por Carrizo (1992). Además, los especímenes citados por Carrizo (op. cit.) como FML 0211819 son realmente 19 especímenes que llevan los números FML 02118/1-19 y el ejemplar 
citado como FML 02120 (esqueleto), es en realidad FML 02118/20.

\section{Bufo rumbolli \\ Carrizo, 1992}

Carrizo G. R. 1992. Cuatro especies nuevas de anuros (Bufonidae: Bufo e Hylidae: Hyla) del norte de la Argentina. Cuadernos de Herpetología 7: 14-23.

Paratipos FML 04680 (2 ejemplares). Abra de Cañas. Departamento Valle Grande. Jujuy. Argentina. 1.707 msnm. O. Budin y T. Fasola. 08-17 diciembre 1972.

Paratipo FML 04681. Abra Colorada, a 1,5 km de Abra de Cañas. Departamento Valle Grande. Jujuy. Argentina. J. M. Gómez. 10 mayo 1971.

Comentarios. - Actualmente Rhinella rumbolli (Carrizo, 1992). Los datos presentados acá son los originales y difieren de los publicados por Carrizo (1992), quien dice: «FML 04680. Abra de Cañas, V. Grande, Jujuy. 1700 m. 12/12/72. Col: Fasola. FML 04681. Abra Colorada, V. Grande, Jujuy. 12/6/71. Col.: J.Gómez.»

\section{Melanophryniscus klappenbachi Prigioni y Langone, 2000}

Prigioni C. M., Langone J. A. 2000. Una nueva especie de Melanophryniscus Gallardo, 1961, de Argentina y Paraguay (Amphibia, Anura, Bufonidae). Comunicaciones Zoológicas del Museo Nacional de Historia Natural de Montevideo 195 (12): 1-12.

Paratipo FML 22656 (macho). No original MNHN 04166. Ruta Nacional 11. Arroyo Palometa. Departamento San Fernando. Chaco. Argentina. $27^{\circ} 43^{\prime} 02,2^{\prime \prime} S 59^{\circ} 13 ' 57,9^{\prime \prime W}$. C. Carbonell et al. 26 febrero 1965.

Comentarios. - Baldo (2001), corrigió los datos publicados originalmente y añadió las coordenadas de la localidad.

\section{Melanophryniscus krauczuki Baldo y Basso, 2004}

Baldo D., Basso N. G. 2004. A new species of Melanophryniscus Gallardo, 1961 (Anura:
Bufonidae), with comments on the species reported for Misiones, Northeastern Argentina. Journal of Herpetology 38: 393-403.

Paratipos FML 10124 - FML 10125 (machos). No de campo DB 977-978. Ruta Provincial 3, a 3,5 km al SE de intersección con Ruta Nacional 12. Departamento Candelaria. Misiones. Argentina. 27 29'26,5”S 55³9'58,3"W. 165 msnm. R. Almada y E. Krauczuk. 17 abril 2000.

\section{Melanophryniscus rubriventris subconcolor \\ Laurent, 1973}

Laurent R. F. 1973. Variación geográfica de Melanophryniscus rubriventris (Vellard). Acta zoologica lilloana 26: 317-336.

Holotipo FML 01704 (hembra). El Duraznito, a $8 \mathrm{~km}$ de Tiraxi. Departamento Dr. Manuel Belgrano. Jujuy. Argentina. 1.600 msnm. R. F. Laurent. 09-12 diciembre 1970.

Alotipo FML 01705 (macho). Los mismos datos que el holotipo.

Paratipos FML 01477. Los mismos datos que el holotipo.

Paratipos FML 01520 (13 machos, 3 hembras). Cerro Labrado. Al N de Capillas. Departamento Capital. Jujuy. Argentina. 1.500 msnm. R. F. Laurent. 06-07 diciembre 1969.

Comentarios. - Actualmente considerado sinónimo junior de Melanophryniscus rubriventris (Vellard, 1947), de acuerdo a los datos de Vaira (2002), y Ferrari y Vaira (2008). El lote FML 01477 tenía originalmente 116 ejemplares, no 108 como figura en Laurent (1973). De ellos, dos están teñidos y transparentados; dos fueron donados al Museu Capão da Imbuia, Curitiba, Paraná, Brasil, y dos al Museo Nacional de Historia Natural, Montevideo, Uruguay; estos últimos 4 ejemplares permanecen sin numerar en la colección de herpetología de la referida institución (J. A. Langone, com. pers.) El ejemplar FML 01520/1 está teñido y transparentado. Frost (2016), menciona por error: «Holotype: FML 01903, by original designation. Type locality: Abra de la Sierra, Prov. de Salta, Argentina». El número y la localidad del holotipo son los 
mencionados acá (ver también Lavilla 1993). Los ejemplares FML 01903 (7 machos) no pertenecen a la serie tipo y son únicamente una «addenda» de Laurent (1973).

\section{Melanophryniscus rubriventris toldosensis Laurent, 1973}

Laurent R. F. 1973. Variación geográfica de Melanophryniscus rubriventris (Vellard). Acta zoologica lilloana 26: 317-336.

Holotipo FML 01706 (hembra). Los Toldos. Departamento Santa Victoria. Salta. Argentina. J. M. Gómez. 01-20 febrero 1960.

Alotipo FML 01707 (macho). Los mismos datos que el holotipo.

Paratipos FML 00816 (9 machos, 10 hembras, 1 juvenil). Los mismos datos que el holotipo.

Comentarios. - Actualmente considerado sinónimo de Melanophryniscus rubriventris (Vellard, 1947), de acuerdo a Vaira (2002), y Ferrari y Vaira (2008). Holotipo fue mencionado por Lavilla (1993). Los ejemplares FML 00816/1 y 00816/2 están teñidos y transparentados.

\section{Rhinella bernardoi \\ Sanabria, Quiroga, Arias y Cortez, 2010}

Sanabria E. A., Quiroga L. B., Arias F., Cortez. O. 2010. A new species of Rhinella (Anura: Bufonidae) from Ischigualasto Provincial Park, San Juan, Argentina. Zootaxa 2396: 50-60.

Holotipo FML 18400 (macho). Parque Provincial Ischigualasto. Departamento Valle Fértil. San Juan. Argentina. 30¹0'9"S 6748'37'W. 1.400 msnm. F. Cano, L. Quiroga, V. Orozco, R. López y E. Sanabria. 24 enero 2006.

\section{FAMILIA CERATOPHRYIDAE}

Ceratophrys pierottii Vellard, 1948

Vellard J. 1948. Batracios del chaco argentino. Acta zoologica lilloana 5 (1948): 137-174.
Paratipos FML 00391 (21 ejemplares). Hickman. Departamento General San Martín. Salta. Argentina. S. A. Pierotti. 28 enero 1947.

Paratipos FML 00392 (18 ejemplares). La Matanza. Hickman. Departamento General San Martín. Salta. Argentina. S. A. Pierotti. 28 enero 1947.

Paratipos FML 00413 (13 ejemplares). Hickman. Departamento General San Martín. Salta. Argentina. S. A. Pierotti. 29 enero 1947.

Comentarios. - Actualmente Chacophrys pierottii (ver Reig y Limeses 1963). Los ejemplares fueron mencionados como «cotipos» en la descripción original. El Tipo (FML 428/1, mencionado como IML por Vellard 1948) está perdido, ver Lavilla (1993). En la colección existen dos ejemplares en el lote FML 00428, que no son los ejemplares descritos por Vellard (1948). Debido a un error, Hayward (1963) solo menciona dos «cotipos».

\section{FAMILIA CRAUGASTORIDAE}

Oreobates barituensis Vaira y Ferrari, 2008

Vaira M., Ferrari L. 2008. A new species of Oreobates (Anura: Strabomantidae) from the Andes of northern Argentina. Zootaxa 1908: 41-50.

Holotipo FML 21079 (macho). No de campo MV 268. Baritú. Departamento Santa Victoria. Salta. Argentina. 22²9'58,53"S $64^{\circ} 45^{\prime} 40,83^{\prime \prime}$ W. 1.100 msnm. M. Vaira. 25 octubre 2001.

Paratipos FML 21077 - FML 21078 (machos) y FML 21080 (hembra). No de campo MV 255-256 y 269, respectivamente. Los mismos datos que el holotipo.

Paratipos FML 24669 - FML 24671 (machos). No de campo MV 238-240. Baritú. Departamento Santa Victoria. Salta. Argentina. $22^{\circ} 29^{\prime} 58,53^{\prime \prime S ~ 64045 ' 40,83 ” W . ~} 1.100$ msnm. M. Vaira. 02 diciembre 2000.

Paratipos FML 24672 - FML 24675 (machos). No de campo MV 410-413. Arazay. Departamento Santa Victoria. Salta. Argentina. 
22019'00"S 6442'59,9”W. 1.300 msnm. M. Vaira. 21 noviembre 2007.

Paratipos FML 24676 - FML 24682 (machos). $\mathrm{N}^{\circ}$ de campo MV 414-416; 418-419 y dos ejemplares sin número. Lipeo. Departamento Santa Victoria. Salta. Argentina. $22^{\circ} 25^{\prime} 52,56$ "S 6444'7,17'W. 1.300 msnm. M. Vaira. 23 noviembre 2007.

Comentarios. - En la descripción original, fueron citados ocho ejemplares (MV 414-421) utilizando el $\mathrm{N}^{\circ}$ de campo, y sólo siete ejemplares fueron entregados a la colección en fecha posterior. De ellos, los paratipos FML 24676 - FML 24678 llevaban las etiquetas MV414-416 y los paratipos FML 24679-24680 las etiquetas MV418-419; los paratipos FML 24681 - FML 24682 no tenían etiquetas de campo. El paratipo FML 24676 está teñido y transparentado.

Oreobates berdemenos

Pereyra, Cardozo, Baldo y Baldo, 2014

Pereyra M. O., Cardozo D. E., Baldo J., Baldo D. 2014. Description and phylogenetic position of a new species of Oreobates (Anura: Craugastoridae) from Northwestern Argentina. Herpetologica 70: 211-227.

Paratipos FML 24621 - FML 24626 (3 machos 2 hembras). No de campo GS 3475 3478, 3480-81. Abra Colorada. Departamento Ledesma. Jujuy. Argentina. 2340'28,7'S 645'18,2”W. 1.667 msnm. D. Baldo y J. Baldo. 19-20 febrero 2012.

\section{FAMILIA DENDROBATIDAE}

\section{Minyobates virolinensis \\ Ruiz Carranza y Ramírez Pinilla, 1992}

Ruiz-Carranza P. M., Ramírez-Pinilla M. P. 1992. Una nueva especie de Minyobates (Anura: Dendrobatidae) de Colombia. Lozania 61: 1-16.

Paratipo FML 05036 (macho). No original ICN 16113. Vereda «El Reloj», Virolín (= Inspección de Policía de Cañaverales). Municipio de Charalá. Departamento de Santander. Colombia. 6²' $13^{\prime} 7^{\circ} 05^{\prime}$ W. 1.750 msnm. P.
M. Ruiz-Carranza, G. de Pérez y M. P Ramirez-Pinilla. 24 octubre 1986.

Comentarios. - Actualmente Andinobates virolinensis (Ruiz-Carranza y Ramírez-Pinilla, 1992), de acuerdo a Twomey et al. in Brown et al. (2011). El ejemplar fue mencionado en la descripción original con el acrónimo y número ICN y posteriormente recibido en nuestra colección por intercambio.

\section{FAMILIA HEMIPHRACTIDAE \\ Gastrotheca chrysosticta Laurent, 1976}

Laurent R. F. 1976. Nuevas notas sobre el género Gastrotheca Fitzinger. Acta zoologica lilloana 32: 31-66.

Holotipo FML 02098 (macho). Palca de San Martín. Serranía del Porongal. Departamento Santa Victoria. Salta. Argentina. 1.530 msnm. J. M. Gómez. 21 setiembre 1972.

Comentarios. - Holotipo citado por Lavilla (1993).

\section{Gastrotheca christiani Laurent, 1967}

Laurent R. F. 1968 (1967). Descubrimiento del género Gastrotheca Fitzinger en Argentina. Acta zoologica lilloana 22: 353-354.

Holotipo FML 00482 (hembra). Abra de Cañas. Parque Nacional Calilegua. Departamento Valle Grande. Jujuy. Argentina. C. Halloy. 04-09 noviembre 1967.

Paratipos FML 01021 (2 hembras y 2 juveniles). Los mismos datos que el holotipo. R. F. Laurent y C. Halloy.

Comentarios. - Lavilla y Kretzschmar (1998) aclararon el número del holotipo y la localidad tipo de esta especie y de Telmatobius barrioi. Holotipo citado por Lavilla (1993).

\section{Gastrotheca excubitor \\ Duellman y Fritts, 1972}

Duellman W. E., Fritts T. H. 1972. A taxonomic review of the southern Andean marsupial frogs (Hylidae: Gastrotheca). Occasional 
Papers of the Museum of Natural History, University of Kansas 9: 1-37.

Paratipo FML 02014. No de campo WED 038314. Crest of Abra Acanacu. Departamento Cuzco. Perú. 3.520 msnm. W. Duellman y H. Fritts. 16 enero 1971.

Comentarios. - Mencionado como IML 2014 en la descripción original.

\section{Gastrotheca gracilis Laurent, 1969}

Laurent R. F. 1969. Una segunda especie del género Gastrotheca Fitzinger en Argentina. Acta zoologica lilloana 25: 143-150.

Holotipo FML 01389 (hembra). La Banderita. Km 51 de la ruta Concepción-Andalgalá. Catamarca. Argentina. $1.900 \mathrm{msnm}$. R. Cei. 07 diciembre 1968.

Comentarios. - El ejemplar está acompañado por sus embriones. Holotipo citado por Lavilla (1993).

\section{Gastrotheca ochoai}

Duellman y Fritts, 1972

Duellman W. E., Fritts T. H. 1972. A taxonomic review of the Southern Andean marsupial frogs (Hylidae: Gastrotheca). Occasional Papers of the Museum of Natural History, University of Kansas 9: 1-37.

Paratipo FML 02012. No de campo WED 038304. SW base of Cordillera de Vilcanota. $\mathrm{W}$ of río Runtumayo, about $3 \mathrm{~km} \mathrm{~N}$ of Chilca, $10 \mathrm{~km}$ (by road) NW of Ollantaytambo. Departamento Cuzco. Perú. 2.760 msnm. W. Duellman y H Fritts. 09 enero 1971.

Comentarios. - Mencionado como IML 2012 en la descripción original.

\section{FAMILIA HYLIDAE \\ Hyla marianitae \\ Carrizo, 1992}

Carrizo G. R. 1992. Cuatro especies nuevas de anuros (Bufonidae: Bufo e Hylidae: Hyla) del norte de la Argentina. Cuadernos de Herpetología 7: 14-23.
Paratipo FML 02920 (macho adulto). Quebrada La Palca. Baritú. Departamento Santa Victoria. Salta. Argentina. O. Pagaburo y E. Terán. 13 setiembre 1981.

Comentarios. - Actualmente Boana marianitae (Carrizo, 1992), de acuerdo a Dubois (2017).

$$
\begin{gathered}
\text { Hyla mixomaculata } \\
\text { Taylor, } 1950
\end{gathered}
$$

Taylor E. H. 1950. A new bromeliad frog from the Mexican state of Veracruz. Copeia 1950 (4): 274-276.

Paratipo FML 09481. No original KU 26785. No de campo WWD 11101. Coscomatepec. Veracruz. México. $5000 \mathrm{ft}$. W. W. Dalquest. 01 diciembre 1948.

Comentarios. - Actualmente Megastomatohyla mixomaculata (Taylor, 1950) de acuerdo a Faivovich et al. (2005). Ejemplar citado en la descripción original con el acrónimo y número KU y recibido posteriormente por intercambio.

\section{Hyla raddiana andina Müller, 1924}

Müller L. 1924. Ueber neue oder seltene Mittel und südamerikanische Amphibien und Reptilien. Mitteilungen aus dem Zoologischen Museum in Berlin 11: 75-93.

Neotipo FML 11174 (macho). Caspinchango. Departamento Santa María. Catamarca. $27^{\circ} 04^{\prime} S 65^{\circ} 30^{\prime}$ W. E. O. Lavilla y D. Casagranda. 10 enero 2002.

Comentarios. - Neotipo designado por Langone y Lavilla (2002). Actualmente considerado sinónimo junior de Hyla riojana Koslowsky, 1895 de acuerdo a Köhler et al. (2010), hoy reconocida en la combinación Boana riojana (Dubois, 2017).

\section{FAMILIA HYPEROLIIDAE}

Hyperolius lateralis bururiensis Laurent, 1950

Laurent R. 1950. Diagnoses préliminaires de treize batraciens nouveaux d'Afrique 
centrale. Revue de Zoologie et de Botanique Africaines 44: 1-18.

Paratipos FML 03111 (15 ejemplares). Bururi. Burundi. 1.850-1.950 msnm. R. F. Laurent. 21-24 diciembre 1949.

Comentarios: los ejemplares formaban parte de un lote de 175 paratipos en la descripción original. Actualmente considerado sinónimo de Hyperolius lateralis Laurent, 1940, de acuerdo a Schiøtz (1999).

\section{Hyperolius platyceps olbrechtsi Laurent, 1952}

Laurent R. F. 1952. Reptiles et batraciens nouveaux de la région des Grands Lacs africains. Revue de Zoologie et de Botanique Africaines 46: 269-279.

Paratipos FML 03118 (9 machos, 1 hembra). Makungu. Limite des territoires d' Albertville et de Fizi. Kivu. República Democrática del Congo. 950 msnm. R. F. Laurent. 19-21 diciembre 1950.

Comentarios. - Coleccionados originalmente en «Belgian Congo», los ejemplares formaban parte de un lote de 200 paratipos en la descripción original.

\section{Hyperolius robustus Laurent, 1979}

Laurent R. F. 1979. Description de deux Hyperolius nouveaux du Sankuru (Zaire) (Amphibia, Hyperoliidae). Revue de Zoologie et de Botanique Africaines 93: 779-791.

Paratipos FML 03083 (macho y hembra). Omaniundu. Territorio de Lodja. República Democrática del Congo. Poelman. 29 julio 1959.

\section{Hyperolius sankuruensis Laurent, 1979}

Laurent R. F. 1979. Description de deux Hyperolius nouveaux du Sankuru (Zaire) (Amphibia, Hyperoliidae). Revue de Zoologie et de Botanique Africaines. Tervuren 93: 779-791.

Paratipo FML 03045 (1 juvenil). Charcos del Río Musii. Omaniundu. Territorio de
Lodja. Sankuru. República Democrática del Congo. Poelman. 29 julio 1959.

FAMILIA LEPTODACTYLIDAE

\section{Leptodactylus laticeps}

Boulenger, 1918

Vellard (1947) estudia la especie en el chaco argentino y, debido a que se había descrito con base en un único ejemplar hembra (Boulenger, 1918), describe al ejemplar macho FML 00159/1 como Alotipo. Tal designación no es válida, ya que el término no está regulado en el Código Internacional de Nomenclatura Zoológica y los ejemplares denominados «Alotipo» en descripciones originales antiguas, se consideran paratipos, condición que no cumple el ejemplar descrito por Vellard.

\section{Paludicola kriegi Müller, 1926}

Müller L. 1926. Neue Reptilien und Batrachier der zoologischen Sammlung des bayerischen Staates. Zoologischer Anzeiger 65: 193-200.

Neotipo FML 20460 (macho). Cerca de La Posta. Pampa de Achala. Departamento San Alberto. Córdoba. Argentina. 31 36'46"S 645'29"W. 2.151 msnm. J. Valetti. 17 Enero 2006 .

Comentarios. - Neotipo designado por Valetti et al., 2009. Actualmente Pleurodema kriegi (Müller, 1926).

\section{Physalaemus cuqui Lobo, 1993}

Lobo F. 1993. Descripción de una nueva especie del genero Physalaemus (Anura: Leptodactylidae) del noroeste de Argentina. Revista Española de Herpetología 7: 13-20.

Holotipo FML 02704 (macho). Angosto del Pescado. Departamento Orán. Salta. Argentina. 580-640 msnm. O. Pagaburo y O. Budin. 25 octubre-10 noviembre 1978.

Paratipos FML 02704 (11 machos, 3 hembras). Los mismos datos que el holotipo. 
Comentarios. - El holotipo se encuentra en un recipiente separado etiquetado como «FML 02704 HOLOTIPO» y los paratipos etiquetados «FML 02704/1 a FML 02704/14».

Pleurodema cordobae

Valetti, Salas y Martino, 2009

Valetti J. A., Salas N. E., Martino A. L. 2009. A new polyploid species of Pleurodema (Anura: Leiuperidae) from Sierra de Comechingones, Córdoba, Argentina and redescription of Pleurodema kriegi (Müller, 1926). Zootaxa 2073: 1-21.

Holotipo FML 20490 (macho). Estancia Los Tabaquillos. Sierra de Comechingones. Departamento Calamuchita. Córdoba. Argentina. $32^{\circ} 23^{\prime} 58,4^{\prime \prime}$ S 6455'35,1”W. 2.105 msnm. A. Martino y J. Valetti. 05 febrero 2006.

Paratipos FML 20483 - FML 20489 y FML 20491 (machos); FML 20492 (hembra). Los mismos datos que el holotipo.

\section{FAMILIA MICROHYLIDAE}

Elachistocleis haroi

Pereyra, Akmentins, Laufer y Vaira 2013

Pereyra L.C, Akmentins M. S., Laufer G., Vaira M. 2013. A new species of Elachistocleis (Anura: Microhylidae) from north-western Argentina. Zootaxa 3694 (6): 525-544.

Holotipo FML 24900 (macho). Paraje El Algarrobal. Departamento Dr. Manuel Belgrano. Jujuy. Argentina. 24¹1'27,30"S 6513'54,41"W (Datum WGS 84). 1.211 msnm. L. Pereyra y M. Akmentins. 25 febrero 2010.

Paratipos FML 24894 - FML 24899 y FML 24901 - FML 24906. Los mismos datos que el holotipo.

\section{Elachistocleis skotogaster Lavilla, Vaira y Ferrari, 2003}

Lavilla E. O., Vaira M., Ferrari L. 2003. A new species of Elachistocleis (Anura: Microhylidae) from the Andean Yungas of Ar- gentina, with comments on the Elachistocleis ovalis-E. bicolor controversy. Amphibia-Reptilia 24: 269-284.

Holotipo FML 07927 (macho). Los Toldos. Departamento Santa Victoria. Salta. Argentina. 1.100 msnm. M. Vaira y L. Ferrari. 27 enero 1999.

Paratipos FML 07920 - FML 07924 (machos) y FML 07925 - FML 07926 y FML 07928 - FML 07929 (hembras). $N^{\circ}$ de campo de FML 07920: MV 247. Los mismos datos que el holotipo.

Comentarios. - El ejemplar FML 07925 está teñido y transparentado.

\section{FAMILIA ODONTOPHRYNIDAE \\ Odontophrynus lavillai Cei, 1985}

Cei J. M. 1985. Un nuevo y peculiar Odontophrynus de la Sierra de Guasayán, Santiago del Estero, Argentina (Anura: Leptodactylidae). Cuadernos de Herpetología 1: 1-13.

Holotipo FML 03701 (macho). Arroyo Casa del Tigre. $2 \mathrm{~km}$ de Villa La Punta. Sierra de Guasayán. Departamento Guasayán. Santiago del Estero. Argentina. 600 msnm. E. Lavilla y O. Pagaburo. 21 noviembre 1982.

Paratipo FML 03702 (macho). Los mismos datos que el holotipo.

Comentarios. - Holotipo citado por Lavilla (1993).

\section{FAMILIA PHRYNOBATRACHIDAE}

\section{Phrynobatrachus asper Laurent, 1951}

Laurent R. F. 1951. Deux Reptiles et onze Batraciens nouveaux d'Afrique centrale. Revue de Zoologie et de Botanique Africaines. Tervuren 44 (4): 360-381.

Paratipos FML 03109 y FML 03144 (juvenil). Haute Sanghe. Bassin de La Ruzizi. Territorio Uvira. Kivu. República Democrática del Congo. 2.800 msnm. R. F. Laurent. 04-08 setiembre 1950. 
Comentarios. - Los ejemplares eran parte de un lote de 12 paratipos en la descripción original.

\section{FAMilia TELMATOBIIDAE \\ Telmatobius atacamensis Gallardo, 1962}

Gallardo J. M. 1962. Los géneros Telmatobius y Batrachophrynus (Amphbia, Leptodactylidae) en la Argentina. Neotropica. La Plata 8: 46-54.

Paratipos FML 03252/1-2 (hembras) y 03252/3 (macho). Número original MACN 2136. San Antonio de Los Cobres. Departamento Los Andes. Salta. Argentina. A. Bachmann, L. Rossi, y J. L. Sirlin. 19 octubre 1948.

Comentarios. - Los ejemplares formaban parte de un lote de 13 paratipos provenientes de la localidad tipo. Recibidos en donación del Museo Argentino de Ciencias Naturales «Bernardino Rivadavia», Buenos Aires, Argentina.

\section{Telmatobius barrioi Laurent, 1970}

Laurent R. F. 1970 (1969). Dos nuevas especies Argentinas del género Telmatobius (Amphibia, Leptodactylidae). Acta zoologica lilloana 25: 207-226.

Holotipo FML 01369 (macho). Sierra de Calilegua, cerca del monumento de la ruta de Calilegua a Valle Grande. Jujuy. Argentina. 1.600-1.700 msnm. C. Halloy. 04-09 noviembre 1967.

Alotipo FML 01370 (hembra). De la misma localidad y fecha que el holotipo. R. F. Laurent y C. Halloy.

Paratipos FML 01371 (45 ejemplares). Los mismos datos que el alotipo.

Comentarios. - Actualmente considerado sinónimo junior de Telmatobius oxycephalus Vellard, 1946, de acuerdo a Laurent (1977). Lavilla y Kretzschmar (1998) aclararon la localidad tipo de la especie. Los paratipos son 45 ejemplares etiquetados FML 01371/1 - FML 01371/45, no 56 ejemplares como se menciona en la descripción original. El alotipo y dos paratipos (FML 01371/1 y FML $01371 / 2$ ) fueron donados al Dr. J. M. Cei, y actualmente probablemente están depositados en la Unidad de Herpetología - Facultad de Química Bioquímica y Farmacia, Universidad Nacional de San Luis, San Luis, Argentina. Desafortunadamente, las etiquetas originales fueron removidas, por lo que no podemos asegurar su identificación (B. Espeche com. pers.).

\section{Telmatobius ceiorum Laurent, 1970}

Laurent R. F. 1970 (1969). Dos nuevas especies Argentinas del genero Telmatobius (Amphibia, Leptodactylidae). Acta zoologica lilloana 25: 207-226.

Holotipo FML 01372 (hembra). Km 51 ruta de Concepción a Andalgalá, cerca de La Banderita. Catamarca. Argentina. Aproximadamente 1.900 msnm. R. Cei.

Alotipo FML 01373 (macho). La misma localidad que el holotipo. C. Halloy.

Paratipo FML 01374 (macho). La misma localidad que el holotipo. C. Halloy.

Paratipos FML 01391 (2 machos, 1 hembra, 1 juvenil). La misma localidad que el holotipo. 07-09 diciembre 1968.

Paratipo FML 01392 (macho). Yunka Suma, cerca de Las Estancias. Catamarca. Argentina. O. A. Budin. Noviembre 1967.

Comentarios. - Holotipo citado por Lavilla (1993). Los paratipos mencionados como «jóvenes y renacuajos» en el lote de paratipos FML 01374, no pudieron ubicarse en la colección.

\section{Telmatobius hauthali Koslowsky, 1895}

Koslowsky J. G. 1895. Batracios y reptiles de la Rioja y Catamarca, recogidos durante los meses de febrero a mayo de 1895. Revista del Museo de La Plata 6: 359-365.

Neotipo FML 03264/9 (hembra). Arroyo Aguas Calientes. Departamento Tinogasta. Catamarca. Argentina. 27ำ $14^{\prime} \mathrm{S} 68^{\circ} 16^{\prime} \mathrm{W}$. 4.050 msnm. E. Terán. 28-30 enero 1983. 
Comentarios. - Neotipo designado por Laurent y Lavilla (1986); citado en Lavilla (1993).

\section{Telmatobius hauthali laticeps Laurent, 1977}

Laurent R. F. 1977. Contribución al conocimiento del género Telmatobius Wiegmann (4a nota). Acta zoologica lilloana 32 (10): 189-206.

Holotipo FML 02255 (hembra). Km 78 ruta Tafí del Valle. Departamento Tafí del Valle. Tucumán. Argentina. S. Halloy. 08 diciembre 1973.

Alotipo FML 02418 (macho). De la misma localidad y fecha que el holotipo. H. Salas y H. Vitalone. 08 diciembre 1973.

Paratipos FML 00637 (2 machos, 1 hembra). Tafí del Valle. Departamento Tafí del Valle. Tucumán. Argentina. J. M. Cei. 03 febrero 1949.

Paratipos FML 00667 (28 renacuajos). Tafí del Valle. Departamento Tafí del Valle. Tucumán. Argentina. S. A. Pierotti. 05 abril 1949.

Paratipos FML 00683 (4 machos, 2 hembras) Tafí del Valle. Departamento Tafí del Valle. Tucumán. Argentina. S. A. Pierotti. 30 abril 1949.

Paratipos FML 00688 (5 machos, 1 hembra y 3 juveniles). Tafí del Valle. Departamento Tafí del Valle. Tucumán. Argentina. S. A. Pierotti. 30 abril 1949.

Paratipos FML 00690 (4 machos). Tafí del Valle. Departamento Tafí del Valle. Tucumán. Argentina. S. A. Pierotti. 03 mayo 1949.

Paratipos FML 00691 (4 machos). Tafí del Valle. Departamento Tafí del Valle. Tucumán. Argentina. S. A. Pierotti. 06 setiembre 1959.

Paratipos FML 01498 (46 ejemplares). Pendiente E de Infiernillo. Km 84-86 de la Ruta Provincial 307. Departamento Tafí del Valle. Tucumán. Argentina. R. F. Laurent. 2627 febrero 1968.

Paratipos FML 01499 (25 ejemplares). Quebrada del Barón, Km 84 de la ruta de Tafí del Valle. Departamento Tafí del Valle. Tucumán. Argentina. R. F. Laurent. 26-27 febrero 1968.
Paratipos FML 01511 (5 machos, 3 hembras, 1 renacuajo). Tafí del Valle. Departamento Tafí del Valle. Tucumán. Argentina. S. A. Pierotti. Mayo 1960.

Paratipos FML 01541 (3 machos, 6 hembras, 6 hembras juveniles). El Rincón. Departamento Tafí del Valle. Tucumán. Argentina. 2.150 msnm. R. F. Laurent. Setiembre 1970.

Paratipo FML 01545 (1 macho). Km 4041 (El Divisadero) de la Ruta Provincial 307. Entre Tafí del Valle y Amaicha del Va1le. Departamento Tafí del Valle. Tucumán. Argentina. 1.560 msnm. R. F. Laurent. 10-12 octubre 1970.

Paratipos FML 01616 (3 machos). Tafí del Valle. Departamento Tafí del Valle. Tucumán. Argentina. P. Halloy. Enero 1971.

Paratipos FML 01793 (5 hembras). Tafí del Valle. Departamento Tafí del Valle. Tucumán. Argentina. S. A. Pierotti. 06 junio 1960.

Paratipos FML 02103 (7 hembras juveniles). El Mollar. Departamento Tafí del Valle. Tucumán. Argentina. 2.000 msnm. T. Fasola. 09 noviembre 1972.

Paratipo FML 02254 (1 macho). Km 78 de la Ruta Provincial 307. Departamento Tafí del Valle. Tucumán. Argentina. H. Salas y H. Vitalone. 08 diciembre 1973.

Paratipos FML 02313 (3 machos, 2 hembras, 2 hembras juveniles). Km 68,5 de la Ruta Provincial 307. Entre Tafí del Valle y Amaicha del Valle. Departamento Tafí del Valle. Tucumán. Argentina. R. F. Laurent. 13 abril 1974.

Paratipos FML 02322 (1 macho, 1 hembra, 2 hembras juveniles). El Rincón. Departamento Tafí del Valle. Tucumán. Argentina. 2.150 msnm. R. F. Laurent. 12 abril 1974.

Paratipos FML 02351 (2 renacuajos). Km 70 de la Ruta Provincial 307. Departamento Tafí del Valle. Tucumán. Argentina. R. F. Laurent. 12 abril 1974.

Paratipos FML 02359 (1 macho). Quebrada del Barón. Km 84 de la Ruta Provincial 307. Entre Tafí del Valle y Amaicha del Valle. Departamento Tafí del Valle. Tucumán. Argentina. 3.000 msnm. T. Fasola. 01 octubre 1974. 
Paratipo FML 02394 (1 macho). Km 70 de la Ruta Provincial 307. Entre Tafí del Valle y Amaicha del Valle. Departamento Tafí del Valle. Tucumán. Argentina. R. F. Laurent. 12 junio 1974.

Comentarios. - Actualmente Telmatobius laticeps, ver Laurent y Terán (1981). Holotipo citado por Lavilla (1993). Ver los comentarios en Telmatobius schreiteri sobre el paratipo FML 00029 citado por Laurent (1977) como paratipo de Telmatobius hauthali laticeps. El número real de ejemplares de los lotes FML 00637, FML 00667, FML 00688, FML 01616 y FML 02359 es diferente al publicado en la descripción original. La fecha de colección del lote FML 00691 probablemente es 1949, no 1959 como fuera publicado en la descripción original; los renacuajos no están en la colección, aunque existe un lote de 13 renacuajos de la misma localidad y fecha con el número FML 04616 que probablemente sean parte del lote original, pero no podemos probarlo. El lote mencionado como FML 01323 por Laurent (op. cit), es realmente FML 02313. El lote citado como FML 02357 por Laurent (op. cit.), es realmente FML 02351, y la fecha de colección de este lote y del lote FML 02394 es realmente 12 abril 1974, no 12 junio 1974. El lote FML 01498 tiene solamente 46 ejemplares en la actualidad; de acuerdo a los registros de la colección, 16 ejemplares fueron enviados a diferentes investigadores pero no pudimos ubicarlos; además de esos 16 ejemplares, dos fueron enviados al Museo Provincial de Ciencias Naturales Florentino Ameghino de Santa Fe, Argentina (números actuales MFA-ZV-AN 337 macho, y MFA-ZV-AN 338, hembra). El lote FML 01499 tiene solamente 25 ejemplares, no 29 como se menciona en la descripción original. Los ejemplares FML 01499-22 a 25 están teñidos y transparentados y dos ejemplares fueron enviados al Museo Provincial de Ciencias Naturales Florentino Ameghino de Santa Fe, Argentina (números actuales MFA-ZV-AN 389 hembra, y MFA-ZV-AN 390, macho).

\section{Telmatobius hauthali pisanoi Laurent, 1977}

Laurent R. F. 1977. Contribución al conocimiento del género Telmatobius Wiegmann (4a nota). Acta zoologica lilloana 32: 189206.

Holotipo FML 02442 (macho). Km 93 de Ruta Provincial 307. Entre Tafí del Valle y Cafayate. Departamento Tafí del Valle. Tucumán. Argentina. S. Halloy, H. Salas y H. Vitalone. 09-12 diciembre 1973.

Alotipo FM 02443 (hembra). Los mismos datos que el holotipo.

Paratipos FML 01500 (45 ejemplares). Km 93 de la Ruta Provincial 307. Entre Acheral y Amaicha del Valle. Departamento Tafí del Valle. Tucumán. Argentina. R. F. Laurent. 21-23 febrero 1968.

Paratipos FML 02241 (9 hembras y 13 juveniles). Los mismos datos que el holotipo.

Comentarios. - Actualmente considerado válido a nivel específico, según Laurent y Lavilla (1986). Holotipo citado por Lavilla (1993). El lote FML 01500 tenía originalmente 50 ejemplares, no 49 como mencionaba la descripción original. De ellos, cuatro ejemplares fueron enviados a diferentes investigadores pero no pudimos ubicarlos; además, un ejemplar fue enviado a la Universidad de Concepción, Chile (número actual MZUC 12574).

\section{Telmatobius hypselocephalus Lavilla y Laurent, 1989}

Lavilla E. O., Laurent R. F. 1989 «1988». Deux nouvelles espèces du genre Telmatobius (Anura: Leptodactylidae) en provenance de El Moreno (Province de Jujuy, Argentina). Alytes. Paris 7: 77-89.

Holotipo FML 03768. El Angosto. 6 km al S de El Moreno. Departamento Tumbaya. Jujuy. Argentina. 3.600 msnm. E. Lavilla, A. Marcus y R. Montero. 12 febrero 1987.

Alotipo FML 03767. Los mismos datos que el holotipo.

Paratipos FML 03766 (6 ejemplares). El Moreno. Departamento Tumbaya. Jujuy. Ar- 
gentina. 3.500 msnm. E. Lavilla, A. Marcus y R. Montero. 13 febrero 1987.

Comentarios. - Holotipo citado por Lavilla (1993).

\section{Telmatobius oxycephalus Vellard, 1946}

Vellard J. 1946. El género Telmatobius en la Rep. Argentina. Acta zoologica lilloana 3: 313-326.

Holotipo FML 00225. Cerro La Escalera. Departamento Orán. Salta. Argentina. 3.800 msnm. S. A. Pierotti. 23 abril 1945.

Comentarios. - Holotipo citado por Lavilla (1993).

Telmatobius pinguiculus

Lavilla y Laurent, 1989

Lavilla E. O., Laurent R. F. 1989 «1988». A new species of Telmatobius (Anura: Leptodactylidae) from Catamarca (Argentina). Alytes. Paris 7: 90-96.

Holotipo FML 03910. La Ciénaga (2730’S $67^{\circ} 00^{\prime} \mathrm{W}$ ). Cerca de Medanitos (2732's 673' W). Departamento Belén. Catamarca. Argentina. O. Pagaburo y J. Bracamonte. 1215 marzo 1987.

Alotipo FML 03920. Los mismos datos que el holotipo.

Paratipos FML 03921 (5 hembras; 2 machos). Los mismos datos que el holotipo.

Comentarios. - Holotipo citado por Lavilla (1993).

\section{Telmatobius platycephalus Lavilla y Laurent, 1989}

Lavilla E. O., Laurent R. F. 1989 «1988». Deux nouvelles espèces du genre Telmatobius (Anura: Leptodactylidae) en provenance de El Moreno (Province de Jujuy, Argentina). Alytes. Paris 7: 77-89.

Holotipo FML 03763 (hembra). El Angosto. $6 \mathrm{~km}$ al S de El Moreno. Departamento Tumbaya. Jujuy. Argentina. 3.600 msnm. E. Lavilla, A. Marcus y R. Montero. 12 febrero 1987.

Alotipo FML 03764 (macho). Ladera W Nevado de Chañi. San José de Chañi. Depar- tamento Tumbaya. Jujuy. Argentina. 3.750 msnm. E. Lavilla, A. Marcus y R. Montero. 13 febrero 1987.

Paratipo FML 03765. El Moreno. Departamento Tumbaya. Jujuy. Argentina. 3.500 msnm. E. Lavilla, A. Marcus y R. Montero. 11 febrero 1987.

Paratipo FML 03769. Los mismos datos que el holotipo.

Paratipo FML 03790. San José de Chañi. Departamento Tumbaya. Jujuy. Argentina. 3.750 msnm. E. Lavilla, A. Marcus y R. Montero. 13 febrero 1987.

Comentarios. - Holotipo citado por Lavilla (1993).

\section{Telmatobius schreiteri Vellard, 1946}

Vellard J. 1946. El género Telmatobius en la Rep. Argentina. Acta zoologica lilloana 3: 313-326.

Holotipo FML 00216 (macho). Aimogasta. Departamento Arauco. La Rioja. Argentina. J. Vellard. 29 abril 1945.

Comentarios. - Vellard (1946), menciona al ejemplar 00029 como «Holotipo» en la descripción original. Sin embargo, esa designación es posterior a la designación, en el mismo trabajo, del ejemplar 00216 como «tipo» (ver Laurent, 1977 y Lavilla, 1993). Por otra parte, el ejemplar 00029 es incluido como «paratipo» de Telmatobius hauthali laticeps por Laurent (op. cit.), aunque el autor aclara que el ejemplar no se encuentra en la colección (situación que se mantiene hasta hoy).

\section{Telmatobius scrocchii Laurent y Lavilla, 1986}

Laurent R. F., Lavilla E. O. 1986. Redescipción de Telmatobius hauthali Koslowsky (Anura: Leptodactylidae) y descripción de una nueva especie del mismo género. Cuadernos de Herpetología 2 (4): 1-24.

Holotipo FML 03532 (hembra). El Ingenio. Campo El Arenal. Ruta No 63. Departamento Andalgalá. Catamarca. Argentina. O. Pagaburo. 27 mayo 1985. 
Alotipo FML 01515/12 (macho). El Arenal. Catamarca. Argentina. $3.050 \mathrm{msnm}$. R. F. Laurent. 21-23 enero 1968.

Comentarios. - Holotipo citado por Lavilla (1993).

\section{Telmatobius stephani Laurent, 1973}

Laurent R. F. 1973. Nuevos datos sobre el género Telmatobius en el noroeste argentino con descripción de una nueva especie de la Sierra del Manchao. Acta zoologica lilloana 30: 163-187.

Holotipo FML 01743 (macho). Río Encrucijada, cerca de Las Juntas. Departamento Ambato. Catamarca. Argentina. 2.000 msnm. S. Halloy, C. Halloy y R. F. Laurent. 26-29 diciembre 1970.

Alotipo FML 01744 (hembra). Los mismos datos que el holotipo.

Paratipos FML 01594 (14 ejemplares). Los mismos datos que el holotipo.

Comentarios. - Ejemplares mencionados con el acrónimo IML en la descripción original. Holotipo citado en Lavilla (1993).

\section{LEPIDOSAURIA \\ SQUAMATA \\ AMPHISBAENIA \\ FAMILIA AMPHISBAENIDAE \\ Amphisbaena hiata \\ Montero y Céspedez, 2002}

Montero R., Céspedez J. 2002. New twopored Amphisbaena (Squamata: Amphisbaenidae) from Argentina. Copeia 2002 (3): 792-797.

Paratipo FML 10217. No original UNNEC 5030. Ciudad de Corrientes. Departamento Capital. Corrientes. Argentina. 27²8'S 5850’W. B. Álvarez. 06 octubre 1996.

Paratipo FML 10218. No original UNNEC 1039. Laguna Brava. Departamento Capital. Corrientes. Argentina. 27 $30^{\circ} \mathrm{S} 58^{\circ} 43^{\prime} \mathrm{W}$. : B. Álvarez y M. E. Tedesco. 03 marzo 1982.
Leposternon bagual

Ribeiro, Santos Jr. y Zaher, 2015

Ribeiro S., Santos Jr A. P., Zaher H. 2015. A new species of Leposternon Wagler, 1824 (Squamata, Amphisbaenia) from northeastern Argentina. Zootaxa 4034 (2): 309324.

Holotipo FML 11319 (hembra). No original REB 21242. Reserva Ecológica El Bagual. Departamento Laishí. Formosa. Argentina. 2610'53” S 5856’39” W. 05 febrero 1993.

Paratipos FML 11312 (macho); 11313 (hembra) y 11318 (hembra). Nos originales REB 20887, 20888 y 21227 respectivamente. La misma localidad del holotipo. 01 octubre 1992, 14 junio 1992 y 01 febrero 1993 respectivamente.

Comentarios. - De acuerdo a los archivos de la colección y las notas de campo, el año de colección del holotipo es 1993, no «1992» como fue publicado por Ribeiro et al. (2015). Los resultados de Mott y Vieites (2009) muestran a Amphisbaena como género parafilético, y por ello sinonimizan Cercolophia, Bronia, Aulura, Anops y Leposternon con Amphisbaena. Posteriormente Ribeiro et al. (2011) sostienen que «that synonymyzation of Leposternon with Amphisbaena, although plausible, needs be better supported by the evidence at hand», y consideran Leposternon como género válido.

\section{Leposternon kisteumacheri Porto, Soares y Caramaschi 2000}

Porto, M., Soares M., Caramaschi U. 2000. A new species of Leposternon Wagler, 1824 from Minas Gerais, Brazil, with a key to the species of the genus (Amphisbaenia, Amphisbaenidae). Boletim do Museu Nacional, Nova Série Zoologia, Rio de Janeiro 412: 1-10.

Paratipo FML 09421. No original MNRJ 4046. Municipio de Manga. Distrito Mocam-

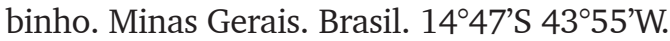
E. Carellos Filho. 01 agosto 1990.

Comentarios. - Ver comentarios en Leposternon bagual. Ejemplar mencionado en la descripción original con el número MNRJ, y 
recibido posteriormente en canje. Los datos de colector y fecha acá mencionados, son los recibidos con el ejemplar en ocasión del canje y son diferentes de los publicados en la descripción original, en la cual figuran como M. Porto y XI/1989, respectivamente.

\section{LACERTILIA \\ FAMILIA LEIOSAURIDAE}

Leiosaurus jaguaris

Laspiur, Acosta y Abdala, 2007

Laspiur A., Acosta J. C., Abdala C. S. 2007. A new species of Leiosaurus (Iguania: Leiosauridae) from central-western Argentina. Zootaxa 1470: 47-57.

Holotipo FML 17584 (macho). № original IMCN-UNSJ 932. Gualcamayo. Departamento Jáchal. San Juan. Argentina. 2949'48,5”S $68^{\circ} 45^{\prime} 45,9$ " W. 2.440 msnm. J. Marinero. R. Buff y J. Villavicencio. 30 setiembre 2000.

Paratipo FML 07484 a FML 07495. No de campo ST18-20, 22, 27-34. Entre Punta de Agua y Las Chacritas. $33 \mathrm{~km}$ al W de Alto Jagüe. Departamento Gral. Lamadrid. La Rioja. Argentina. S. Torres, S. Kretzschmar, J. C. Moreta y C. Salvatierra. Febrero 1997.

Paratipo FML 17585 (macho). No de campo CA 612. Entre Escuela Entre Ríos y Pueblo Villa Mercedes. Departamento Jáchal. San Juan. Argentina. C. Abdala, S. Barrionuevo y M. J. Tulli. 05 noviembre 2004.

Comentarios. - La fecha de colección del holotipo (31 setiembre 2000) y de los paratipos FML 07484 a FML 07495 (febrero 1998) en la descripción original probablemente se deben a errores de mecanografiado.

\section{FAMILIA LIOLAEMIDAE}

Liolaemus abaucan Etheridge, 1993

Etheridge R. 1993. Lizards of the Liolaemus darwini complex (Squamata: Iguania: Tropiduridae) in northern Argentina. Bollettino del Museo regionale di Scienze naturali di Torino 11 (1): 137-199.
Holotipo FML 02638 (macho). No de campo SDSU 1458. $12 \mathrm{~km}$ al S de Palo Blanco, sobre Ruta Provincial 34. Departamento Tinogasta. Catamarca. Argentina. 27019'S 67²5'W 1.900 msnm. R. Etheridge, E. Lavilla, R. Montero, A. Marcus y O. Pagaburo. 05 febrero 1991.

Paratipos FML 02639 (4 ejemplares). Los mismos datos que el holotipo.

\section{Liolaemus abdalai Quinteros, 2012}

Quinteros A. S. 2012. Taxonomy of the Liolaemus alticolor-bibronii group (Iguania: Liolaemidae), with descriptions of two new species. Herpetologica 68 (1): 100-120.

Paratipo FML 07843 - FML 07844. № de campo 954 y 960. Ruta Provincial 23, 8 km al N de Pilolil. Departamento Catan Lil. Neuquén. Argentina. 39²2'29"S 7057'21”W. L. Ávila, F. Lobo, M. Morando y C. Abdala. 10 enero 1999.

\section{Liolaemus acostai \\ Abdala y Juárez Heredia, 2013}

Abdala C. S., Juárez Heredia V. I. 2013. Taxonomía y filogenia de un grupo de lagartos amenazados: el grupo de Liolaemus anomalus (Iguania: Liolaemidae). Cuadernos de Herpetología 27 (2): 109-153.

Holotipo FML 22438 (macho). No de campo GS 3003. Baños del Salado. La Laja. $20 \mathrm{~km}$ al N de la ciudad de San Juan. Departamento Albardón. San Juan. Argentina. G. Scrocchi, C. Abdala, J. Nori y A. Laspiur. 11 octubre 2008.

Paratipos FML 16336 y FML 16337. No de campo CSA 497-498. La Laja. Departamento Albardón. San Juan. Argentina. C. Abdala, A. Laspiur, J. Marinero y E. Sanabria. Octubre 2004.

Paratipos FML 22437. No de campo GS 3002. Los mismos datos que el holotipo.

Paratipos FML 22439 a FML 22443. Los mismos datos que el holotipo. 


\section{Liolaemus albiceps \\ Lobo y Laurent, 1995}

Lobo F., Laurent R. F. 1995. Un nouveau Liolaemus andin. (Tropiduridae). Revue française d'Aquariologie 22 (3-4): 107116.

Holotipo FML 03370 (macho). $10 \mathrm{~km}$ al $S$ de Estación Muñano hacia los Nevados del Acay. San Antonio de los Cobres. Departamento Los Andes. Salta. Argentina. O. Pagaburo. 16 diciembre 1992.

Paratipo FML 00454 (macho). Quebrada del Toro. S de Santa Rosa de Tastil. Departamento Rosario de Lerma. Salta. Argentina. O. Pagaburo. 07 abril 1971.

Paratipos FML 01824 (6 machos, 4 hembras, 1 juvenil). Estación Cachiñal. Departamento Rosario de Lerma. Salta. Argentina. E. Lavilla, A. Marcus y R. Montero. 14 febrero 1987.

Paratipos FML 01865 (4 machos, 8 hembras). Cachiñal. Departamento Rosario de Lerma. Salta. Argentina. O. Pagaburo, T. Noriega, O. Fogliatto, L. Claps y J. Bracamonte. 31 marzo 1987.

Paratipos FML 01880 (4 machos, 5 hembras). Las Cuevas, camino a Cachiñal. Departamento Rosario de Lerma. Salta. Argentina. $3.350 \mathrm{msnm}$. O. Pagaburo, T. Noriega, O. Fogliatto, L. Claps y J. Bracamonte. 31 marzo 1987.

Paratipos FML 01884 (2 machos, 1 hembra). Las Cuevas, camino a Cachiñal. Departamento Rosario de Lerma. Salta. Argentina. $3.350 \mathrm{msnm}$. O. Pagaburo, T. Noriega, O. Fogliatto, L. Claps y J. Bracamonte. 31 marzo 1987.

Paratipos FML 01888 (1 macho, 1 hembra). Cachiñal. Departamento Rosario de Lerma. Salta. Argentina. O. Pagaburo, T. Noriega, O. Fogliatto, L. Claps y J. Bracamonte. 31 marzo 1987.

Paratipos FML 02963 (10 machos). 10 $\mathrm{km}$ al S de Estación Muñano hacia los Nevados del Acay. San Antonio de los Cobres. Departamento Los Andes. Salta. Argentina. O. Pagaburo. 16-21 diciembre 1992.

Paratipos FML 02964 (5 hembras). 10 $\mathrm{km}$ al S de Estación Muñano hacia los Ne- vados del Acay. San Antonio de los Cobres. Departamento Los Andes. Salta. Argentina. O. Pagaburo. 16 diciembre 1992.

Paratipos FML 03331 (4 machos). $\mathrm{N}^{\circ}$ de campo GS 1463 a 1465 y GS 1470. Santa Rosa de Tastil. Departamento Rosario de Lerma. Salta. Argentina. 3.060 msnm. G. Scrocchi, F. Lobo y L. Fernández. 06 diciembre 1994.

Paratipos FML 03371 a FML 03375 (4 machos, 1 hembra). No de campo 1215 a 1217, y 1221-1222. 9,4 km al S de la intersección de las Rutas Nacionales 40 y 51, sobre Ruta 40. Departamento Los Andes. Salta. Argentina. $24^{\circ} 20^{\prime} 20^{\prime \prime} \mathrm{S} 66^{\circ} 13^{\prime} 13,2^{\prime \prime} \mathrm{W} .4 .010$ msnm. R. Etheridge, R. Espinoza, E. Lavilla, F. Lobo y J. C. Moreta. 10 enero 1995.

Comentarios. - El ejemplar FML 00454 fue incluido como paratipo de Liolaemus irregularis por Laurent (1986). En el lote FML 02963 solamente existen 10 ejemplares, no hay referencias en los registros sobre el ejemplar faltante. La fecha de colección de FML 01824 es Febrero, no Enero como se menciona en la descripción original.

\section{Liolaemus bitaeniatus Laurent, 1984}

Laurent R. F. 1984. Tres especies nuevas del género Liolaemus (Reptilia: Iguanidae). Acta zoologica lilloana 37 (2): 273-294.

Holotipo FML 00999-1 (macho). La Angostura. Tafí del Valle. Departamento Tafí del Valle. Tucumán. Argentina. 1.900 msnm. O. Pagaburo. 14 octubre 1980.

Paratipos FML 00271 (2 juveniles). Tafí del Valle. Departamento Tafí del Valle. Tucumán. Argentina. J. Bennassar de Herrera. 17 noviembre 1957.

Paratipo FML 00506 (macho). Km 47 Ruta Provincial 307. Departamento Tafí del Valle. Tucumán. Argentina. J. M. Gómez. 27 octubre 1971.

Paratipo FML 00742 (hembra). Sierra de Medina. Departamento Burruyacú. Tucumán. Argentina. J. González, E. Lavilla, G. Scrocchi y E. Terán. 31 enero - 7 febrero 1977.

Paratipos FML 00770 (3 machos, 1 hembra). Agua Negra. Sierra de Medina. Depar- 
tamento Burruyacú. Tucumán. Argentina. S. Halloy, A. Marcus, C. Pérez, O. Pagaburo, G. Scrocchi y E. Terán. 17-21 agosto 1977.

Paratipos FML 00772 (1 ejemplar). Estancia Agua Negra. Sierra de Medina. Departamento Burruyacú. Tucumán. Argentina. S. Halloy, A. Marcus, O. Pagaburo, C. Pérez y E. Terán. 17-21 agosto 1977.

Paratipos FML 00822 (11 ejemplares). Sierra de Medina, Departamento Burruyacú. Tucumán. Argentina. $1.500-1.800$ msnm. O. Pagaburo, G. Scrocchi y E. Terán. 15-22 abril 1978.

Paratipos FML 00826 (2 hembras, 1 juvenil). Sierra de Medina, Departamento Burruyacú. Tucumán. Argentina. 1.500 msnm. O. Pagaburo, G. Scrocchi y E. Terán. 15-22 abril 1978.

Paratipos FML 00827 (5 juveniles). Sierra de Medina, Departamento Burruyacú. Tucumán. Argentina. 1.500 msnm. O. Pagaburo, G. Scrocchi y E. Terán. 15-22 abril 1978.

Paratipo FML 00846 (macho). Estancia Gutiérrez. Morro de Balderrama. Sierra de Metán. Departamento Metán. Salta. Argentina. 2.450 msnm. S. Halloy. 23 agosto 1978.

Paratipo FML 00881 (macho). Purmamarca. Quebrada de Humahuaca. Departamento Humahuaca. Jujuy. Argentina. G. Scrocchi y P. Fidalgo. Enero 1979.

Paratipos FML 00921 (4 ejemplares). Dique La Angostura. Tafí del Valle. Departamento Tafí del Valle. Tucumán. Argentina. O. Pagaburo y E. Terán. 18 noviembre 1979.

Paratipos FML 00943 (9 ejemplares). Punta del Agua. $4 \mathrm{~km}$ pasando Las Estancias (a orillas del camino). Departamento Andalgalá. Catamarca. Argentina. 1.600 msnm. O. Pagaburo. 13-14 marzo 1980.

Paratipo FML 00998 (hembra). Río Pila. Cuesta de Hualinchay. Departamento Trancas. Tucumán. Argentina. 1.960 msnm. O. Pagaburo y E. Terán. 30 setiembre 1980.

Paratipo FML 00999-2 (macho). Los mismos datos que el holotipo.

Paratipos FML 01047 (1 macho, 3 hembras, 2 juveniles). El Duraznillo. Cl. Alto Calilegua. Departamento Valle Grande. Jujuy. Argentina. 2.600-2.800 msnm. O. Pagaburo y E. Terán. 19 octubre 1980.
Paratipos FML 01065 (4 ejemplares). «La Ripiera». 7 km adentro desde km 58. Tafí del Valle. Departamento Tafí del Valle. Tucumán. Argentina. O. Pagaburo. 24 diciembre 1980.

Comentarios. - Cuatro ejemplares canjeados con el Museu de Zoologia da Universidade de São Paulo, Brasil: FML 00611 (actualmente MZUSP 58030); dos ejemplares del lote FML 00943 que originalmente eran 11 ejemplares, no 10 como figura en la descripción original (actualmente MZUSP 72491 y MZUSP 72492); y el ejemplar FML 00946 (actualmente MZUSP 58031). El paratipo 0822-12 fue enviado a la Universidad de Concepción, Chile (actualmente MZUC 12580). De acuerdo a los registros de la colección, los ejemplares FML 00921-2 y 00921-5 fueron enviados al Museo Nacional de Historia Natural de Chile; sin embargo, el Museo nunca recibió ese material (Dr. H. A. Nuñez Cepeda com. pers.). Dos ejemplares del lote FML 00772 fueron enviados al Dr. J. M. Cei, y probablemente están depositados en la Unidad de Herpetología - Facultad de Química Bioquímica y Farmacia, Universidad Nacional de San Luis, San Luis, Argentina. Desafortunadamente, las etiquetas originales fueron removidas, por lo que no podemos asegurar su identificación (B. Espeche com. pers.). El ejemplar FML 01065-5 fue enviado a la Facultad de Ciencias Exactas Físicas y Naturales, Universidad Nacional de Córdoba, Córdoba, Argentina (actualmente AC 196). Los coleccionistas de los ejemplares FML 00770, FML 00772 y FML 00946 son los mencionados acá. La fecha de colección de los paratipos FML 00921 fue erróneamente citada como 18 setiembre 1979 en la descripción original.

\section{Liolemus calchaqui \\ Lobo y Kretzschmar 1996}

Lobo F., Kretzschmar S. 1996. Descripción de una nueva especie de Liolaemus (Iguania: Tropiduridae) de la provincia de Tucumán, Argentina. Neotropica 42 (107108): 35-40.

Holotipo FML 03082 (macho). Punta de 
Agua. Departamento Trancas. Tucumán. Argentina. 3.600 msnm. O. Pagaburo. 22 diciembre 1991.

Paratipos FML 00890 (4 machos, 2 hembras). CI. Puesto Muñoz. Cerro Muñoz. Departamento Tafí del Valle. Tucumán. Argentina. 3.600 msnm. S. Halloy. 12 enero 1979.

Paratipos FML 02425 (3 machos, 1 hembra, 4 juveniles). Puesto El Muñoz (desde El Infiernillo). Departamento Tafí del Valle. Tucumán. Argentina. 3.550 msnm. O. Pagaburo. 14-18 febrero 1990.

Paratipos FML 02750 (5 machos, 4 hembras). Punta de Agua. Departamento Trancas. Tucumán. Argentina. 3.600 msnm. O. Pagaburo. 22 diciembre 1991.

Liolaemus camarones

Abdala, Díaz Gómez y Juárez Heredia, 2012

Abdala C. S., Díaz Gómez J. M., Juárez Heredia V. I. 2012. From the far reaches of Patagonia: New phyllogenetic analyses and description of two new species of the Liolaemus fitzingerii clade (Iguania: Liolaemidae). Zootaxa 3301: 34-60.

Holotipo FML 23301 (macho). Bahía Camarones. Playa $3 \mathrm{~km}$ al $\mathrm{S}$ de Camarones. Departamento Florentino Ameghino. Chubut. Argentina. C. Abdala, J. Abdala y E. Malovini. 22 enero 2002.

Paratipos FML 23302 - FML 23308 (5 machos, 2 hembras). Los mismos datos que el holotipo.

Paratipos FML 24140 - FML 24144 (3 machos, 2 hembras). No de campo FBC 1605 , 1688-1691. Bahía Camarones. Camino a Playa Elola. Playa $1 \mathrm{~km}$ al S de Camarones. Departamento Florentino Ameghino. Chubut. Argentina. 4448'33,0"S 65'44'8,9"W. C. Abdala, F. Cruz, G. Perotti y R. Semhan. 18 diciembre 2009.

\section{Liolaemus chaltin Lobo y Espinoza, 2004}

Lobo F., Espinoza R. E. 2004. Two new Liolaemus from the Puna region of Argentina and Chile: Further resolution of purported reproductive bimodality in Liolaemus alticolor (Iguania: Liolaemidae). Copeia 2004 (4): 850-867.

Holotipo FML 09874 (macho). $\mathrm{N}^{\mathrm{O}}$ de campo REE 341. Ruta Provincial 71, 4,2 $\mathrm{km}$ al $\mathrm{W}$ de Abra Pampa. Departamento Cochinoca. Jujuy. Argentina. 22 42'24,4”S 65'43'12,4”W. 3.360 msnm. R. Espinoza, R. Etheridge, E. Lavilla, F. Lobo y J. C. Moreta. 5-6 enero 1995.

Paratipos FML 09875 - FML 09913. No de campo REE 342-353; 355-359; 361-362; $364-365$; 367-368; 370-374; 376-377; 379$381 ; 383 ; 385-389$. Los mismos datos que el holotipo.

\section{Liolaemus chehuachekenk Ávila, Morando y Sites, 2008}

Ávila L. J., Morando M., Sites Jr. J. W. 2008. New species of the Iguanian Lizard genus Liolaemus (Squamata, Iguania, Liolaemini) from Central Patagonia, Argentina. Journal of Herpetology 42 (1): 186-196.

Paratipos FML 15105 y FML 15106. № de campo 5630 y 5633 respectivamente. Ladera SW de Cerro Calcatapul. Ruta Provincial 13, $8 \mathrm{~km}$ al N de El Molle. Departamento Cushamen. Chubut. Argentina. 42 $10^{\circ}$ S 69 32 'W. L. Ávila y C. H. F. Pérez. 03 febrero 2003.

\section{Liolaemus choique Abdala, Quinteros, Scrocchi y Stazzonelli, 2010}

Abdala C., Quinteros S., Scrocchi G. J., Stazzonelli J. C. 2010. Three new species of the Liolaemus elongatus group (Iguania: Liolaemidae) from Argentina. Cuadernos de Herpetología 24 (2): 93-109.

Holotipo FML 22453 (macho). No de campo GS 3040. Paso El Choique. Ruta Provincial 221. Departamento Malargüe. Mendoza. Argentina. 36¹9'11,8"S 6948'31,1”W. 2.111 msnm. C. S. Abdala, G. Scrocchi, J. Nori, C. Martínez y H. Carrizo. 19 octubre 2008.

Paratipo FML 22452. No de campo GS 3039. Paso El Choique. Ruta Provincial 221. Departamento Malargüe. Mendoza. Argentina. 36²2'01, 1"S 6948'07,2”W. 2.407 m. C. 
S. Abdala, G. Scrocchi, J. Nori, C. Martínez y H. Carrizo. 19 octubre 2008.

Paratipos FML 22454-FML22458. No de campo GS 3041- 3045. Los mismos datos que el holotipo.

Comentarios. - Las coordenadas y altitud de las localidades del holotipo y del paratipo FML 22452 fueron intercambiadas por error en la descripción original.

\section{Liolaemus chungara}

Quinteros, Valladares, Semhan, Acosta, Barrionuevo y Abdala, 2014

Quinteros A. S., Valladares P., Semhan R., Acosta J. L., Barrionuevo S., Abdala C. S. 2014. A new species of Liolaemus (Iguania: Liolaemidae) of the alticolor-bibronii group from Northern Chile. South American Journal of Herpetology 9 (1): 20-29.

Holotipo FML 26502 (macho). $\mathrm{N}^{\circ}$ de campo CSA 1278. Entrada a Putre. Región de Arica y Parinacota. Chile. $18^{\circ} 10^{\prime} 53,4^{\prime \prime} \mathrm{S}$ 69³1'58,6"W. 3.874 msnm. C. Abdala, J. L. Acosta, R. Semhan y P. Valladares.

Paratipo FML 26503 (hembra). No de campo CSA 1279. Los mismos datos que el holotipo.

Paratipos FML 26504 - FML 26508. No de campo CSA 1295-1298, 1300. Márgen S del Lago Chungara. Región de Arica y Parinacota. Chile. $18^{\circ} 16^{\prime} 17,0^{\prime \prime}$ S 6909'37,7'W. 4.583 msnm. C. Abdala, J. L. Acosta, R. Semhan y P. Valladares.

Paratipos FML 26509 - FML 26513. No de campo CSA 1311-1315. Cerca de Putre, Desvío a Colpita. Región de Arica y Parinacota. Chile. C. Abdala, J. L. Acosta, R. Semhan y P. Valladares.

Comentarios. - Un serio error de mecanografiado causó que el holotipo y uno de los paratipos fueran publicados con el mismo acrónimo y número (FML 26505). El número correcto del holotipo es FML 26502.

\section{Liolaemus crepuscularis} Abdala y Gómez, 2006

Abdala C. S., Díaz-Gómez J. M. 2006. A new species of the Liolaemus darwinii group
(Iguania: Liolaemidae) from Catamarca province, Argentina. Zootaxa 1317: 21-33.

Holotipo FML 16622 (macho). $\mathrm{N}^{\mathrm{o}}$ de campo FBC 415. Puesto Flores, $2 \mathrm{~km}$ al S de Mina Capillitas. Km 50-52 Ruta Provincial 47. Departamento Andalgalá. Catamarca. Argentina. 3.100 msnm. C. Abdala, S. Quinteros, G. Scrocchi y S. Barrionuevo. 03 marzo 2005.

Paratipos FML 03611 (1 macho, 2 hembras, 1 juvenil). No de campo FL 116-117; 124-125. Mina Capillitas. Departamento Andalgalá. Catamarca. 2.800 msnm. F. Lobo, A. Marcus, J. Montero y R. Montero. 18 diciembre 1995.

Paratipos FML 16623 - FML 16626 (3 machos, 1 hembra). No de campo FBC 414; 416-418. Los mismos datos que el holotipo.

Paratipos FML 16627 - FML16629 (2 machos, 1 hembra). $N^{\circ}$ de campo CSA 527, 528 y 530. Puesto Flores, $2 \mathrm{~km}$ al S de Mina Capillitas. Km 50-52 Ruta Provincial 47. Departamento Andalgalá. Catamarca. Argentina. 3.100 msnm. C. Abdala y S. Barrionuevo. 12 noviembre 2004.

Comentarios. - Los paratipos FML 16624 a FML 16626 fueron citados en la descripción original como un lote: FML 16623.

Liolaemus cuyumhue

Ávila, Morando, Pérez y Sites, 2009

Ávila L. J., Morando M., Pérez D. R., Sites J. W. 2009. A new species of Liolaemus from Añelo sand dunes, northern Patagonia, Neuquén, Argentina and molecular phylogenetic relationships of the Liolaemus wiegmannii species group (Squamata, Iguania, Liolaemini). Zootaxa 2234: 39-55.

Paratipo 17592 (macho). No de campo 4519. Dunas de arena en el lado S de la Ruta Provincial 7. Departamento Añelo. Neuquén. Argentina. $38^{\circ} 13^{\prime} \mathrm{S} 68^{\circ} 57^{\prime} \mathrm{W}$. 260 msnm. D. R. Pérez, J. Pérez, M. Pérez y M. Pérez Carrió. 15 noviembre 2003.

Paratipos 17593 (hembra) y FML 17594 (macho). No de campo 3697 y 3694 respectivamente. Dunas de arena cerca de la Ruta Provincial 7. Departamento Añelo. Neuquén. Argentina. $38^{\circ} 13^{\prime} \mathrm{S} 68^{\circ} 57^{\prime} \mathrm{W}$. $258 \mathrm{msnm}$. D. 
R. Pérez, C. de la Vega y D. Zuñiga. 10 febrero 2006.

\section{Liolaemus diaguita}

Abdala, Quinteros, Arias, Portelli

y Palavecino, 2011

Abdala C. S., Quinteros A. S., Arias F., Portelli S., Palavecino A. 2011. A new species of the Liolaemus darwinii group (Iguania: Liolaemidae) from Salta Province, Argentina. Zootaxa 2968: 26-38.

Paratipos FML 23821 - FML 23825. N ${ }^{\circ}$ original MCN 3241-3242, 3244-3246. Quebrada de Las Conchas. $400 \mathrm{~m}$ al S de Río Las Conchas. $61 \mathrm{~km}$ al $\mathrm{N}$ de Cafayate. Departamento Guachipas. Salta. Argentina. 1.328 msnm. S. Quinteros, F. Arias, A. Palavecino y S. Portelli. 27 enero 2010.

\section{Liolaemus dicktracyi Espinoza y Lobo, 2003}

Espinoza R. E., Lobo F. 2003. Two new species of Liolaemus lizards from Northwestern Argentina: Speciation within the Northern subclade of the elongatus group (Iguania: Liolaemidae). Herpetologica 59 (1): 89-105.

Holotipo FML 09928 (macho). No de campo REE 184. Portezuelo Blanco. 26,5 km W de Famatina, en ruta a Cueva de Pérez. Departamento Famatina. La Rioja. Argentina. $2^{\circ} 54^{\prime} 30^{\prime \prime S} 67^{\circ} 41^{\prime} 30^{\prime \prime} W .2 .800$ msnm. F. Cruz y R. Espinoza. 16-17 febrero 1998.

Paratipos FML 09929 a FML 09933. N ${ }^{\circ}$ de campo PT 3286-3289; 3292. Los mismos datos que el holotipo.

\section{Liolaemus disjunctus Laurent, 1990}

Laurent R. F. 1990. Una especie apartada del género Liolaemus Wiegmann (Iguanidae, Lacertilia). Acta zoologica lilloana 39 (2): 79-84.

Holotipo FML 01201/1 (macho). Huamachuco. La Libertad. Perú. W. Weyrauch.

Paratipos FML 01201/2 a FML 01201/5 (macho, 2 hembras, hembra subadulta). Los mismos datos que el holotipo.
Comentarios. - Por un error de mecanografiado el número del holotipo se mencionó como 201/1 en la descripción original.

$$
\begin{gathered}
\text { Liolaemus dumerili } \\
\text { Abdala, Semhan, Moreno Azócar, } \\
\text { Bonino, Paz y Cruz } 2012
\end{gathered}
$$

Abdala C. S., Semhan R. V., Moreno Azócar D. L., Bonino M., Paz M. M., Cruz F. 2012. Taxonomic study and morphology based phylogeny of the patagonic clade Liolaemus melanops group (Iguania: Liolaemidae), with the description of three new taxa. Zootaxa 3163: 1-32.

Holotipo FML 24169. No de campo FBC 1294. Camino a Los Menucos, km 212 de Ruta Nacional 23. Sierra Colorada. Departamento 9 de Julio. Río Negro. Argentina. 40³2'54,5"S 67³7’10,4”W. C. Abdala, F. Cruz, M. Bonino, R. Semhan y L. Moreno. Febrero 2009.

Paratipos FML 24170 - FML 24179. No de campo FBC 1293, 1509, 1561-1562, 1609, 1628 , 1709-1712, respectivamente. Los mismos datos que el holotipo.

Paratipos FML 24180 - FML 24188. $\mathrm{N}^{\circ}$ de campo GS 3265-3266, 3282, 32843288 , y sin número, respectivamente. De la misma localidad que el holotipo. C. Abdala, F. Cruz, G. Perotti y R. Semhan. Diciembre 2009.

\section{Liolaemus espinozai Abdala, 2005}

Abdala C. 2005. Una nueva especie del género Liolaemus perteneciente al complejo darwinii (Iguania: Liolaemidae) de la provincia de Catamarca, Argentina. Revista Española de Herpetología 19: 5-17.

Holotipo FML 15527 (anteriormente FML 03604/9). No de campo FL 71. El Ingenio. 67 $\mathrm{km}$ al S de Santa María por Ruta Provincial 47. Laderas al E de Campo El Arenal. Departamento Andalgalá. Catamarca. Argentina. 2.620 msnm. F. Lobo, A. Marcus, J. Montero y R. Montero. 18 diciembre 1995.

Paratipos FML 03604/1-8; 10-21 (20 ejemplares). No de campo FL 63-70; 91-96; 
111-114, y 122-123. Los mismos datos que el holotipo.

Paratipos FML 15528 - FML 15531. El Ingenio. Campo El Arenal. $67 \mathrm{~km} \mathrm{~S}$ de Santa María por Ruta Provincial 47. Departamento Andalgalá. Catamarca. Argentina. 2.620 msnm. C. Abdala y P. Schliserman. Enero 2000 .

Liolaemus (Eulaemus) islugensis erguetae Laurent 1995

Laurent R. F. 1995. Sobre una pequeña colección de lagartos del género Liolaemus (Tropiduridae) proveniente del extremo suroeste de Bolivia. Cuadernos de Herpetología 9 (1): 1-6.

Paratipo FML 03207 (macho). Laguna Colorada. Departamento Potosí. Bolivia. O. Rocha y L. Pacheco. 26 octubre 1989.

Paratipo FML 03208 (3 juveniles). Laguna Colorada. Departamento Potosí. Bolivia. L. Pacheco. 29 octubre 1989.

Comentarios. - Actualmente Liolaemus erguetae según Langstroth (2005).

\section{Liolaemus (Eulaemus) jamesi pachecoi Laurent, 1995}

Laurent R. F. 1995. Sobre una pequeña colección de lagartos del género Liolaemus (Tropiduridae) proveniente del extremo suroeste de Bolivia. Cuadernos de Herpetología 9 (1): 1-6.

Paratipo FML 02788 (hembra). No de campo 71. Laguna Colorada. Provincia Sud Lipez. Departamento Potosí. Bolivia. 4.270 msnm. Salazar y L. Pacheco. 29 octubre 1989.

Comentarios. - Actualmente Liolaemus pachecoi según Lobo et al. (2010).

\section{Liolaemus (Eulaemus) melanogaster Laurent, 1998}

Laurent R.F. 1998. New forms of lizards of the subgenus Eulaemus of the genus Liolaemus (Reptilia: Squamata: Tropiduridae) from Perú and northern Chile. Acta zool. lilloana 44 (1): 1-26.
Paratipos FML 02491 (2 ejemplares). No original LSUMZ 27205 y $27207.45 \mathrm{~km}$ al E de Puquio. Ayacucho. Perú. $14^{\circ} 42^{\prime}$ S $74^{\circ} 08^{\prime} W$. 4.570 msnm. R. Thomas. 31 Agosto 1974.

Comentarios. - Ejemplares mencionados en la descripción original con los números LSUMZ y recibidos posteriormente en canje.

Liolaemus gracielae
Abdala, Acosta, Cabrera, Villavicencio
y Marinero, 2009

Abdala C. S., Acosta J. C., Cabrera M. R., Villavicencio H. J., Marinero J. 2009. A New Andean Liolaemus of the L. montanus Series (Squamata: Iguania: Liolaemidae) from Western Argentina. South American Journal of Herpetology 4 (2): 91-102.

Holotipo FML 17866 (macho). $\mathrm{N}^{\mathrm{o}} \mathrm{de}$ campo FBC $511.2 \mathrm{~km}$ al W de Laguna Brava. Camino a Mula Muerta. Departamento Vinchina. La Rioja. Argentina. $28^{\circ} 16^{\prime} 10,4^{\prime \prime} \mathrm{S}$ 68 51'26,0"W. 4.300 msnm. C. Abdala, S. Quinteros y C. Robles. Octubre 2005.

Paratipos FML 17861 - FML 17865 y FML 17867 - FML 17880. No de campo FBC 497$500,503,516$ y $519-531$ respectivamente. Los mismos datos que el holotipo.

Paratipos FML 18346 - FML 18355. Llano Negro. $6 \mathrm{~km}$ al N del Río Santa Rosa. Reserva Provincial y Reserva de la Biósfera San Guillermo. Departamento Iglesia. San Juan. Argentina. $28^{\circ} 56^{\prime} 12,3^{\prime \prime}$ S 69 $9^{\circ} 15^{\prime} 31,6^{\prime \prime} W$. J. C. Acosta, J. Villavicencio y J. Marinero. Febrero 2005.

\section{Liolaemus griseus Laurent, 1984}

Laurent R. F. 1984. Tres especies nuevas del género Liolaemus (Reptilia, Iguanidae). Acta zoologica lilloana 37 (2): 273-294.

Holotipo FML 01068 (macho). Falda E, cerca del filo $\mathrm{N}$ del Cerro Isabel. Cumbres Calchaquíes. Departamento Tafí del Valle. Tucumán. Argentina. 4.600 msnm. S. Halloy. 16 febrero 1981.

Alotipo FML 01069 (hembra). Laguna Perdida. Macizo del Cerro Adriana. Cum- 
bres Calchaquíes. Departamento Tafí del Valle. Tucumán. Argentina. 4.500 msnm. S. Halloy. 16 febrero 1981.

\section{Liolaemus grosseorum Etheridge, 2001}

Etheridge R. 2001. A new species of Liolaemus (Reptilia: Squamata: Tropiduridae) from Mendoza province, Argentina. Cuadernos de Herpetología 15 (1): 3-15.

Holotipo FML 03444 (macho). No de campo 2493. Playa SE de Embalse Nihuil. Departamento San Rafael. Mendoza. Argentina. 3502'36,2"S 68 40'42,2"W. 1.380 msnm. R. Etheridge, R. Espinoza y S. Torres. 11 febrero 1995.

Paratipo FML 02972. Lago Embalse Nihuil. Departamento San Rafael. Mendoza. Argentina. 1.380 msnm. M. Halloy, C. Grosse, A. Grosse y P. Grosse. 17 enero 1992.

Paratipos FML 09711 - FML 09718. No de campo 2490-2492; 2494, y 2496-2499. Los mismos datos que el holotipo.

Paratipos FML 09719 - FML 09726. Lago Embalse Nihuil. Departamento San Rafael. Mendoza. Argentina. $1.380 \mathrm{msnm}$. M. Halloy, C. Grosse, A. Grosse y P. Grosse. 17 enero 1992.

Comentarios. - En la descripción original se intercambiaron, por error, los símbolos de latitud y longitud de la localidad tipo.

\section{Liolaemus gununakuna \\ Ávila, Morando, Pérez y Sites, 2004}

Ávila L. J., Morando M., Pérez C. H. F., W. Sites Jr. J. 2004. Phylogenetic relationships of lizards of the Liolaemus petrophilus group (Squamata, Liolaemidae), with description of two new species from western Argentina. Herpetologica 60 (2): 187-203.

Holotipo FML 12717 (macho). No de campo LJAMM 2437. $2 \mathrm{~km}$ al SE de La Amarga. Departamento Zapala. Neuquén. Argentina. 3906'S 69³4'W. L. Ávila y M. Morando. 7 marzo 2000.

Paratipo FML 12718 (hembra). No de campo LJAMM 162. Colinas rocosas cerca de La Amarga. Departamento Zapala. Neu- quén. Argentina. L. Ávila, M. Morando y C. Pérez. 2 mayo 1998.

Paratipo FML 12719 (hembra). No de campo LJAMM 288. Los Candeleros. SE de Cerro Lotena. $45 \mathrm{~km}$ al SW de Cutral-Có. Departamento Zapala. Neuquén. Argentina. L. Ávila. 29 noviembre 1995.

Paratipo FML 12720 (macho). No de campo LJAMM 2692. $2 \mathrm{~km}$ al SE de La Amarga. Departamento Zapala. Neuquén. Argentina. L. Ávila y M. Morando. 07 marzo 2000.

Paratipo FML 13043 - FML 13044 (hembras). N$^{\circ}$ de campo LJAMM 141-142. Bosque Petrificado. Departamento Zapala. Neuquén. Argentina. L. Ávila, M. Morando y C. Pérez. 01 mayo 1998.

Liolaemus heliodermis

Espinoza, Lobo y Cruz, 2000

Espinoza R. E., Lobo F., Cruz F. B. 2000. Liolaemus heliodermis, a new lizard from northwestern Argentina with remarks on the content of the elongatus group (Iguania: Tropiduridae). Herpetologica 56 (4): 507-516.

Holotipo FML 07196 (macho). Km 95 de Ruta Provincial 307. Aproximadamente $32 \mathrm{~km}$ (por ruta) de Tafí del Valle. Departamento Tafí del Valle. Tucumán. Argentina. 2640,82'S 6548,74'. 2.820 msnm. F. Cruz y F. Lobo. 02 octubre 1997.

Paratipo FML 06006 (macho) y FML 06007 (hembra juvenil). De la misma localidad que el holotipo. F. Cruz, R. Espinoza, F. Lobo y C. Abdala. 11 noviembre 1996.

\section{Liolaemus huacahuasicus Laurent, 1985}

Laurent R. F. 1985. Description de Liolaemus huacahuasicus spec. nov. (Iguanidae, Reptilia) des Cumbres Calchaquíes, Province de Tucumán, Argentine. Spixiana 8 (3): 241-249.

Holotipo FML 00535/2 (macho). Lagunas de Huaca Huasi. Cumbres Calchaquíes. Departamento Tafí del Valle. Tucumán. Argentina. 4.200 msnm. A. Sobral y E. Krapovickas. 27 abril al 03 mayo 1972. 
Alotipo FML 00535/3. Los mismos datos que el holotipo.

Paratipos FML 00535/1 y FML 00535/4. Los mismos datos que el holotipo.

Paratipos FML 00066 (3 ejemplares). Lagunas de El Negrito. Departamento Tafí del Valle. Tucumán. Argentina. $4.300 \mathrm{msnm}$.

Paratipos FML 00203 (2 ejemplares). Cerro Negrito. Departamento Tafí del Valle. Tucumán. Argentina. 4.700 msnm. F. Monrós. Marzo 1948.

Paratipo FML 00469. $4 \mathrm{~km}$ al N de Cerro Negrito. Departamento Tafí del Valle. Tucumán. Argentina. 4.100 msnm. C. Halloy. 26 abril 1971.

Paratipo FML 00470. Cumbre del Cerro Negrito. S. Halloy. 24 mayo 1971.

Paratipos FML 00531 (3 ejemplares). Lagunas en Cerro Negrito. Departamento Tafí del Valle. Tucumán. Argentina. 4.200 msnm. S. Halloy y C. Grosse. 01 abril 1972.

Paratipos FML 00532 (6 ejemplares). Lagunas en Cerro El Negrito. Departamento Tafí del Valle. Tucumán. Argentina. 4.200 msnm. S. Halloy y C. Grosse. 01 abril 1972.

Paratipos FML 00536 (2 ejemplares). Cerro Negrito. Cerros Calchaquíes. Departamento Tafí del Valle. Tucumán. Argentina. $4.400 \mathrm{msnm}$. S. Halloy y R. González. 30 abril 1972.

Paratipos FML 00538 (21 ejemplares). Lagunas de Huaca Huasi. Cumbres Calchaquíes. Departamento Tafí del Valle. Tucumán. Argentina. 4.200 msnm. S. Halloy, A. Sobral, R. González y E. Krapovickas. 27 abril al 03 mayo 1972.

Paratipo FML 00606 (2 ejemplares). Cerro El Negrito. Departamento Tafí del Valle. Tucumán. Argentina. 4.300 msnm. C. Halloy. 17 agosto 1973.

Paratipos FML 00622. Cerro de las Minas. Cumbres Calchaquíes. Departamento Tafí del Valle. Tucumán. Argentina. 4.500 msnm. C. Halloy. 03 noviembre 1973.

Paratipos FML 00633 y FML 00635. Laguna de Huaca Huasi. Cumbres Calchaquíes. Departamento Tafí del Valle. Tucumán. Argentina. $4.100 \mathrm{msnm}$. S. Halloy. 22 febrero 1974.
Paratipo FML 00639. Cerro Las Minas. Cumbres Calchaquíes. Departamento Tafí del Valle. Tucumán. Argentina. 4.300 msnm. C. Halloy. 14 abril 1974.

Paratipo FML 00649. Cerca de Laguna Blanca. Lagunas de Huaca Huasi. Cumbres Calchaquíes. Departamento Tafí del Valle. Tucumán. Argentina. 4.250 msnm. S. Halloy. 12 abril 1974.

Paratipo FML 00652. $1 \mathrm{~km}$ al NE de Laguna de Huaca Huasi. Cumbres Calchaquíes. Departamento Tafí del Valle. Tucumán. Argentina. 4.300 msnm. S. Halloy. 26 agosto 1974.

Paratipo FML 00655. Cumbre de El Negrito. Cumbres Calchaquíes. Departamento Tafí del Valle. Tucumán. Argentina. 4.500 msnm. S. Halloy. 29 setiembre 1974.

Paratipo FML 00656 (1 hembra, 2 embriones). Cumbre de El Negrito. Cumbres Calchaquíes. Departamento Tafí del Valle. Tucumán. Argentina. 4.500 msnm. S. Halloy. 29 setiembre 1974.

Paratipo FML 00660. E del Filo N del Cerro Bayo. Alto de las Nieves. Cumbres Calchaquíes. Departamento Tafí del Valle. Tucumán. Argentina. Entre 4.420 y 4.460 msnm. S. Halloy. 29 setiembre 1974.

Paratipo FML 00661. E del Filo N del Cerro Bayo. Alto de las Nieves. Cumbres Calchaquíes. Departamento Tafí del Valle. Tucumán. Argentina. Entre 4.420 y 4.460 msnm. S. Halloy. 29 setiembre 1974.

Paratipo FML 00664. NW de la Quebrada del Alazán. Cumbres Calchaquíes. Departamento Tafí del Valle. Tucumán. Argentina. $3.700 \mathrm{msnm}$. S. Halloy. 01 octubre 1974.

Paratipo FML 00666. Cumbre del Cerro Negrito. Cumbres Calchaquíes. Departamento Tafí del Valle. Tucumán. Argentina. 4.500 msnm. C. Halloy. 29 setiembre 1974.

Paratipos FML 00683 (4 ejemplares). Cerro Negrito. Cumbres Calchaquíes. Departamento Tafí del Valle. Tucumán. Argentina. 4.000-4.300 msnm. C. Halloy. 21 diciembre 1974.

Paratipo FML 00684. Cerro Negrito. Cumbres Calchaquíes. Departamento Tafí del Valle. Tucumán. Argentina. 4.000-4.300 msnm. C. Halloy. 21 diciembre 1974. 
Paratipo FML 00776. Vega Pozuelos. Cumbres Calchaquíes. Departamento Tafí del Valle. Tucumán. Argentina. 4.150 msnm. S. Halloy. Abril 1977.

Paratipo FML 00850. Morena W del Valle del Mina. Cumbres Calchaquíes. Departamento Tafí del Valle. Tucumán. Argentina. 4.250 msnm. S. Halloy. 23 setiembre 1978.

Paratipo FML 00884. Camino a Huaca Huasi desde la Piedra Grande (Falda W). Cumbres Calchaquíes. Departamento Tafí del Valle. Tucumán. Argentina. $4.150 \mathrm{msnm}$. A. Marcus. 15 abril 1979.

Comentarios. - Los paratipos FML 00531/1 y FML 00532/1 fueron enviados al Dr. J. M. Cei, y probablemente están depositados en la Unidad de Herpetología - Facultad de Química Bioquímica y Farmacia, Universidad Nacional de San Luis, San Luis, Argentina. Desafortunadamente, las etiquetas originales fueron removidas, por lo que no podemos asegurar su identificación (B. Espeche com. pers.). El paratipo FML 00532/8 fue enviado al Dr. R. Etheridge, número actual desconocido. Dos ejemplares del lote FML 00538 fueron enviados en canje al Zoologische Staatssammlung München, Munich, Alemania; números actuales: ZSM 258/1982/1 (macho), y ZSM 258/1982/2 (hembra) (Franzen y Glaw, 2007). Un paratipo FML 00538 enviado en canje a la Universidad de Concepción, Chile; número actual MZUC 12579. Los paratipos FML 00605 y FML 00663 fueron enviados en canje al Museu de Zoologia da Universidade de São Paulo, Brasil; números actuales MZUSP 58033 y MZUSP 58032. Dos paratipos del lote FML 00683 fueron enviados en canje al Carnegie Museum of Natural History, Pittsburgh, Pennsylvania, USA; números actuales CM Herps 76256 (hembra) y CM Herps 76257 (macho). El paratipo FML 00962 fue enviado en canje al Instituto de Biología Animal, Mendoza, Argentina; número actual IBA R01397. Los embriones de los ejemplares FML 00660 y FML 00661 no se encuentran en la colección.
Liolaemus huayra

Abdala, Quinteros y Espinoza, 2008

Abdala C.S., Quinteros S., Espinoza R. 2008. Two new species of Liolaemus (Iguania: Liolaemidae) from the puna of Northwestern Argentina. Herpetologica 64 (4): 458-471.

Holotipo FML 18069 (macho). Cerro El Pichao. Departamento Tafí del Valle. Tucumán. Argentina. 26²2'26,7”S 6604'54,2”W. $3.545 \mathrm{msnm}$. C. Abdala y S. Quinteros. 21 noviembre 2006.

Paratipos FML 01219 (2 machos, 2 hembras, 3 juveniles). Puesto Pacheco. Sierra de Quilmes, subiendo desde Pichao. Departamento Tafí del Valle. Tucumán. Argentina. O. Pagaburo y E. Terán. 08 marzo 1982.

\section{Liolaemus inacayali Abdala, 2003}

Abdala C.S. 2003. Cuatro nuevas especies del género Liolaemus (Iguania: Liolaemidae), pertenecientes al grupo boulengeri, de la $\mathrm{Pa}$ tagonia, Argentina. Cuadernos de Herpetología 17 (1-2): 3-32.

Holotipo FML 13221 (macho). No de campo REE 750. 2,3 km al S de intersección de Rutas Provinciales 76 y 23, sobre Ruta 76. $3,4 \mathrm{~km}$ al $\mathrm{S}$ de Ingeniero Jacobacci. Departamento 25 de Mayo. Río Negro. Argentina. 4120,022'S 69²8,233'W. 898 msnm. C. Abdala, R. Espinoza y J. Wiens. Febrero 2001.

Paratipo FML 08328 - FML 08329. No de campo 676 y 678. Ingeniero Jacobacci. Departamento 25 de Mayo. Río Negro. Argentina. J. C. Acosta. 05 marzo 1992.

Paratipos FML 13222 - FML 13236 (4 machos, 11 hembras). No de campo REE 749, 751-763, 781 respectivamente. Los mismos datos que el holotipo.

Paratipo FML 13237 (hembra). No de campo REE 775. 9,1 km al E de Maquinchao. Km 330 de Ruta Provincial 23. Departamento 25 de Mayo. Río Negro. Argentina.

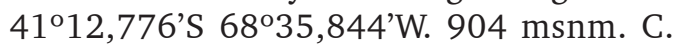
Abdala, R. Espinoza y J. Wiens. 13 febrero 2001. 
Paratipos FML 13258 - FML 13261 (2 machos, 2 hembras). No de campo JCA 37443746 y 3749 . Ingeniero Jacobacci. Departamento 25 de Mayo. Río Negro. Argentina. J. C. Acosta y G. Blanco. Marzo 1992.

\section{Liolaemus inti}

Abdala, Quinteros y Espinoza, 2008

Abdala C.S., Quinteros S., Espinoza R. 2008. Two new species of Liolaemus (Iguania: Liolaemidae) from the puna of Northwestern Argentina. Herpetologica 64 (4): 458-471.

Holotipo FML 18399 (macho). Estación 15 del Via Crucis. Cerro de la Virgen. Cachi Adentro. Departamento Cachi. Salta. Argentina. 2503'07,6"S 66¹7'29,4”W. 3.938 msnm. C. Abdala y S. Quinteros. 18 noviembre 2006.

Paratipos FML 01669 (7 ejemplares). Cerro de la Virgen. Cachi Adentro. Departamento Cachi. Salta. Argentina. 3.700-3.860 msnm. O. Pagaburo y E. Pereyra. 28 enero 1985.

Comentarios. - La fecha de colección de los paratipos FML 01669 en la descripción original (21 enero 1985) se debe probablemente a un error de mecanografiado.

\section{Liolaemus irregularis Laurent, 1986}

Laurent R. F. 1986. Descripciones de nuevos Iguanidae del género Liolaemus. Acta zoologica lilloana 38 (2): 87-105.

Holotipo FML 01360 (macho). San Antonio de los Cobres. Departamento Los Andes. Salta. Argentina. E. Terán y O. Pagaburo. 0911 enero 1983.

Paratipos FML 00085 (10 ejemplares). San Antonio de los Cobres. Departamento Los Andes. Salta. Argentina. $4.000 \mathrm{msnm}$. A. Budin. Noviembre 1929.

Paratipos FML 00442 (1 macho, 4 hembras). Río San Antonio, cerca de San Antonio de los Cobres. Departamento Los Andes. Salta. Argentina. S. Halloy y C. Halloy. Febrero 1970.
Paratipos FML 00444 (2 ejemplares). Sey. Departamento Susques. Jujuy. Argentina. S. Halloy y C. Halloy. Febrero 1970.

Paratipo FML 00454 (macho). Quebrada del Toro. S de Santa Rosa de Tastil. Departamento Rosario de Lerma. Salta. Argentina. O. Pagaburo. 07 abril 1971.

Paratipo FML 00688. San Antonio de los Cobres. Departamento Los Andes. Salta. Argentina. 3.700 msnm. E. Lavilla y G. Scrocchi. Febrero 1975.

Paratipos FML 00689 (5 machos). San Antonio de los Cobres. Departamento Los Andes. Salta. Argentina. $3.700 \mathrm{msnm}$. E. Lavilla y G. Scrocchi. Febrero 1975.

Paratipo FML 00753 (macho). Pastos Chicos. Departamento Susques. Jujuy. Argentina. 3.700 msnm. O. Pagaburo y G. Scrocchi. 11-14 mayo 1977.

Paratipo FML 00925 (macho). San Antonio de los Cobres. Departamento Los Andes. Salta. Argentina. H. Salas. Enero 1980.

Paratipo FML 01313 (macho). Abra de Pives. Arroyo Aguas Blancas. Departamento Tumbaya. Jujuy. Argentina. E. Lavilla. 22 noviembre 1981.

Paratipos FML 01359 (22 ejemplares). San Antonio de los Cobres. Departamento Los Andes. Salta. Argentina. E. Terán y O. Pagaburo. 09-11 enero 1983.

Comentarios. - El paratipo FML 00454 fue designado posteriormente por Lobo y Laurent (1995) como paratipo de Liolaemus albiceps. Los paratipos FML 00085 son diez ejemplares, no ocho como se mencionó en la descripción original. Por error, los paratipos FML 01359 fueron citados en la descripción original como FML 01360, aunque una de las hembras se identificó con el número verdadero en la Figura 9. Dos paratipos del lote FML 01359 fueron enviados en canje a la University of Kansas Natural History Museum; números actuales KUH 206712 206713. Dos paratipos del lote FML 01359 fueron enviados al Dr. J. M. Cei, y probablemente están depositados en la Unidad de Herpetología - Facultad de Química Bioquímica y Farmacia, Universidad Nacional de San Luis, San Luis, Argentina. Desafortunadamente, las etiquetas originales fueron re- 
movidas, por lo que no podemos asegurar su identificación (B. Espeche com. pers.).

\section{Liolaemus josei Abdala, 2005}

Abdala C. S. 2005. Dos nuevas especies del género Liolaemus (Iguania: Liolaemidae) y redescripción de Liolaemus boulengeri (Koslowskyi, 1898) Cuadernos de Herpetología 19 (1): 3-33.

Holotipo 15544 (macho). No de campo CA 294. Puente El Zampal. Por Ruta Nacional 40. Médanos a orillas de Río Grande. Departamento Malargüe. Mendoza. Argentina. C. Abdala, E. Malovini y J. Abdala. Enero 2002.

Paratipos FML 07219 - FML 07223 (1 macho, 1 hembra, 3 juveniles). Ruta Nacional 40. Departamento Malargüe. Mendoza. Argentina. 3545'04" 69034'49"W. 2.064 msnm. F. Lobo, C. S. Abdala y F. Parisi. Enero 1998.

Paratipos FML15545 - FML 15547 (1 macho, 2 hembras). Los mismos datos que el holotipo.

Comentarios. - La fecha de colección de los paratipos FML 07219 a FML 07223 en la descripción original (Enero 1997) se debió probablemente a un error de mecanografiado.

\section{Liolaemus kingi baguali Cei y Scolaro, 1983}

Cei J. M., Scolaro J. A. 1983. Una nueva forma geográfica de Liolaemus kingi de Santa Cruz, Argentina (Lacertilia: Iguanidae). Neotrópica 29 (82): 209-214.

Paratipo FML 01247 (hembra). Pedregal volcánico de la Sierra del Bagual. 40 km al S de Lago Cardiel. Santa Cruz. Argentina. 600 msnm. J. M. Cei y J. Olazábal. 14 marzo 1982.

Comentarios: actualmente Liolaemus baguali Cei y Scolaro, 1983, según Cei y Scolaro (1996).

\section{Liolaemus kolengh \\ Abdala y Lobo, 2006}

Abdala C., F. Lobo. 2006. Description of a new patagonian Lizard of the Liolaemus silvanae group (Iguania: Liolaemidae). South American Journal of Herpetology 1 (1): 18.

Holotipo FML 10870 (macho). No de campo PMC 254. Cerca de Río Ceballos. Ruta Provincial 39 camino a Monte Ceballos. Aproximadamente $80 \mathrm{~km}$ al S de Los Antiguos. Departamento Lago Buenos Aires. Santa Cruz. Argentina. 47 $01,542^{\prime} \mathrm{S}$ 71²8,475’W. 1.485 msnm. C. Abdala, P. Cacivio, L. Federico y F. Lobo. 18 enero 2000.

Paratipos FML 10871 (macho). No de campo REE 845. Ruta Provincial 39 camino a Monte Ceballos. Aproximadamente $80 \mathrm{~km}$ al S de Los Antiguos. Departamento Lago Buenos Aires. Santa Cruz. Argentina.

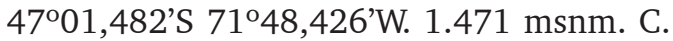
Abdala, R. E. Espinoza y J. J. Wiens. 18 enero 2001.

Paratipos FML10872 - FML 10879 (4 machos, 4 hembras). $\mathrm{N}^{\circ}$ de campo PMC 221, 224- 225, 229, 231, 244, 246 у 251 respectivamente. Los mismos datos que el holotipo.

Comentarios. - Los datos mencionados acá son los que figuran en los ejemplares y en los registros de la colección y son algo diferentes a los publicados en la descripción original.

\section{Liolaemus koslowskyi Etheridge, 1993}

Etheridge R. 1993. Lizards of the Liolaemus darwinii complex (Squamata: Iguania: Tropiduridae) in Northern Argentina. Bollettino del Museo regionale di Scienze naturali di Torino 11 (1): 137-199.

Holotipo FML 02659. 9,2 km al E de la Plaza Central de Pituil, sobre Ruta Provincial 11. Departamento Famatina. La Rioja. Argentina. 28 $34^{\prime} \mathrm{S} 67^{\circ} 27^{\prime} \mathrm{W}$. R. Etheridge, E. Lavilla, R. Montero, A. Marcus y O. Pagaburo. 07 febrero 1991. 
Paratipos FML 02660. (6 ejemplares). Los mismos datos que el holotipo.

Comentarios. - La localidad tipo pertenece a la provincia de La Rioja, no a Catamarca como se mencionó en la descripción original. Además, la ruta que sale hacia el este desde Pituil, es la Ruta Nacional 40, no la Ruta Provincial 11.

\section{Liolaemus laurenti Etheridge, 1992}

Etheridge R. 1992. A new psammophilus lizard of the genus Liolaemus (Squamata: Tropiduridae) from Northwestern Argentina. Bollettino del Museo regionale di Scienze naturali di Torino 10 (1): 1-19.

Holotipo FML 02518. $12 \mathrm{~km}$ al E de la Plaza Central de Pituil, sobre Ruta Provincial 11. Departamento Famatina. La Rioja. Argentina. R. Etheridge, E.Lavilla, A.Marcus, R.Montero y O.Pagaburo. 7 febrero 1991.

Paratipos FML 02519 - FML 02522. Los mismos datos que el holotipo.

Comentarios. - La localidad tipo pertenece a la provincia de La Rioja, no a Catamarca como se mencionó en la descripción original. Además, la ruta que sale hacia el este desde Pituil, es la Ruta Nacional 40, no la Ruta Provincial 11.

\section{Liolaemus lavillai Abdala y Lobo, 2006}

Abdala C., Lobo F. 2006. Nueva especie del grupo de Liolaemus darwinii (Iguania: Liolaemidae) del noroeste de Argentina. Cuadernos de Herpetologia 19 (2): 3-18.

Holotipo FML 16597 (macho). Cuesta del Acay. Departamento La Poma. Salta. Argentina. 3.800 msnm. O. Pagaburo, E. Terán y E. Pereyra. 22 enero 1985.

Paratipos FML 03009 (12 ejemplares). $3,5 \mathrm{~km}$ al W de Agua Negra, sobre ruta provincial 33. Departamento Chicoana. Salta. Argentina. O. Pagaburo. R. Etheridge, L. Grismer y J. McGuire. 19 enero 1991.

Paratipos FML 01670-1 - 1670-8 (4 machos, 1 hembra, 3 juveniles). Ladera W-NW del Cerro de la Virgen. Cachi Adentro. De- partamento Cachi. Salta. Argentina. 3.7003.860 msnm. O. Pagaburo y E. Pereyra. 28 enero 1985.

Paratipos FML 16598 - FML 16607 (5 machos, 5 hembras). Los mismos datos que el holotipo.

Paratipos FML 16608 - FML 16611. Cuesta del Acay. Departamento La Poma. Salta. Argentina. 4.100 msnm. O. Pagaburo, E. Terán y E. Pereyra. 22 enero 1985.

Paratipos FML 16612 - FML 16621. 26,1 $\mathrm{km}$ al $\mathrm{N}$ de La Poma, sobre Ruta Nacional 40. Departamento La Poma. Salta. Argentina. O. Pagaburo, R. Etheridge, L. Grismer y J. McGuire. 19 enero 1991.

\section{Liolaemus loboi Abdala, 2003}

Abdala C. S. 2003. Cuatro nuevas especies del género Liolaemus (Iguania: Liolaemidae), pertenecientes al grupo boulengeri, de la Patagonia, Argentina. Cuadernos de Herpetología 17 (1-2): 3-32.

Holotipo FML 14802 (macho). No de campo CSA 270. Intersección de Rutas Nacionales 237 y 231. Departamento Los Lagos. Neuquén. Argentina. C.Abdala, E. Malovini y J. Abdala. Enero 2003.

Paratipos FML 07770. No de campo 2. Parque Nacional Nahuel Huapi. Intersección de Rutas Nacionales 237 y 231. Departamento Los Lagos. Neuquén. Argentina. M. Halloy y A. Labra (Proyecto Head Bobbing). 08 enero 1999.

Paratipo FML 07780 - FML 07782. № de campo 12-14. Parque Nacional Nahuel Huapi. Intersección de Rutas Nacionales 237 y 231. Departamento Los Lagos. Neuquén. Argentina. M. Halloy y A. Labra (Proyecto Head Bobbing). 10 enero 1999.

Paratipo FML 07789. No de campo 21. Parque Nacional Nahuel Huapi. Intersección de Rutas Nacionales 237 y 231. Departamento Los Lagos. Neuquén. Argentina. M. Halloy y A. Labra (Proyecto Head Bobbing). 19 enero 1999.

Paratipos FML 13253 - FML 13256 (2 machos, 1 hembra, 1 macho juvenil). $N^{\circ}$ de campo CSA 151-154. Intersección de Rutas 
Nacionales 237 y 231. Departamento Los Lagos. Neuquén. Argentina. C. Abdala, G. Mena y C. Carrizo. Abril 2002.

Paratipos FML 14796 - FML 14801. No de campo CSA 264-269. Los mismos datos que el holotipo.

\section{Liolaemus mapuche Abdala, 2002}

Abdala C. S. 2002. Nuevo Liolaemus (Iguania: Liolaemidae) perteneciente al grupo boulengeri de la provincia de Neuquén, Argentina. Cuadernos de Herpetología 16 (1): 3-13.

Holotipo FML 11462 (macho). $\mathrm{N}^{\circ}$ de campo CSA $9.15 \mathrm{~km}$ al S de Paso de Indios, sobre Ruta Provincial 10. Departamento Zapala. Neuquén. Argentina. C. Abdala, E. Malovini y J. Abdala. Enero 2002.

Paratipos FML 11463 - FML 11472 (7 machos, 3 hembras). $\mathrm{N}^{\circ}$ de campo CSA 2-4, 6-8, 10-12 y sin número. Los mismos datos que el holotipo.

Paratipos FML 11473-11481 (4 machos, 5 hembras). $\mathrm{N}^{\circ}$ de campo CSA 1, 34-38, 4041 y $45.3 \mathrm{~km}$ al SW de Ramón Castro, sobre Ruta Nacional 22. Departamento Zapala. Neuquén. Argentina. C. Abdala, E. Malovini y J. Abdala. Enero 2002.

Paratipos FML 11482 - FML 11487 (1 macho, 5 hembras). $N^{\circ}$ de campo CSA 2730, 32-33. $33 \mathrm{~km}$ al SE de Zapala, sobre Ruta Nacional 40. Departamento Zapala. Neuquén. Argentina. C. Abdala, E. Malovini y J. Abdala. Enero 2002.

\section{Liolaemus martorii Abdala, 2003}

Abdala C. S. 2003. Cuatro nuevas especies del género Liolaemus (Iguania: Liolaemidae), pertenecientes al grupo boulengeri, de la Patagonia, Argentina. Cuadernos de Herpetología 17 (1-2): 3-32.

Holotipo FML 13238 (macho). $\mathrm{N}^{\circ}$ de campo RM 3800. Médanos a orillas del mar. Las Grutas. Departamento San Antonio Oeste. Río Negro. Argentina. R. Martori y L. Aún. 20 enero 1996.
Paratipos FML 02968 (4 hembras). Caleta de los Loros. Departamento Adolfo Alsina. Río Negro. Argentina. J. M. Chañi y P. Bellagamba. Octubre 1985.

Paratipos FML 13239 - FML 13247 (9 ejemplares). $\mathrm{N}^{\mathrm{O}}$ de campo RM 3791-3798 y RM 3801. Los mismos datos que el holotipo.

Paratipo FML 13248 - FML 13251 (4 ejemplares). $\mathrm{N}^{\circ}$ de campo CSA $128 ; 130$; 132 y 133. Médanos a orillas del mar. Las Grutas. Departamento San Antonio Oeste. Río Negro. Argentina. C. Abdala, E. Malovini y J. Abdala. Enero 2002.

Paratipo FML 13252 (macho). $\mathrm{N}^{\mathrm{o}} \mathrm{de}$ campo RM 4057. La Lobería, $30 \mathrm{~km}$ al $\mathrm{S}$ de Viedma. Departamento Adolfo Alsina. Río Negro. Argentina. R. Martori y L. Aún. Enero 1997.

Comentarios.- En la descripción original los paratipos FML 13248 - FML 13251 fueron mencionados como si fueran cinco ejemplares (dos machos y tres hembras). También, los paratipos FML13239 - FML 13247 fueron citados como si fueran 8 ejemplares (cuatro machos y cuatro hembras).

\section{Liolaemus millcayac}

Abdala y Juárez Heredia, 2013

Abdala C. S., Juárez Heredia V. 2013. Taxonomía y filogenia de un grupo de lagartos amenazados: el grupo de Liolaemus anomalus (Iguania: Liolaemidae). Cuadernos de Herpetología 27 (2): 109-153.

Holotipo FML 28600 (macho). No de campo GS 3339. A $1 \mathrm{~km}$ de Ruta Nacional 40, desvío hacia las Lagunas del Rosario. Departamento Lavalle. Mendoza. Argentina. C. Abdala, J. L. Acosta, A. Laspiur y R. Semhan. Diciembre 2010.

Paratipos FML 22434 - FML 22436. N ${ }^{\circ}$ de campo GS 3000-3001 y sin número. 46 km al NW de El Encón. Ruta Nacional 141. Departamento 25 de Mayo. San Juan. Argentina. G. Scrocchi, C. Abdala, J. Nori, A. Laspiur. 11 octubre 2008.

Paratipos FML 28601 - FML 28603. No de campo GS 3338, 3340-3341. Los mismos datos que el holotipo.

Comentarios. - el holotipo fue citado 
en la descripción original por el número de campo pero como si fuera número de la colección (FML 3339). Otros ejemplares fueron citados con los números de campo copiados erróneamente y además como si fueran números de la colección (FML): los paratipos FML 28601 - FML 28603 fueron mencionados como FML 33338 y FML 840-841. La numeración correcta es la mencionada acá.

\section{Liolaemus montanus Koslowsky, 1898}

Koslowsky J. 1898. Enumeración sistemática y distribución geográfica de los reptiles argentinos. Rev. Mus. La Plata 8: 161-200

Neotipo FML 00909 (macho). Base N del Cerro Manchao. Catamarca. Argentina. 3.900 msnm. S. Halloy. 25 octubre 1979.

Comentarios.-Designado por Laurent (1982).

\section{Liolaemus morenoi}

Etheridge y Christie, 2003

Etheridge R., Christie M. I. 2003. Two new species of the lizard genus Liolaemus (Squamata: Liolaemidae) from northern Patagonia, with comments on Liolaemus rothi. Journal of Herpetology 37 (2): 325-341.

Paratipo FML 11922 y FML 11923. No de campo MIC 1518 y 1535 respectively. Ruta Nacional 40, $12 \mathrm{~km} \mathrm{~N}$ de la intersección con la Ruta Provincial 13. Departamento Zapala. Neuquén. Argentina. 900 msnm. M. I. Christie. 27 noviembre 2000 .

\section{Liolaemus olongasta Etheridge, 1993}

Etheridge R. 1993. Lizards of the Liolaemus darwinii complex (Squamata: Iguania: Tropiduridae) in Northern Argentina. Bollettino del Museo regionale di Scienze naturali di Torino 11 (1): 137-199.

Holotipo FML 02667. 51,3 km al S de Villa Unión, sobre Ruta Provincial 26. Departamento General Lavalle. La Rioja. Argentina. $29^{\circ} 18^{\prime}$ S $68^{\circ} 12^{\prime}$ W. R. Etheridge, E. Lavilla, R. Montero, A. Marcus y O. Pagaburo. 10 febrero 1991.
Paratipos FML 02668 (2 ejemplares). Los mismos datos que el holotipo.

\section{Liolaemus orientalis chlorostictus Laurent, 1991}

Laurent R. F. 1991. Sobre algunas especies nuevas y poco conocidas de Liolaemus (Iguanidae) de la provincia de Jujuy, Argentina. Acta zoologica lilloana 40 (2): 91-108.

Holotipo FML 02284 (macho). Camino a Mina Pirquitas, $42 \mathrm{~km}$ antes del asentamiento poblacional, sobre la cuesta Fundiciones. Departamento Rinconada. Jujuy. Argentina. 22 ${ }^{\circ} 41^{\prime}$ ' 66³1'W. 4.150 msnm. O. Pagaburo, E. Pereyra y J. Bracamonte. 25 enero 1984.

Paratipos FML 01510/1-2; 4-7; 9-13; 15 17 (14 ejemplares). Los mismos datos que el holotipo.

Paratipos FML 01515 (14 ejemplares). Los mismos datos que el holotipo.

Paratipos FML 01522/1-15, 17-22 (21 ejemplares). Mina Pirquitas. Departamento Rinconada. Jujuy. Argentina. O. Pagaburo, E. Pereyra y J. Bracamonte. 19-24 enero 1984.

Comentarios. - Actualmente Liolaemus chlorostictus Laurent, 1991, según Abdala et al. (2008). El paratipo 01522-16 fue donado al Museo Nacional de Historia Natural, La Paz, Bolivia: número actual CBF 499. Los paratipos FML 01510/3 y FML 01510/14 fueron enviados en canje al Museu de Zoología de São Paulo, Brasil; números actuales MZUSP 72503 y 72504. El paratipo FML 01510/18 no se encuentra en la colección. Las coordenadas del lote FML 01522 mencionadas en la descripción original son erróneas.

\section{Liolaemus orko Abdala y Quinteros 2008}

Abdala C. S., Quinteros A. S. 2008. Una nueva especie de Liolaemus (Iguania: Liolaemidae) endémica de la Sierra de Fiambalá, Catamarca Argentina. Cuadernos de Herpetología 22 (1): 35-47.

Holotipo FML 18416 (macho). Puesto La Lagunita. Sierra de Fiambalá. Departamen- 
to Tinogasta. Catamarca. Argentina. 4.0004.200 msnm. S. Barrionuevo, J. M. Díaz Gómez y S. Quinteros. 22 marzo 2006.

Paratipos FML 18417-18421. Los mismos datos que el holotipo.

\section{Liolaemus (Ortholaemus) salinicola Laurent, 1986}

Laurent R.F. 1986. Descripciones de nuevos Iguanidae del género Liolaemus. Acta zoologica lilloana 38 (2): 87-105.

Holotipo FML 01307 (macho). Extremo septentrional del Salar de Pipanaco. Departamento Pomán. Catamarca. Argentina. O. Pagaburo y E. Terán. 31 octubre 1982.

Liolaemus pacha

Juárez Heredia, Robles y Halloy, 2013

Juárez Heredia V., Robles C., Halloy M. 2013. A new species of Liolaemus from the darwinii group (Iguania: Liolaemidae) Tucumán province, Argentina. Zootaxa 3681:524538.

Holotipo FML 02448/1 (macho). Km 98 Ruta Provincial 307. Departamento Tafí del Valle. Tucumán. Argentina. 26 40’1,5”S 6549'5,1”W. 2.725 msnm. O. Pagaburo. 21 abril 1990.

Paratipos FML 02448/3-4 y 6-9. Los mismos datos que el holotipo.

Comentarios.- El año de colección fue mencionado erróneamente como 1999 en la descripción original.

\section{Liolaemus pagaburoi \\ Lobo y Espinoza, 1999}

Lobo, F., Espinoza R. E. 1999. Two new cryptic species of Liolaemus (Iguania: Tropiduridae) from Northwestern Argentina: Resolution of the purported reproductive bimodality of Liolaemus alticolor. Copeia 1999 (1): 122-140.

Holotipo FML 06069 (macho). Abra de El Infiernillo. Ruta Provincial 307. Departamento Tafí del Valle. Tucumán. Argentina. 2644'S 6545'W. 3.042 msnm. F. Lobo, C. Terán y J. M. Lefebvre. 26 enero 1997.
Paratipos FML 06070 (10 ejemplares). Los mismos datos que el holotipo.

\section{Liolaemus parthenos \\ Abdala, Baldo, Juárez y Espinoza, 2016}

Abdala C. S. A., Baldo D., Juárez R. A., Espinoza R. 2016. The first parthenogenetic pleurodont Iguanian: A new all-females Liolaemus (Squamata: Liolaemidae) from Western Argentina. Copeia 104 (2): 487-497.

Holotipo FML 16221 (hembra). No de campo CSA 112. Ruta Provincial 180. Médanos en márgen de Embalse El Nihuil. Departamento San Rafael. Mendoza. Argentina. 3502'19,77'S 6840'12,60”W. 1.305 msnm. C. Abdala, J. Abdala y E. Malovini. Enero 2002.

Paratipos FML 16222 - FML 16224. No de campo CSA 096, 109-110. Los mismos datos que el holotipo.

Comentarios. - El año de colección fue mencionado erróneamente como 2001 en la descripción original.

\section{Liolaemus parvus \\ Quinteros, Abdala, Díaz Gómez y Scrocchi, 2008}

Quinteros, A. S., Abdala C. S., Díaz-Gómez J. M., Scrocchi G. J. 2008. Two new species of Liolaemus (Iguania: Liolaemidae) from Central West Argentina. South American Journal of Herpetology 3 (2): 101-111.

Holotipo FML 16548 (macho). No de campo CA $594.58 \mathrm{~km}$ al W de Jagüé, camino a Laguna Brava. Departamento General Sarmiento. La Rioja. Argentina. 28 29'24,3"S 68 49'45,3”W. 3.532 msnm. C. Abdala, S. Quinteros y C. Robles. 09 octubre 2005.

Paratipos FML 02593 (3 machos). 67 km al W de Mendoza, por ruta Nacional 7. Departamento Las Heras. Mendoza. Argentina. M. Halloy. 21 enero 1991.

Paratipos FML 16121-FML 16125 (3 machos, 2 hembras). No de campo CA 454-458. Río Gualcamayo. El Peñón. Departamento Jáchal. San Juan. 2941'28,9"S 6848'39,3”W. $2.820 \mathrm{msnm}$. C. Abdala, M. J. Tulli y S. Barrionuevo. 02 octubre 2004. 
Paratipos FML 16546 - FML 16547 y FML 16549 (2 machos, 1 hembra). $\mathrm{N}^{\circ}$ de campo CA 592-593, 595. Los mismos datos que el holotipo.

Comentarios. - La localidad de origen de los paratipos FML 02593 fue mencionada en la descripción original, por error, como 67 $\mathrm{km}$ al W de Uspallata; de acuerdo a las notas de campo y a los registros de la colección, la localidad es la mencionada acá.

\section{Liolaemus paulinae}

Donoso Barros 1961

Donoso-Barros R. 1961. Three new lizards of the genus Liolaemus from the highest Andes of Chile and Argentina. Copeia 1961 (4): 387-391.

Paratipo FML 01196 (macho). No original 538. Orillas del Río Loa. Calama. Antofagasta. Chile. R. Donoso Barros. 14 febrero 1958.

Comentarios. - Ejemplar citado con el número original en la descripción de la especie y posteriormente recibido en intercambio.

Liolaemus pipanaco

Abdala y Juárez Heredia, 2013

Abdala C. S., Juárez Heredia V. 2013. Taxonomía y filogenia de un grupo de lagartos amenazados: el grupo de Liolaemus anomalus (Iguania: Liolaemidae). Cuadernos de Herpetología 27 (2): 109-153.

Holotipo FML 19225. Salar de Pipanaco, entrando por Puesto Río Blanco. 36 $\mathrm{km}$ al S de Andalgalá. Departamento Pomán. Catamarca. Argentina. 2749'42,4" S 66¹4'59,0”W. 737 msnm. G. Scrocchi, C. Abdala, S. Quinteros, J. P. Juliá y J. C. Stazzonelli. 21 octubre 2007.

Paratipo FML 18396. No de campo GS 2738. Pasando por Puesto Río Blanco al W para llegar al Salar de Pipanaco. Departamento Andalgalá. Catamarca. Argentina. 2749'23,9"S 65¹4'38,2" W. 731 msnm. G. Scrocchi, C. Abdala y S. Quinteros. 20 marzo 2007.

Comentarios. - Las fechas de colección del holotipo y el paratipo fueron intercam- biadas por error en la descripción original de la especie.

\section{Liolaemus poecilochromus Laurent, 1986}

Laurent R. F. 1986. Descripciones de nuevos Iguanidae del género Liolaemus. Acta zoologica lilloana 38 (2): 87-105.

Holotipo FML 01176-5 (macho). Los Nacimientos. $3 \mathrm{~km}$ al SE de la Escuela. Departamento Antofagasta de la Sierra. Catamarca. Argentina. E. Terán y O. Pagaburo. 02 diciembre 1981.

Alotipo FML 01176-1. Los mismos datos que el holotipo.

Paratipos FML 01170 (3 hembras). Filos del Pirqueal. Los Nacimientos. Departamento Antofagasta de la Sierra. Catamarca. Argentina. O. Pagaburo y E. Terán. 27 noviembre 1981.

Paratipos FML 01171 (10 ejemplares). Campos frente a Peña Beltrán. Los Nacimientos. Departamento Antofagasta de la Sierra. Catamarca. Argentina. O. Pagaburo y E. Terán. 26 noviembre 1981.

Paratipos FML 01172 (17 ejemplares). Campo entre Escuela y Vega Ancha, a lo largo de $8 \mathrm{~km}$. Los Nacimientos. Departamento Antofagasta de la Sierra. Catamarca. Argentina. O. Pagaburo y E. Terán. 28 noviembre 1981.

Paratipos FML 01173 (6 machos, 1 hembra, 2 juveniles). Holladita El Barreal. Volcanes de Los Nacimientos. Departamento Antofagasta de la Sierra. Catamarca. Argentina. O. Pagaburo y E. Terán. 02 diciembre 1981.

Paratipos FML 01174 (1 macho, 1 hembra, 2 juveniles). Cerro Beltrán. Departamento Antofagasta de la Sierra. Catamarca. Argentina. O. Pagaburo y E. Terán. 01 diciembre 1981.

Paratipos FML 01176-2 - FML 01176-4 y FML 01176-6 - FML 01176-12 (10 ejemplares). Los mismos datos que el holotipo.

Paratipos FML 01177 (4 machos, 1 hembra). SE de Los Nacimientos. Departamento Antofagasta de la Sierra. Catamarca. Argentina. E. Terán y O. Pagaburo. 26 noviembre - 01 diciembre 1981. 
Paratipos FML 01181 (1 hembra, 5 juveniles). Los Nacimientos. Pie del Cerro Chinina. Departamento Antofagasta de la Sierra. Catamarca. Argentina. O. Pagaburo y E. Terán. 02 diciembre 1981.

Paratipos FML 01182 (3 ejemplares). Los Nacimientos. Pie del Cerro Chinina. Departamento Antofagasta de la Sierra. Catamarca. Argentina. E. Terán y O. Pagaburo. 28 noviembre 1981.

Comentarios. - Dos ejemplares del lote FML 01171 fueron enviados a la Facultad de Ciencias, Universidad Nacional de Mar del Plata. Argentina; números actuales UNMdP 821 (macho) y UNMdP 813 (hembra). Quince ejemplares del lote FML 01172 fueron canjeados o donados a diferentes museos: Museo Provincial de Ciencias Naturales Florentino Ameghino, Santa Fe, Argentina, (número actual MFA ZV-Squa 153); Natural History Museum of Los Angeles County, Los Angeles, California, USA (números actuales LACM 136711-136712); Muséum d'Histoire naturelle, Geneva, Suiza (números actuales MHNG 2213.74 y MHNG 2213.75); University of Michigan Museum of Zoology, USA, (números actuales UMMZ 180423-180424); Instituto de Biología Animal, Mendoza, Argentina, (número actual IBA R-01434, 2 ejemplares); dos ejemplares fueron enviados al Dr. J. M. Cei, y probablemente están depositados en la Unidad de Herpetología - Facultad de Química Bioquímica y Farmacia, Universidad Nacional de San Luis, San Luis, Argentina. Desafortunadamente, las etiquetas originales fueron removidas, por lo que no podemos asegurar su identificación (B. Espeche com. pers.). Dos ejemplares fueron enviados al Muséum national d'Histoire naturelle, Paris, Francia; uno al Dr. R. Etheridge y uno al Dr. Borsuk Bialinika y lamentablemente desconocemos sus números actuales.

\section{Liolaemus polystictus Laurent, 1992}

Laurent R.F. 1992. On some overlooked species of the genus Liolaemus Wiegmann
(Reptilia: Tropiduridae) from Perú. Breviora 494: 1-33.

Paratipos FML 01683 (2 ejemplares). No original MCZ 45846 (macho) y MCZ 45848 (juvenil). Santa Inez aproximadamente 100 $\mathrm{km}$ al S de Huancavelica. Departamento Huancavelica. Perú. $13^{\circ} 12^{\prime}$ S $75^{\circ} 05^{\prime}$ W. W. F. Walker Sr. Febrero 1939.

Comentarios: ejemplares mencionados con el número MCZ en la descripción original y posteriormente recibidos en canje.

\section{Liolaemus porosus \\ Abdala, Paz y Semhan, 2013}

Abdala C. S., Paz M. M., Semhan R. V. 2013. Nuevo Liolaemus (Iguania: Liolaemidae) con novedoso carácter morfológico, de la frontera entre Argentina y Chile. Revista de Biología Tropical 61 (4): 1563-1584.

Holotipo FML 24771 (macho). $\mathrm{N}^{\mathrm{O}} \mathrm{de}$ campo OGS 4367. $20 \mathrm{~km}$ al E de Gendarmería de Socompa. Departamento Los Andes.

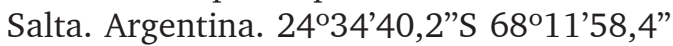
W. 3.707 msnm. C. Abdala y R. Semhan. 04 abril 2012.

Paratipo FML 24772 (hembra). No de campo OGS 4366. $23 \mathrm{~km}$ al E de Gendarmería de Socompa. Departamento Los Andes. Salta. Argentina. 2436'16,5"S 68²12'33,1"W. $3.861 \mathrm{msnm}$. C. Abdala y R. Semhan. 04 abril 2012.

Paratipo FML 24773 (macho). $\mathrm{N}^{\circ}$ de campo OGS 4368. Los mismos datos que el holotipo.

Paratipo FML 24774 (macho). No de campo OGS 4369. $13 \mathrm{~km}$ al NW de Chuculaqui. Departamento Los Andes. Salta. Argentina. 2440'17,3"S 6809'18,5”W. 4.209 msnm. C. Abdala y R. Semhan. 03 abril 2012.

Paratipos FML 24778 - FML 24779 (hembras). No de campo OGS 4373-4374. $29 \mathrm{~km}$ al E de Gendarmería de Socompa. Departamento Los Andes. Salta. Argentina. 24³8'39,8"S 68¹1'22,6”W. 3.884 msnm. C. Abdala y R. Semhan. 04 abril 2012.

Paratipo FML 24780 (macho). $\mathrm{N}^{\circ}$ de campo OGS 4396. Pie E del Volcán Socompa. Departamento Los Andes. Salta. Argentina. 
$24^{\circ} 28^{\prime} 24,1^{\prime \prime S} 68^{\circ} 14^{\prime} 44,0^{\prime \prime}$ W. 3.685 msnm. C. Abdala y R. Semhan. 03 abril 2012.

Comentarios. - El número de colección del holotipo fue citado por error como FML 2497 en la descripción original.

\section{Liolaemus pulcherrimus Laurent, 1991}

Laurent R. F. 1991. Sobre algunas especies nuevas y poco conocidas de Liolaemus (Iguanidae) de la provincia de Jujuy, Argentina. Acta zoologica lilloana 40 (2): 91-108.

Holotipo FML 02202 (macho). Mudana. Aproximadamente $9 \mathrm{~km}$ al S de Río Caleta. Departamento Humahuaca. Jujuy. Argentina. $23^{\circ} 20^{\prime}$ 'S $65^{\circ} 12^{\prime}$ W. O. Pagaburo y J. Bracamonte. 1987.

Paratipos FML 01961/1- 2 (2 machos). Mudana. Al E de Huacalera. Cordillera Oriental. En la Línea del Trópico. Departamento Humahuaca. Jujuy. Argentina. 4.100 msnm. N. Manca y E. Barber. 1986.

Paratipos FML 02184/1-6 y 8-14 (13 ejemplares). Los mismos datos que el holotipo.

\section{Liolaemus puna \\ Lobo y Espinoza, 2004}

Lobo F., Espinoza R. E. 2004. Two new Liolaemus from the Puna region of Argentina and Chile: Further resolution of purported reproductive bimodality in Liolaemus alticolor (Iguania: Liolaemidae). Copeia 2004 (4): 850-867.

Holotipo FML 01364 (macho). Quebrada Los Berros. Aproximadamente $5 \mathrm{~km}$ al E de Olacapato. Departamento Los Andes. Salta. Argentina. $24^{\circ} 08,35^{\prime} \mathrm{S} 66^{\circ} 42,05^{\prime}$ W. 4.200 msnm. E. Terán y O. Pagaburo. 9-11 enero 1983.

Paratipos FML 09914 - FML 009927 (10 machos, 4 hembras). Los mismos datos que el holotipo.

\section{Liolaemus punmahuida Ávila, Pérez y Morando, 2003}

Ávila L. J., Pérez C. H. F., Morando M. 2003. A new species of Liolaemus (Squama- ta: Iguania: Liolaemidae) from Northwestern Patagonia (Neuquén, Argentina). Herpetologica 59 (4): 534-545

Holotipo FML 11958 (macho). No de campo 2626. Volcán Tromen. Ruta Provincial 37. Departamento Chos Malal. Neuquén. Argentina. $37^{\circ} 06^{\prime} 16^{\prime \prime}$ ' $70^{\circ} 08^{\prime} 27^{\prime \prime}$ W. 3.000 msnm. C. Pérez. 18 enero 2000.

Paratipos FML 11959 (macho) y FML 11960 (hembra). $\mathrm{N}^{\circ}$ de campo 2649 y 2627 . La misma localidad que el holotipo. Enero 2000.

\section{Liolaemus purul \\ Abdala, Semhan, Moreno Azócar, Bonino, Paz y Cruz, 2012}

Abdala C. S., Semhan R. V., Moreno Azócar D. L., Bonino M., Paz M. M., Cruz F. 2012. Taxonomic study and morphology based phylogeny of the patagonic clade Liolaemus melanops group (Iguania: Liolaemidae), with the description of three new taxa. Zootaxa 3163: 1-32.

Holotipo FML 24153. N $^{\circ}$ de campo FBC 1694. $6 \mathrm{~km}$ al N de San Ignacio, camino a Zapala por Ruta Nacional 40. Departamento La Rinconada. Neuquén. Argentina. $39^{\circ} 50^{\prime} 54,4^{\prime \prime} \mathrm{S} 70^{\circ} 39^{\prime} 52,6$ '”W $^{\prime} 1.071 \mathrm{msnm}$. C. Abdala, F. Cruz, M. Bonino, R. Semhan y L. Moreno. 03 diciembre 2009.

Paratipos FML 21473 - FML 21474. $\mathrm{N}^{\circ}$ de campo FBC 980-981. Alrededores de la casa del guardaparques. Parque Nacional Laguna Blanca. Departamento Zapala. Neuquén. Argentina. $39^{\circ} 02^{\prime} 38,5^{\prime \prime}$ ' 70 $10^{\prime} 36,4^{\prime \prime}$ W. 1.272 msnm. G. Scrocchi, C. Abdala, S. Quinteros y J. C. Stazzonelli. 18 noviembre 2007.

Paratipo FML 21482. No de campo FBC 1030. Parque Nacional Laguna Blanca. Departamento Zapala. Neuquén. Argentina. 1.306 msnm. G. Scrocchi, C. Abdala, S. Quinteros y J. C. Stazzonelli. 18 noviembre 2007.

Paratipos FML 21499, FML 21534 - FML 21535. No de campo FBC 1063, 1065-1066. Ruta Provincial 46, antes de la entrada al Parque Nacional Laguna Blanca. Departamento Zapala. Neuquén. Argentina. $39^{\circ} 02^{\prime} 55,8^{\prime \prime} \mathrm{S}$ 70¹6’36,2”W. 1.306 msnm. G. Scrocchi, C. Abdala, S. Quinteros y J. C. Stazzonelli. 17 noviembre 2007. 
Paratipos FML 22187 - FML 22188. No de campo CSA 56-57. $35 \mathrm{~km}$ al S de Collón Curá. Departamento Collón Curá. Neuquén. Argentina. C. Abdala, J. Abdala y E. Malovini. 18 enero 2002.

Paratipo FML 22211. No de campo CSA 69. 2 km al S de Puente Collón Curá. Departamento Collón Curá. Neuquén. Argentina. C. Abdala, J. Abdala y E. Malovini. 18 enero 2002.

Paratipos FML 24154 - FML 24163. No de campo FBC 1463-1464, 1467-1468, 1485, 1686-1687, 1692, 1695-1696. Los mismos datos que el holotipo.

Paratipos FML 24164 - FML 24165. N ${ }^{\circ}$ de campo FBC 1693-1693 B. En dirección a Primeros Pinos, sobre Ruta Provincial 13. Departamento Zapala. Neuquén. Argentina. 3852'16,1"S 70¹9'17,9”W. 1.275 msnm. C. Abdala, F. Cruz, M. Bonino, R. Semhan y L. Moreno. 02 diciembre 2009.

Paratipos FML 24166 - FML 24168. No de campo FBC 1465-1466, 1469. $41 \mathrm{~km}$ al W de Zapala y $1 \mathrm{~km}$ al S de Ruta Provincial 13. Departamento Zapala. Neuquén. Argentina. 38 $51^{\prime} 14,4^{\prime \prime}$ 70³0'22,3”W. 1.288 msnm. C. Abdala, F. Cruz, M. Bonino, R. Semhan y L. Moreno. 02 diciembre 2009.

\section{Liolaemus pyriphlogos Quinteros, 2012}

Quinteros A. S. 2012. Taxonomy of the Liolaemus alticolor-bibronii group (Iguania: Liolaemidae), with descriptions of two new species. Herpetologica 68 (1):100-120.

Holotipo FML 18199 (macho). No de campo GS 2633. Alrededores de Laguna Leandro. Departamento Humahuaca. Jujuy. Argentina. 2301'50"S 6514'46,8'W. 4.278 msnm. G. Scrocchi, C. Abdala, S. Quinteros y J. C. Stazzonelli. 28 febrero - 06 marzo 2007.

Paratipos FML 18198, FML 18200-18201. $\mathrm{N}^{\mathrm{o}}$ de campo GS 2632, 2634-2635. Los mismos datos que el holotipo.

Paratipos FML 18208-FML 18210. No de campo GS 2642-2644. $10 \mathrm{~km}$ antes de Aparzo, desde Humahuaca. Departamento Humahuaca. Jujuy. Argentina. 2309'50,5”S
65ำ1'48”W. 4.135 msnm. G. Scrocchi, C. Abdala, S. Quinteros y J. C. Stazzonelli. 28 febrero - 06 marzo 2007.

Paratipo FML 18236. No de campo GS 2667. Afueras de Chorcán, camino a Laguna Leandro. Departamento Humahuaca. Jujuy. Argentina. 4.024 msnm. G. Scrocchi, C. Abdala, S. Quinteros y J. C. Stazzonelli. 28 febrero - 06 marzo 2007.

Paratipos FML 18250 - FML 18252. No de campo GS 2681-2683. Camino a Mudana desde Uquía. Departamento Humahuaca. Jujuy. Argentina. 2320'30"S 65¹3'27,5”W. 4.184 msnm. G. Scrocchi, C. Abdala, S. Quinteros y J. C. Stazzonelli. 28 febrero 06 marzo 2007.

Paratipos FML 18258 - FML 18259. N ${ }^{\circ}$ de campo GS 2689-2690. Entre Aparzo y Humahuaca. Departamento Humahuaca. Jujuy. Argentina. $23^{\circ} 10^{\prime} 09,3^{\prime \prime} \mathrm{S} 65^{\circ} 11^{\prime} 01,4^{\prime \prime} \mathrm{W}$. G. Scrocchi, C. Abdala, S. Quinteros y J. C. Stazzonelli. 28 febrero - 06 marzo 2007.

Paratipos FML 18260 - FML 18262. N ${ }^{\circ}$ de campo GS 2691-2693. Entre Chorcán y Laguna Leandro. Departamento Humahuaca. Jujuy. Argentina. 2301'57,5”S 65¹4'14,3”W. 4.210 msnm. G. Scrocchi, C. Abdala, S. Quinteros y J. C. Stazzonelli. 28 febrero 06 marzo 2007.

\section{Liolaemus quilmes Etheridge, 1993}

Etheridge R. 1993. Lizards of the Liolaemus darwinii complex (Squamata: Iguania: Tropiduridae) in Northern Argentina. Bollettino del Museo regionale di Scienze naturali di Torino 11 (1): 137-199.

Holotipo FML 02644 (macho). 3,2 km al S de Animaná, sobre Ruta Nacional 40. Departamento Cafayate. Salta. Argentina. 2559'S 6558'W. 1.695 msnm. R. Etheridge, L. Grismer, M. Halloy, J. Mc Guire y O. Pagaburo. 11 enero 1991.

Paratipos FML 02645 (6 ejemplares). No de campo 5413-5415 y 5448-5450. Los mismos datos que el holotipo. 


\section{Liolaemus ramirezae \\ Lobo y Espinoza, 1999}

Lobo F., Espinoza R. E., 1999. Two new cryptic species of Liolaemus (Iguania: Tropiduridae) from Northwestern Argentina: Resolution of the purported reproductive bimodality of Liolaemus alticolor. Copeia 1999 (1): 122-140.

Holotipo FML 06071 (hembra). Km 95 Ruta Provincial 307. Departamento Tafí del Valle. Tucumán. Argentina. 26²0,82’S 6548,74’W. 2.820 msnm. O. Pagaburo. 1113 Marzo 1993.

Paratipos FML 02248 (2 machos). $\mathrm{N}^{\circ}$ de campo MP 66-67. Km 95 Ruta Provincial 307. Departamento Tafí del Valle. Tucumán. Argentina. $26^{\circ} 40,82^{\prime} \mathrm{S} 65^{\circ} 48,74^{\prime} \mathrm{W} .2 .820$ msnm. O. Pagaburo. 20 diciembre 1988.

Paratipos FML 02921 (3 hembras). Los mismos datos que el holotipo.

\section{Liolaemus robustus Laurent, 1992}

Laurent R.F. 1992. On some overlooked species of the genus Liolaemus Wiegmann (Reptilia: Tropiduridae) from Perú. Breviora 494: 1-33.

Paratipos FML 01682 (2 ejemplares). No original MCZ 45809 y MCZ 45810. Departamento Junín. Perú. W. F. Walker Sr. 14 abril 1939.

Comentarios. - Ejemplares mencionados con el número MCZ en la descripción original de la especie y posteriormente recibidos en canje.

\section{Liolaemus sagei Etheridge y Christie, 2003}

Etheridge R., Christie M. I. 2003. Two new species of the lizard genus Liolaemus (Squamata: Liolaemidae) from northern Patagonia, with comments on Liolaemus rothi. Journal of Herpetology 37 (2): 325-341.

Paratipos FML 11918 - FML 11920. No original numbers SDSU 4323-4324 y 4326 respectivamente. $\mathrm{N}^{\mathrm{O}}$ de campo MIC 15611562 y 1564 . Ruta Nacional 46, límite del
Parque Nacional Laguna Blanca. Departamento Zapala. Neuquén. Argentina. 1.300 msnm. M. Christie. 29 noviembre 2000.

Paratipo FML 11921. No original SDSU 4330. No de campo MIC 1566. Cruce Laguna Jabón. Parque Nacional Laguna Blanca. Departamento Zapala. Neuquén. Argentina. M. Christie. 28 noviembre 2000.

\section{Liolaemus sanjuanensis Cei, 1982}

Cei J. M. 1982. A new endemic lizard from Sierra Pie de Palo in Western Argentina. Journal of Herpetology 16 (2): 179-182.

Paratipos FML 01016 (macho y hembra). Cerca de Mogote Corralitos. Sierra de Pie de Palo. San Juan. Argentina. J. M. Cei. 11 noviembre 1980.

Comentarios.- Mencionados con el acrónimo IML en la descripción original.

$$
\begin{gathered}
\text { Liolaemus saxatilis } \\
\text { Ávila, Cei, Martori y Acosta, } 1992
\end{gathered}
$$

Ávila L. J., Cei J. M., Martori R. A., Acosta J. C. 1992. A new species of Liolaemus of the bibroni group from granitic ravines of Achiras, Sierra de Comechingones, Córdoba, Argentina (Reptilia: Tropiduridae). Bollettino del Museo regionale di Scienze naturali di Torino 10 (1): 101-111.

Holotipo FML 02530. $5 \mathrm{~km}$ al W de Achiras, cerca de Ruta Provincial 1. Departamen-

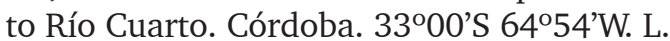
Ávila y R. Martori. 12 noviembre 1990.

Paratipo FML 02531. Achiras. Departamento Río Cuarto. Córdoba. L. Ávila y R. Martori. 05 febrero 1990.

Paratipos FML 02532 y FML 02534. Achiras Departamento Río Cuarto. Córdoba. L. Ávila y P. Pettinicchi. 04 noviembre 1990.

Paratipos FML 02533 y FML 02535. Achiras. Departamento Río Cuarto. Córdoba. J. C. Acosta, R. Martori y L. Ávila. 28 octubre 1989.

Paratipo FML 02536. Achiras. Departamento Río Cuarto. Córdoba. L. Ávila y R. Martori. 02 noviembre 1990.

Paratipos FML 19212 - FML 19220. No 
original UNRC-DCN-ZV 668, 1220, 1316, 1319, 1320, 1322, 1370, 1371 y 1372 respectivamente. Achiras. Departamento Río Cuarto. Córdoba. L. Ávila. 29 diciembre 1990.

Comentarios.- Los ejemplares FML 19212 - FML 19220 fueron mencionados en la descripción original con el acrónimo y número UNRC-DCN-ZV y posteriormente fueron donados a la colección. Los datos, fechas y coleccionistas son los que figuran en las etiquetas originales de los ejemplares y tienen pequeñas diferencias con lo publicado en la descripción original.

\section{Liolaemus scapularis Laurent, 1982}

Laurent R. F. 1982. Description de trois espèces nouvelles du genre Liolaemus (Sauria: Iguanidae). Spixiana 5 (2): 139-142.

Paratipos FML 00947 (1 macho, 1 juvenil). Santa María. Departamento Santa María. Catamarca. Argentina. O. Pagaburo. 25 febrero 1980.

Paratipos FML 01126 (26 ejemplares). Santa María. Departamento Santa María. Catamarca. Argentina. 1915.

Comentarios.- El paratipo FML 00948, proveniente de Colalao del Valle, Tucumán, Argentina, fue enviado a Kansas University Museum of Natural History; número actual KUH 206724. Tres paratipos del lote FML 01126 fueron enviados a diferentes investigadores y museos: un ejemplar fue enviado al Dr. J. M. Cei, y probablemente están depositados en la Unidad de Herpetología Facultad de Química Bioquímica y Farmacia, Universidad Nacional de San Luis, San Luis, Argentina, desafortunadamente, las etiquetas originales fueron removidas, por lo que no podemos asegurar su identificación (B. Espeche com. pers.); un ejemplar al Muséum d'Histoire naturelle, Ginebra, Suiza; número actual MHNG 2213.64. Un ejemplar enviado en canje al Dr. R. Etheridge, no conocemos el número actual.

\section{Liolaemus scrocchii \\ Quinteros, Abdala y Lobo, 2008}

Quinteros S., Abdala C. S. A., Lobo F. 2008. Redescription of Liolaemus dorbignyi Koslowsky, 1898 and description of a new species of Liolaemus (Iguania: Liolaemidae) Zootaxa 1717: 51-67.

Holotipo FML 17228 (macho). No de campo CA 614. $2 \mathrm{~km}$ al SE de Susques. Ruta Nacional 52. Departamento Susques. Jujuy. Argentina. C. Abdala, G. Scrocchi, S. Barrionuevo y S. Quinteros. 25 febrero 2005.

Paratipo FML 00992. (1 macho y 2 hembras). Alrededores del Pie de Cerro Paño. Serranía de Chañi. Departamento M. Belgrano. Jujuy. Argentina. 4.200-4.300 m. G. Scrocchi. 9 setiembre 1980.

Paratipo FML 06481 (macho). La Mesada, $48 \mathrm{~km}$ de La Poma hacia Abra del Acay. Departamento La Poma. Salta. Argentina. 4.665 m. F. Lobo y S. Torres. 24-28 febrero 1997.

Paratipo FML 01759 (macho y hembra). Agua de los Sapos. (Puesto de Cruz Soriano), 20 km de Mina Tincalayo. Departamento Los Andes. Salta. Argentina. O. Pagaburo. 10 febrero 1986.

Paratipo FML 01763 (23 ejemplares). Santa Rosa de los Pastos Grandes. Departamento Los Andes. Salta. Argentina. O. Pagaburo. 14-18 febrero 1986.

Paratipo FML 01817 (2 ejemplares). El Quemado. Abra de Pives. Departamento Tumbaya. Jujuy. Argentina. 4.000 m. E. Lavilla, A. Marcus y R. Montero. 11 febrero 1987.

Paratipo FML 17229. No de campo CA 615. Los mismos datos que el holotipo.

Comentarios.- El número de ejemplares, fecha y coleccionista de algunos de los lotes de paratipos son algo diferentes a lo publicado en la descripción original.

\section{Liolaemus senguer Abdala, 2005}

Abdala C. S. 2005. Dos nuevas especies del género Liolaemus (Iguania: Liolaemidae) y redescripción de Liolaemus boulengeri (Kos- 
lowskyi, 1898) Cuadernos de Herpetología 19 (1): 3-33.

Holotipo FML 15548 (macho). $\mathrm{N}^{\mathrm{O}}$ de campo CA 79. $26 \mathrm{~km}$ al N de Alto Río Senguer. Ruta Nacional 40. Departamento Río Senguer. Chubut. Argentina. C. Abdala, S. Quinteros y J. Abdala. Enero 2002.

Paratipo FML 15549 y FML 15550 (macho, hembra). $\mathrm{N}^{\mathrm{O}}$ de campo CA 81-82. Los mismos datos que el holotipo.

Liolaemus shehuen

Abdala, Díaz Gómes y Juárez, 2012

Abdala C. S. A., Díaz-Gómez J. M., Juárez Heredia V. I. 2012. From the far reaches of Patagonia: new phylogenetic analyses and description of the Liolaemus fitzingeri clade (Iguania: Liolaemidae). Zootaxa 3301: 3460.

Holotipo FML 22191 (macho). No de campo CSA $408.60 \mathrm{~km}$ al W de Telsen. Departamento Telsen. Chubut. Argentina. C. Abdala, J. Abdala y M. Juárez. 23 enero 2004.

Paratipos FML 22192 - FML 22195 (1 macho, 3 hembras) y FML 22204 - FML 22205 (2 machos). $\mathrm{N}^{\mathrm{o}}$ de campo CSA 409-414. Los mismos datos que el holotipo.

Paratipos FML 22217 - FML 22219 (1 macho, 2 hembras). No de campo CSA 405$407.80 \mathrm{~km}$ al $\mathrm{W}$ de Telsen. Departamento Telsen. Chubut. Argentina. C. Abdala, J. Abdala y M. Juárez. 23 enero 2004.

\section{Liolaemus shitan \\ Abdala, Quinteros, Scrocchi \\ y Stazzonelli, 2010}

Abdala C., Quinteros S., Scrocchi G. J., Stazzonelli J. C. 2010. Three new species of the Liolaemus elongatus group (Iguania: Liolaemidae) from Argentina. Cuadernos de Herpetología 24 (2): 93-109.

Holotipo 19276 (macho). No de campo FBC 954. Estancia Piedras Blancas. A 175 km desde General Roca por Ruta Provincial 6. Departamento 25 de Mayo. Río Negro. Argentina. 40¹7'17,8”S 68²7'26,9”W. 820 msnm. G. Scrocchi, C. Abdala, S. Quinteros y J. C. Stazzonelli. Noviembre 2007.
Paratipos FML 19277-19283. No de campo FBC 955-961. Los mismos datos que el holotipo.

Paratipos FML 23832 - FML 23836. No de campo GS 3150-3154. Estancia Piedras Blancas. A $175 \mathrm{~km}$ desde General Roca por Ruta Provincial 6. Departamento 25 de Mayo. Río Negro. Argentina. 40¹7’17,8”S 68²7'26,9”W. 820 msnm. C. Abdala, F. Cruz, M. Bonino y L. Moreno. Febrero 2009.

\section{Liolaemus smaug Abdala, Quinteros, Scrocchi y Stazzonelli, 2010}

Abdala C., Quinteros S., Scrocchi G. J., Stazzonelli J. C. 2010. Three new species of the Liolaemus elongatus group (Iguania: Liolaemidae) from Argentina. Cuadernos de Herpetología 24 (2): 93-109.

Holotipo FML 22449. No de campo GS 3016. Camino al Volcán Peteroa desde Las Loicas, por Ruta Provincial 186. Departamento Malargüe. Mendoza. Argentina. 35039'51,3"S 70¹2'00,9'W. 1.688 msnm. C. S. Abdala, G. Scrocchi, J. Nori, C. Martinez y H. Carrizo. 19 octubre 2008.

Paratipos FML 23817 - FML 23818. No de campo FBC 740 y 750. Ruta Provincial 186. $11 \mathrm{~km}$ desde Las Loicas, camino a Paso Pehuenche. Departamento Malargüe. Mendoza. Argentina. C. Abdala, C. Robles y R. Juárez. 26 febrero 2006.

Paratipos FML 22444 - FML 22448 y FML 22451. No de campo GS 3011-3015 y GS 3038. Los mismos datos que el holotipo.

\section{Liolaemus talampaya \\ Ávila, Morando, Pérez y Sites, 2004}

Ávila L. J., Morando M., Pérez C. H. F., W. Sites Jr. J. 2004. Phylogenetic relationships of lizards of the Liolaemus petrophilus group (Squamata, Liolaemidae), with description of two new species from western Argentina. Herpetologica 60 (2): 187-203.

Holotipo FML 13411 (macho). No de campo LJAMM 2274. Río Las Yeguas. Sierra de los Tarjados. Parque Nacional Talampaya. Departamento Felipe Varela. La Rioja. 
Argentina. 2944'S 67²5’W. 1.200 msnm. M. Archangelsky. 08 febrero 2000.

Paratipo FML 13045 (macho). No de campo 1980. Río Las Yeguas. Sierra de los Tarjados. Parque Nacional Talampaya. Departamento Felipe Varela. La Rioja. Argentina. 1.200 msnm. L. Ávila, F. Cruz y M. Morando. 29 octubre 1999.

Paratipo FML 13412 (macho) y FML 13413 (hembra). № de campo 1972 y 2685 . Río Las Yeguas. Sierra de los Tarjados. Parque Nacional Talampaya. Departamento Felipe Varela. La Rioja. Argentina. $1.200 \mathrm{msnm}$. L. Ávila, F. Cruz y M. Morando. 29 octubre 1999.

\section{Liolaemus tehuelche Abdala, 2003}

Abdala C.S. 2003. Cuatro nuevas especies del género Liolaemus (Iguania: Liolaemidae), pertenecientes al grupo boulengeri, de la $\mathrm{Pa}-$ tagonia, Argentina. Cuadernos de Herpetología 17 (1-2): 3-32.

Holotipo 13205 (macho). No de campo CSA 64. Cerro Alto. Sobre Ruta Nacional 40. 54 km N de Pilcaniyeu. Departamento Pilcaniyeu. Río Negro. Argentina. 4044,074'S 70³4,696'W. 1.014 msnm. C. Abdala, E. Malovini y J. Abdala. 13-28 febrero 2002.

Paratipos FML 13206 - FML 13216 (6 machos, 5 hembras). No de campo CSA 58$63,65-68$ y 70 . Los mismos datos que el holotipo.

Paratipos FML 13217 - FML 13220 (2 machos, 2 hembras). No de campo REE 740743. La misma localidad que el holotipo. C. Abdala, R. E. Espinoza y J. J. Wiens. 12 febrero 2001.

\section{Liolaemus tromen \\ Abdala, Semhan, Moreno Azócar, Bonino, Paz y Cruz, 2012}

Abdala C. S., Semhan R. V., Moreno Azócar D. L., Bonino M., Paz M. M., Cruz F. 2012. Taxonomic study and morphology based phylogeny of the patagonic clade Liolaemus melanops group (Iguania: Liolaemidae), with the description of three new taxa. Zootaxa 3163: 1-32.
Holotipo FML 17735 (macho). No de campo FBC 731. Km 140 de Ruta Provincial 21 que une El Cholar con El Huecú. 7 km al N de El Huecú. Departamento Ñorquín. Neuquén. Argentina. C. Abdala, C. Robles y R. Juárez. 21 febrero 2006.

Paratipos FML 17731 - FML 17734, FML 17736. No de campo FBC 727-730 y 732. Los mismos datos que el holotipo.

Paratipos FML 22386 - FML 22387. $N^{o}$ de campo FBC 992-993. Alrededores del Volcán Tromen. Departamento Chos Malal. Neuquén. Argentina. 3704'56,8”S 7006'15,5”W. 2.189 msnm. G. Scrocchi, C. Abdala, S. Quinteros y J. C. Stazzonelli. 15 noviembre 2007.

Comentarios.-El Departamento El Cholar mencionado para la localidad tipo en la descripción original es inexistente. La fecha de colección de los paratipos FML 22386-22387 es la mencionada acá y no la utilizada en la descripción original (15 febrero 2007).

$$
\begin{aligned}
& \text { Liolaemus tulkas } \\
& \text { Quinteros, Abdala, Díaz Gómez } \\
& \text { y Scrocchi, } 2008
\end{aligned}
$$

Quinteros, A. S., Abdala C. S., Díaz-Gómez J. M., Scrocchi G. J. 2008. Two new species of Liolaemus (Iguania: Liolaemidae) from Central West Argentina. South American Journal of Herpetology 3 (2): 101-111.

Holotipo FML 18316. No de campo GS 2706. $37 \mathrm{~km}$ al $\mathrm{N}$ de Fiambalá, camino a Paso de San Francisco. Departamento Belén. Catamarca. Argentina. 27²3'12,8'S 67058'33,4”W. 2.825 msnm. G. Scrocchi, C. Abdala y S. Quinteros. 22 marzo 2007.

Paratipos FML 18317 - FML 18321. No de campo GS 2707-2711. Los mismos datos que el holotipo.

Comentarios.- Por un error de mecanografiado, el holotipo fue mencionado como FML 18136 en la descripción original.

\section{Liolaemus umbrifer} Espinoza y Lobo, 2003

Espinoza R. E., Lobo F. 2003. Two new species of Liolaemus lizards from Northwes- 
tern Argentina: Speciation within the Northern subclade of the elongatus group (Iguania: Liolaemidae). Herpetologica 59 (1): 89-105.

Holotipo FML 09934 (macho). No de campo ACUNSa 52. Quebrada de Randolfo. Ruta provincial 43. $60,3 \mathrm{~km} \mathrm{NW}$ de la intersección de Ruta Nacional 40 y ruta Provincial 43. $166 \mathrm{~km}$ SE de Antofagasta de la Sierra. Departamento Antofagasta de la Sierra. Catamarca. Argentina. 26 $51,456^{\prime} \mathrm{S}$ $66^{\circ}$ 44,804'W. 3.192 msnm. C. Abdala, R. Espinoza, F. Lobo, M. I. Martínez Oliver. 18 enero 2001.

Paratipos FML 09935 - FML 09945. No de campo ACUNSa 50; 53 - 55; 57; 82-87. Los mismos datos que el holotipo.

Comentarios. - La Ruta Nacional 40 fue erróneamente mencionada como Ruta Provincial 4 en la descripción original. También por error, los ejemplares ACUNSa 88 y 89 se citaron como ejemplares de la colección FML.

\section{Liolaemus variegatus Laurent, 1984}

Laurent R.F. 1984. Tres especies nuevas del género Liolaemus (Reptilia: Iguanidae) Acta zoologica lilloana 37 (2): 273-294.

Paratipos FML 01210 (2 ejemplares). Cochabamba, 1.800-2.000 m. Bolivia. Zischka. 26 julio 1954.

\section{Liolaemus vulcanus \\ Quinteros y Abdala, 2011}

Quinteros, A. S. y C. S. Abdala. 2011. A new species of Liolaemus of the Liolaemus montanus section (Iguania: Liolaemidae) from Northwestern Argentina. Zootaxa 2789: 35-48.

Holotipo FML 01169. Pocitos y Loma Cortada, al SW de Los Nacimientos. Departamento Antofagasta de la Sierra. Catamarca. Argentina. O. Pagaburo y E. Terán. 01 diciembre 1981.

Paratipos FML 01167 (10 ejemplares). Trapiche. Tramo del Río de la Punilla. Departamento Antofagasta de la Sierra. Cata- marca. Argentina. O. Pagaburo y E. Terán. 29 noviembre 1981.

Paratipo FML 23819. Los mismos datos que el holotipo.

Comentarios. - Tres ejemplares del lote FML 01167 fueron donados a otros museos e investigadores (uno al Dr. J. M. Cei y dos al Museo Nacional de Historia Natural de París) antes de la descripción de la especie, por lo que el lote tiene sólo diez ejemplares y no trece como se menciona en Quinteros y Abdala (2011).

\section{Liolaemus williamsi Laurent, 1992}

Laurent, R.F. 1992. On some overlooked species of the genus Liolaemus Wiegmann (Reptilia: Tropiduridae) from Perú. Breviora 494: 1-33.

Paratipo FML 01701. No original LACM 9325. Pampa Galeras, entre Nazca y Puquio. Departamento Ayacucho. Perú. S. W. Taft. Octubre 1965.

Paratipo FML 13403. No original LACM 9334. Lucanas. Pampa Galeras. 96 km de Nazca. Departamento Ayacucho. Perú. S. W. Taft. Abril a Julio 1963.

Comentarios. - Ejemplares mencionados con los números LACM en la descripción original y posteriormente recibidos en canje.

\section{Liolaemus yalguaraz}

Abdala, Quinteros y Semhan, 2015

Abdala C. S.; Quinteros A. S., Semhan R. V. 2015. A new species of Liolaemus of the Liolaemus alticolor bibronii group (Iguania: Liolaemidae) from Mendoza, Argentina. South American Journal of Herpetology 10 (2): 104-115.

Holotipo FML 27622 (macho). No de campo OGS 4191. Pampa de Yalguaráz. Uspallata. Departamento Las Heras. Mendoza. Argentina. $32^{\circ} 19^{\prime} 59,0$ "S 69²2'54,5”W. 2.325 msnm. C. Abdala, J. L. Acosta, A. Laspiur y R. Semhan. Noviembre 2010.

Paratipos FML 27623 - FML 27634. No de campo OGS 4183-4190, 4193-4196. Los mismos datos que el holotipo. 


\section{Liolaemus yanalcu Martínez y Lobo, 2002}

Martínez O. I., Lobo F. 2002. Una nueva especie de Liolaemus del grupo alticolor (Iguania: Liolaemidae) de la puna salteña, Argentina. Cuadernos de Herpetologia 16 (1): 47-64.

Paratipos FML 01361 (8 ejemplares). San Antonio de los Cobres. Departamento Los Andes. Salta. Argentina. E. Terán y O. Pagaburo. 9-11 enero 1983.

Paratipos FML 01891 (5 ejemplares). Cachiñal. Departamento Rosario de Lerma. Salta. Argentina. $3.730 \mathrm{msnm}$. T. Noriega, O. Pagaburo, O. Fogliato, L. Claps y J. Bracamonte. 31 marzo 1987.

Paratipos FML 03339. No de campo GS 1499. Km 158 de Ruta Nacional 51. Aproximadamente $2 \mathrm{~km} \mathrm{SW}$ de San Antonio de los Cobres. Departamento Los Andes. Salta. Argentina. G. Scrocchi, F. Lobo y L. Fernández. 08 diciembre 1994.

Paratipos FML 06342 (8 ejemplares). $\mathrm{N}^{\circ}$ de campo 23, 24, 34, 35 y 71-74. $10 \mathrm{~km}$ al $S$ de Muñano. Camino de Muñano hacia El Acay. Departamento La Poma. Salta. Argentina. F. Lobo y S. Torres. 24-28 febrero 1997.

Comentarios. - Hay algunas diferencias con lo que dice el trabajo de descripción original. El lote FML 01361 posee ocho ejemplares y no seis. El lote FML 01891 no dice cuantos ejemplares son. En el lote FML 06342, uno de los autores (I. Martínez Oliver) añadió números de colector personales (IMO1-8) a los ejemplares en una revisión posterior a la descripción.

\section{Liolaemus yatel}

Abdala, Procopio, Stellatelli, Travaini, Rodríguez y Ruiz Monachesi, 2014

Abdala C. S., Procopio S., Stellatelli O. A., Travaini A., Rodríguez A., Ruiz Monachesi M. R. 2014. New Patagonian species of Liolaemus (Iguania: Liolaemidae) and novelty in the lepidosis of the southernmost lizard of the world: Liolaemus magellanicus. Zootaxa 3866 (4): 526-542

Holotipo FML 24646 (hembra). No de campo CIPD 628. Monumento Natural Bosque Petrificado. Departamento Deseado. San-

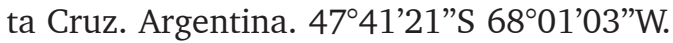
D. Procopio. 03 marzo 2009.

Paratipo FML 24647 (macho). № de campo CIPD 329. Monumento Natural Bosque Petrificado. Departamento Deseado. Santa

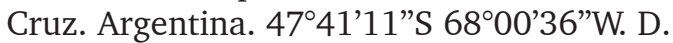
Procopio. 27 octubre 2006.

Paratipo FML 24648 (hembra). No de campo CIPD 629. Monumento Natural Bosque Petrificado. Departamento Deseado. San-

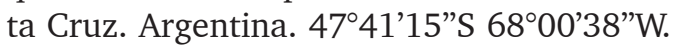
D. Procopio. 06 marzo 2009.

Paratipo FML 24649 (macho). No de campo CIPD 394. Monumento Natural Bosque Petrificado. Departamento Deseado. Santa

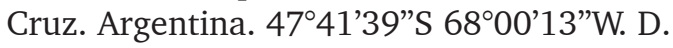
Procopio. 11 marzo 2007.

Paratipo FML 24650 (hembra). No de campo CIPD 396. Monumento Natural Bosque Petrificado. Departamento Deseado. San-

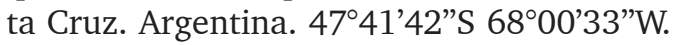
D. Procopio. 11 marzo 2007.

Comentarios.-El departamento es mencionado erróneamente como «Puerto Deseado» en la descripción original.

\section{Phymaturus antofagastensis Pereyra, 1985}

Pereyra E. A. 1985. Nuevo iguánido del género Phymaturus del Noroeste Argentino. Boletín Asociación Herpetológica Argentina 2 (4): 3-4.

Holotipo FML 01162-6. Los Nacimientos, paredes rocosas al W-E de la Vega y Peña de La Cueva. Departamento Antofagasta de la Sierra. Catamarca. Argentina. E. Terán y O. Pagaburo. 28 noviembre 1981.

Paratipos FML 01163 (2 machos, 3 hembras y 1 juvenil). Los Nacimientos, paredes rocosas al W de la vega. Departamento Antofagasta de la Sierra. Catamarca. Argentina. E. Terán y O. Pagaburo. 27 noviembre 1981.

Paratipo FML 01394 (macho). Río Cazadero Grande. Departamento Tinogasta. Catamarca. Argentina. 3.760 msnm. E. Terán y M. Hernández. 27 enero 1983. 
Paratipo FML 01396 (macho juvenil). Aguas Calientes. Departamento Tinogasta. Catamarca. Argentina. $4.050 \mathrm{msnm}$. E. Lavilla. 10 febrero 1983.

Comentarios. - Si bien la descripción original no identifica holotipo y paratipos, los mismos fueron identificados por el autor de la especie en un trabajo posterior (Pereyra, 1991). El lote FML 01161 fue enviado en préstamo al Ing. Pereyra (Instituto de Biología Animal, Mendoza, Argentina) en 1989 y aun no pudo recuperarse.

\section{Phymaturus etheridgei \\ Lobo, Abdala y Valdecantos, 2010}

Lobo F., Abdala C. S. A., Valdecantos S. 2010. Taxonomic studies of the genus Phymaturus (Iguania: Liolaemidae): Description of four new species. South American Journal of Herpetology 5 (2): 102-126.

Holotipo FML 23495 (macho). $\mathrm{N}^{\circ}$ de campo GS 3158. Ruta Provincial 76. Entre Ingeniero Jacobacci y El Moligüe. Departamento 25 de Mayo. Río Negro. Argentina. 41 34'47,2"S 69²3'33"W. 818 msnm. C. Abdala, M. Bonino, F. Cruz y L. Moreno. 05 febrero 2009.

Paratipo FML 08435 (macho). $\mathrm{N}^{\circ}$ de campo FBC 108. $43 \mathrm{~km}$ al N de El Moligüe. Departamento 25 de Mayo. Río Negro. Argentina. F. B. Cruz. 15 marzo 1999.

Paratipos FML 23496 - FML 23501 (3 machos, 3 hembras). No de campo GS 31293130; 3156-3157; 3160-3161. Los mismos datos que el holotipo.

\section{Phymaturus querque \\ Lobo, Abdala y Valdecantos, 2010}

Lobo F., Abdala C. S. A., Valdecantos S. 2010. Taxonomic studies of the genus Phymaturus (Iguania: Liolaemidae): Description of four new species. South American Journal of Herpetology 5 (2): 102-126.

Holotipo FML 21556 (macho). $\mathrm{N}^{\circ}$ de campo FBC 1095. Alrededores de Laguna Blanca. Parque Nacional Laguna Blanca. Departamento Zapala. Neuquén. Argentina. 3902'32,4"S 70¹8'27,1"W. 1.308 msnm.
G. Scrocchi, C. Abdala, S. Quinteros y J. C. Stazzonelli. 18 noviembre 2007.

Paratipo FML 21211 (hembra). Los mismos datos que el holotipo. 17 noviembre 2007.

\section{Vilcunia periglacialis \\ Cei y Scolaro, 1982}

Cei J. M., Scolaro J. A. 1982. A new species of the patagonian genus Vilcunia, with remarks on its morphology, ecology and distribution. Journal of Herpetology 16 (4): 354-363.

Paratipo FML 01032 (macho). Cerro Beltza. 10 km al E de Lago Belgrano. Santa Cruz. Argentina. 1.000 msnm. J. Scolaro y J. Upton. 29 enero 1981.

Paratipo FML 01033 (macho). Márgenes N del Río Belgrano. Santa Cruz. Argentina. 950-970 msnm. J. Scolaro y J. Upton. 02 febrero 1981.

Paratipo FML 01034 - FML 01036. Meseta Aguila - Asador, cerca del Lago Guitarra. Santa Cruz. Argentina. 1.300 msnm. J. Scolaro y J. Upton. 30 enero 1981.

Comentarios. - Actualmente considerado sinónimo junior de Liolaemus hatcheri Stejneger, 1909, según Etheridge (1998). El género Vilcunia fue sinonimizado con Liolaemus por Etheridge (1995).

\section{FAMILIA TEIIDAE \\ Cnemidophorus serranus \\ Cei y Martori, 1991}

Cei J. M., Martori R. 1991. A new species of Cnemidophorus of the lacertoides species group from the eastern sierras de Córdoba, Central Argentina (Lacertilia, Teiidae). Bollettino del Museo regionale di Scienze naturali di Torino 9 (1): 33-38.

Holotipo FML 02053/1 (macho). Icho Cruz. Departamento Punilla. Córdoba. Argentina. 800 msnm. P. Blendinger. 23-24 noviembre 1987.

Paratipos FML 02053/2-3 (2 ejemplares). Los mismos datos que el holotipo.

Paratipos FML 19221 - FML 19223 (1 
hembra, 2 machos). $\mathrm{N}^{\mathrm{o}}$ original UNRC-DCNZV 737, 738 y 744. Estancia Vieja. Río Los Chorrillos, cerca de Villa Carlos Paz. Departamento Punilla. Córdoba. Argentina. R. Martori, J. C. Acosta, D. Pérez y L. Ávila. 10 noviembre 1989.

Comentarios. - Actualmente Contomastix serrana (Cei y Martori, 1991), de acuerdo a Harvey et al. (2012). El holotipo y los paratipos FML 02053/2-3 fueron citados erróneamente con el acrónimo FML.IH en la descripción original. Los ejemplares FML 19221 - FML 19223 fueron mencionados con el número UNRC-DCN-ZV en la descripción original y posteriormente donados a la colección.

\section{Kentropyx lagartija Gallardo, 1962}

Gallardo J.M. 1962. El género Kentropyx (Sauria, Teiidae) en la República Argentina. Acta zoologica lilloana 18: 243-250.

Holotipo FML 00001 (macho). Río Salí. Tucumán. Argentina.

Comentarios.- Mencionado como Instituto Miguel Lillo en la descripción original.

\section{Teius suquiensis \\ Ávila y Martori, 1991}

Ávila L. J., Martori R. A. 1991. A unisexual species of Teius Merrem 1820 (Sauria: Teiidae) from central Argentina. Tropical Zoology 4 (2): 193-201.

Holotipo FML 02537. Barrio Villa Caeiro. Bialet Massé. Departamento Punilla. Córdoba. Argentina. $31^{\circ} 18^{\prime} S 64^{\circ} 27^{\prime \prime W}$. J. C. Acosta. 29 diciembre 1988.

Paratipos FML 02538 - FML 02542. Bialet Massé. Departamento Punilla. Córdoba. Argentina. L. Ávila. 27 diciembre 1988.

Paratipo FML 13161. No original UNRCDCN-ZV 556. Bialet Massé. Departamento Punilla. Córdoba. Argentina. J. C. Acosta. 27 diciembre 1988.

Paratipo FML 13162. No original UNRCDCN-ZV 583. Santa María de Punilla. Departamento Punilla. Córdoba. Argentina. L. Ávila. 29 diciembre 1988.
Comentarios.- Los ejemplares FML 1361 y FML 1362 fueron mencionados con el número UNRC-DCN-ZV en la descripción original y posteriormente donados a la colección.

\section{FAMILIA TROPIDURIDAE}

Tropidurus spinulosus guarani Álvarez, Cei y Scolaro, 1994

Álvarez B. B., Cei J. M., Scolaro J. A. 1994. A new subspecies of Tropidurus spinulosus (Cope, 1862) from the subtropical wet mesic Paraguayan region (Reptilia, Squamata, Tropiduridae). Tropical Zoology 7 (1): 161-179.

Holotipo FML 02752. No original UNNECHC 00608. Cerro Hu. Departamento Paraguarí. Paraguay. 25³0’S 5700’W. B. B. Álvarez y M. Culzoni. 03 marzo 1989.

Comentarios. - Actualmente considerado Tropidurus guarani, de acuerdo a Harvey y Gutberlet (1998).

\section{SERPENTES \\ FAMILIA LEPTOTYPHLOPIDAE \\ Leptotyphlops teaguei \\ Orejas Miranda, 1964}

Orejas-Miranda B. R. 1964. Dos nuevos Leptotyphlopidae de Sur America. Comunicaciones Zoologicas del Museo de Historia Natural de Montevideo 8 (103): 1-7 + I-III láminas.

Paratipo FML $00682 \mathrm{~N}^{\circ}$ de campo CWW 12526. $20 \mathrm{~km}$ NE de Cutervo. Cerca de Socota. Perú. W. Weyrauch. 17 junio 1956.

Comentarios.- Orejas-Miranda (op. cit.) menciona solamente el $\mathrm{N}^{\mathrm{O}}$ de campo. Actualmente Epictia teaguei (Orejas Miranda, 1964), según Adalsteinsson et al. (2009).

\section{Leptotyphlops vellardi Laurent 1984}

Laurent R. F. 1984. El género Leptotyphlops en la colección de la Fundación Miguel Lillo. Acta zoologica lilloana 38 (1): 29-34. 
Holotipo FML 00110 (hembra). Ciudad de Formosa. Formosa. Argentina. J. Vellard. Diciembre 1944.

Paratipo FML 00295 (juvenil). Ingeniero Juárez. Departamento Matacos. Formosa. Argentina. R. Golbach. 02-08 enero 1949.

Comentarios. - La fecha de colección del paratipo fue publicada, por error, como 28 enero 1949 en la descripción original. Actualmente Epictia vellardi (Laurent, 1984), según Adalsteinsson et al. (2009).

\section{Leptotyphlops weyrauchi Orejas Miranda 1964}

Orejas-Miranda B. R. 1964. Dos nuevos Leptotyphlopidae de Sur America. Comunicaciones Zoologicas del Museo de Historia Natural de Montevideo 8 (103): 1-7 + I-III láminas.

Paratipo FML $00757 \mathrm{~N}^{\circ}$ de campo CWW 12701. Jardín de una casa en San Miguel de Tucumán. Departamento Capital. Tucumán, Argentina. 430 msnm. W. Weyrauch. 05 diciembre 1963.

Paratipo FML $00764 \mathrm{~N}^{\mathrm{O}}$ de campo CWW 12700. Jardín de una casa en San Miguel de Tucumán. Departamento Capital. Tucumán, Argentina. Z. Tomsic. 25 octubre 1962.

Comentarios.- La descripción original menciona los ejemplares mediante el $\mathrm{N}^{\mathrm{O}}$ de campo. Actualmente considerada sinónimo junior de Epictia albipunctus (Burmeister, 1861) según Kretzschmar (2006) y Adalsteinsson et al. (2009).

\section{FAMILIA COLUBRIDAE}

\section{Chironius fuscus leucometapus Dixon, Wiest y Cei 1993}

Dixon J. R., Wiest Jr. J. A., Cei J. M. 1993. Revision of the Neotropical snake genus Chironius Fitzinger (Serpentes: Colubridae). Museo Regionale di Scienze Naturali - Torino Monografie XIII: 1-280.

Paratipo FML 00692. Junín. Valle Chanchamayo. Hacienda Naranjal, cerca de Pichita Caluga. Perú. 1500 m. W. Weyrauch. 10 junio 1958.
Comentarios.- Actualmente Chironius leucometapus Dixon, Wiest y Cei, 1993, según Hollis (2006). Los datos que presentamos acá son los que acompañan al ejemplar y figuran en los registros de la colección. En la descripción de la especie sólo se incluyó parte de los mismos.

\section{FAMILIA DIPSADIDAE \\ Apostolepis quirogai \\ Giraudo y Scrocchi, 1998}

Giraudo A. R., Scrocchi G. J. 1998. A new species of Apostolepis (Serpentes: Colubridae) and comments on the genus in Argentina. Herpetologica 54 (4): 470-476.

Holotipo FML 06000. Posadas. Departamento Capital. Misiones. Argentina. R. Martínez. 08 abril 1995.

Paratipo FML 06001. Posadas. Departamento Capital. Misiones. Argentina. N. E. Franke. 09 diciembre 1990.

\section{Atractus canedii \\ Scrocchi y Cei, 1986}

Scrocchi G. J., Cei J. M. 1991. A new species of the genus Atractus from the Northwestern Argentina (Serpentes, Colubridae). Bollettino del Museo regionale di Scienze naturali di Torino 9 (1): 205-208.

Holotipo FML 01082. Entre Anta y Joaquín V. González. Departamento Anta. Salta. Coleccionista desconocido. Verano de 1986. Originalmente perteneciente a la colección del Museo de Ciencias Naturales de la Universidad Nacional de Salta, Salta, Argentina.

Comentarios.- Actualmente considerada sinónimo junior de Atractus bocki, Werner, 1909, según Pasos et al. (2009).

\section{Elapomorphus punctatus Lema 1979}

Lema T. 1979. Elapomorphus punctatus, nova espécie de Colubridae para a Argentina (Ophidia). Revista Brasileira de Biologia 39 (4): 835-853. 
Paratipo FML 00015. Belén. Departamento Belén. Catamarca. Argentina. R. Schreiter. 1924.

Paratipo FML 00710. Misiones. Argentina. S. Pierotti. 1956.

Comentarios.- Citados en la descripción original con el acrónimo «FMLT». El género Phalotris Cope, 1862 fue revalidado como subgénero de Elapomorphus por Lema (1984). Posteriormente Ferrarezzi (1993) lo considera como género válido para las especies de Elapomorphus, excepto Elapomorphus quinquelineatus (Raddi, 1820) y Elapomorphus wuchereri Günther, 1861. Lema et al. (2005) consideran a Phalotris punctatus como sinónimo junior de Phalotris tricolor (Duméril, Bibron \& Duméril, 1854) y otros autores como Cacciali y Motte (2007) y Giraudo et al (2012) aceptan la sinonimización. Wallach et al (2014) la incluyeron como especie válida (página 547) y como sinónimo de Phalotris tricolor (página 548).

\section{Hydrops caesurus \\ Scrocchi, Ferreira, Giraudo, Ávila y Mothe, 2005}

Scrocchi G. J. Ferreira V. L., Giraudo A. R., Ávila R. W., Mothe M. 2005. A new species of Hydrops (Serpentes: Colubridae: Hydropsini) from Argentina, Brazil and Paraguay. Herpetologica 61: 468-477.

Paratipos FML 24882. No original CEUCH 027. Agosto 1997. FML $24883 \mathrm{~N}^{\circ}$ original CEUCH 043. Octubre 1997. FML $24884 \mathrm{~N}^{\circ}$ original CEUCH 077. Julio 1998. Ladário. Mato Grosso do Sul, Brasil.

Paratipos FML $24885 \mathrm{~N}^{\circ}$ original CEUCH 208 y FML $24886 \mathrm{~N}^{\circ}$ original CEUCH 279. 01 abril 1999. FML 024887, $\mathrm{N}^{\circ}$ original CEUCH 453. 03 agosto 1999. FML 024888, 024889, 024890 y $024891 \mathrm{~N}^{\circ}$ original CEUCH 454, 455, 456 y 699 respectivamente. 02 agosto 1999. Lagoa Negra. Ladário. Mato Grosso do Sul, Brasil. 1858'15" S 57³3'45”W.

Comentarios.- Ejemplares mencionados en la descripción original con los números originales (CEUCH) y recibidos posteriormente en donación.

\section{Liophis vanzolinii \\ Dixon, 1985}

Dixon J. R. 1985. A review of Liophis anomalus and Liophis elegantissimus and a description of a new species (Serpentes: Colubridae). Copeia 1985 (3): 565-573.

Paratipo FML 00565. Copina. Departamento Punilla. Córdoba. Argentina. R. Laurent. 14 enero 1968.

Paratipos FML 01053 y FML 01061 (3 ejemplares). Villa Giardino. Departamento Punilla. Córdoba. Argentina. E. Lavilla. 19 octubre 1978.

Comentarios.- Citados con el acrónimo IML en la descripción original. Actualmente Lygophis vanzolinii (Dixon, 1985), según Zaher et al. (2009) y Grazziotin et al. (2012).

\section{Phalotris nigrilatus \\ Ferrarezzi, 1993}

Ferrarezzi H. 1993. Nota sobre o gênero Phalotris com revisão do grupo nasutus e descrição de tres novas especies (Serpentes: Colubridae: Xenodontinae). Memorias Instituto Butantan, 55 supl. 1: 21-38.

Holotipo FML 00709 (hembra). Carumbé. Departamento San Pedro. Paraguay. R. Golbach. Julio 1973.

\section{Philodryas patagoniensis haywardi Laurent 1973}

Laurent R. F. 1973. Una nueva subespecie de culebra del Noroeste argentino y de Bolivia. Acta zoologica lilloana 26 (20): 293-297.

Holotipo FML 00604 (hembra). El Divisadero (Km 40-41 Ruta Acheral - Tafí del Valle). Departamento Tafí del Valle. Tucumán. Argentina. 1.560 m. R. Laurent. 10-12 octubre 1970.

Paratipo FML 00017 (macho). Cochabamba. Bolivia. J. Vellard.

Paratipos FML 00075; 00077 y 00080 (hembras). Chimoré. Cochabamba. Bolivia. H. Marcus. 16 Septiembre 1944.

Paratipo FML 00209 (hembra). Quebrada Pucará. Departamento General San Martín. 
Salta. Argentina. S. Pierotti. 03 abril 1945. Paratipos FML 00576 (macho y hembra). Horco Molle. Departamento Tafí Viejo. Tucumán. Argentina. C. Grosse. 01 febrero 1966.

Paratipo FML 00581 (macho). Lagunas de Yala. Departamento Capital. Jujuy. Argentina. R. Laurent. 22 diciembre 1964.

Paratipo FML 00683 (hembra). A mitad del camino Lipeo - Baritú - El Salto. Departamento Santa Victoria. Salta. Argentina. 1.600 m. J. M. Gómez. 23 setiembre 1972.

Paratipo FML 00695; FML 00696 y FML 00698. (macho y 2 hembras) sin datos.

Paratipo FML 00697 (macho). Yunca Suma. Distrito Aconquija. Departamento Andalgalá. Catamarca. Argentina. R. Laurent y A. Budin. 01 noviembre 1967.

Comentarios. - La fecha de colección de los ejemplares FML 00075, 00077 y 00080 es 16 setiembre 1944, no 16 octubre 1944 como fue publicado en la descripción original. Actualmente considerado sinónimo junior de Philodryas patagoniensis.

\section{Sibynomorphus lavillai Scrocchi, Porto y Rey, 1993}

Scrocchi G., Porto M., Rey L. 1993. Descripción de una especie nueva y situación del género Sibynomorphus (Serpentes: Colubridae) en la Argentina. Revista Brasileira de Biologia 53 (2): 197-208.

Holotipo FML 02053 (hembra). No de campo PT 441. $10 \mathrm{~km}$ al N de J. V. González y 14,7 km al E del cruce de Ruta Nacional 16 y Ruta Provincial 30, sobre Ruta Provincial 30. Departamento Anta. Salta. Argentina. F. Cruz, G. Perotti y O. Donadío. 16 enero 1988.

Paratipo FML 00151 (macho). Orilla del Río Grande. Jujuy. Argentina. Lizer. Abril 1917.

Paratipo FML 02055 (hembra). No de campo PT 350. Finca San Javier, $8 \mathrm{~km}$ al S de Joaquín V. González. Departamento Anta. Salta. Argentina. F. Cruz. 05 enero 1988.

Paratipo FML 02056 (hembra). No de campo PT 618. Finca San Javier, sobre Ruta Nacional 16, 4 km al S de Joaquín V. Gonzá- lez. Departamento Anta. Salta. Argentina. G. Perotti y Silva. 25 enero 1988.

Paratipo FML 02057 (macho). $\mathrm{N}^{\mathrm{O}}$ de campo PT 2323. Finca San Javier, $8 \mathrm{~km}$ al S de Joaquín V. González. Departamento Anta. Salta. Argentina. F. Cruz. 25 febrero 1988.

\section{AGRADECIMIENTOS}

Son muchas las personas que mediante su ayuda nos permitieron desarrollar este trabajo.

Diego Baldo, Alejandro Laspiur y Esteban Lavilla nos ayudaron a conseguir trabajos de descripciones originales que no teníamos. Dione Seripieri, del Museu de Zoología de la Universidad de São Paulo, Brasil, con la simpatía y gentileza de siempre, nos consiguió algunas obras que buscábamos hace tiempo y no habríamos conseguido sin su ayuda.

James Aparicio (Museo Nacional de Historia Natural, La Paz, Bolivia), Aline Staskowian Benetti (Museu de Zoologia, São Paulo, Brasil), Beatriz Espeche (UN de San Luis, Argentina), Robert E. Espinoza (California State University, Northridge, USA), Vanesa Faccioli (Museo Florentino Ameghino, Santa Fe, Argentina), Daniela Gennari (Museu de Zoologia, São Paulo, Brasil), José Pepe Langone (Museo Nacional de Historia Natural, Montevideo, Uruguay), Leonardo A. Leiva (Museo Florentino Ameghino, Santa Fe, Argentina), Sofia Literas (Instituto de Biología Animal, Universidad Nacional de Cuyo, Mendoza, Argentina), Herman Antonio Nuñez Cepeda (Museo Nacional de Historia Natural, Santiago, Chile), Juan Carlos Ortiz Zapata (Museo de Zoologia, Universidad de Concepción, Concepción, Chile), Andreas Schmitz (Muséum d'Histoire naturelle. Ginebra, Suiza), Jorge Williams (Museo de La Plata, Buenos Aires, Argentina) y Hussam Zaher (Museu de Zoologia, São Paulo, Brasil) nos ayudaron muchísimo para poder localizar la mayoría de los ejemplares que se depositaron en otras colecciones.

Los comentarios de los árbitros anónimos, ayudaron a subsanar algunos errores.

Como siempre, nuestros amigos del Instituto de Herpetología, en particular Paula 
Cabrera, Marta Cánepa, Esteban Lavilla y Juan Carlos Stazzonelli, nos ayudaron a lo largo de todo el trabajo.

\section{LITERATURA CITADA}

Abdala C. S., Quinteros S., Espinoza R. E. 2008. Two new species of Liolaemus (Iguania: Liolaemidae) from the Puna of Northwestern Argentina. Herpetologica 64 [4]: 458-471.

Adalsteinsson S. A., Branch W. R., Trape S., Vitt, L. J., Hedges S. B. 2009. Molecular phylogeny, classification and biogeography of snakes of the Family Leptotyphlopidae (Reptilia, Squamata). Zootaxa 2244: 1-50.

Aranda S. G., Córdoba S. P., Sánchez F. R. 2016. Catálogo de los tipos primarios de Coleoptera depositados en la Colección Entomológica del Instituto - Fundación Miguel Lillo. Acta zoologica lilloana 60 (1): 10-46.

Baldo D. 2001. Acerca de la localidad tipo y la distribución geográfica de Melanophryniscus klappenbachi Prigioni y Langone, 2000 (Anura: Bufonidae). Cuadernos de Herpetología 15: 141-142.

Brown J. L., Twome E., Amézquita A., de Souza M. B., Caldwell J. P., Lötters, S., von May R., Melo-Sampaio P. R., MejíaVargas D., Pérez-Peña P. E., Pepper M., Poelman E. H., Sánchez-Rodríguez M., Summers K. 2011. A taxonomic revision of the Neotropical poison frog genus Ranitomeya (Amphibia: Dendrobatidae). Zootaxa 3083: 1-120.

Cacciali P., Motte M. 2007. Variación intraespecífica en Phalotris matogrossensis y P. tricolor: una evaluación de sus caracteres diagnósticos (Squamata, Colubridae). Cuadernos de Herpetología 21 (2): 75-82.

Cei J. M. 1950. Leptodactylus chaquensis n. sp. y el valor sistemático real de la especie linneana Leptodactylus ocellatus en la Argentina. Acta zoologica lilloana 4: 395-423.

Cei J. M. 1987. Additional notes - "Amphibians of Argentina": an update, 1980-1986. Monitore Zoologico Italiano. Nuova Serie, Supplemento. Firenze 21: 209-272.

Cei J M., Scolaro J. A. 1996. A new species of Liolaemus of the archeforus group from the precordilleran valley of the Zeballos river, Santa Cruz Province, Argentina (Reptilia, Tropiduridae). Bollettino del Museo regionale di Scienze naturali di Torino 14 (2): 389-401.
Chaparro J. C., Pramuk J. B., Gluesenkamp A. G. 2007. A new species of arboreal Rhinella (Anura: Bufonidae) from cloud forest of southeastern Peru. Herpetologica 63: 203-212.

Colomo M. V., Berta D. C. 2005 a. Los ejemplares tipo de Masarinae y Polistinae (Hymenoptera: Vespidae) depositados en la colección del Instituto Fundación Miguel Lillo (IFML), Argentina. Revista de la Asociación Entomológica Argentina 64 (1-2): 71-84.

Colomo M. V., Berta D. C. 2005 b. Los ejemplares tipo de Eumeninae (Hymenoptera: Vespidae) depositados en la colección del Instituto Fundación Miguel Lillo (IFML), Argentina. Revista de la Asociación Entomológica Argentina 64 (3): 23-33.

Dubois A. 2017. The nomenclatural status of Hysaplesia, Hylaplesia, Dendrobates and related nomina (Amphibia, Anura), with general comments on zoological nomenclature and its governance, as well as on taxonomic databases and websites. Bionomina 11:1-48.

Etheridge R. 1995. Redescription of Ctenoblepharys adspersa Tschudi 1845 y the taxonomy of Liolaeminae (Reptilia: Squamata: Tropiduridae). American Museum Novitates 3142, 34 pp.

Etheridge R. 1998. Redescription y status of Liolaemus hatcheri Stejneger, 1909 (Reptilia, Squamata, Tropiduridae). Cuadernos de Herpetologia. 12 [1]: 33-36.

Ferrarezzi H. 1993. Nota sobre o gênero Phalotris com revisão do grupo nasutus e descrição de três novas espécies [Serpentes, Colubridae, Xenodontinae). Memórias do Instituto Butantan, 55 (1):21-38.

Ferrari L., Vaira M. 2008. Análisis comparativo de la estructura del canto de anuncio de tres poblaciones de Melanophryniscus rubriventris (Vellard, 1947). Cuadernos de Herpetología, 22 [1]:25-34.

Franzen M., Glaw F. 2007. Type catalogue of reptiles in the Zoologische Staatssammlung München. Spixiana 30 (2): 201-274

Frost D. R. 2016. Amphibian Species of the World: an Online Reference. Version 6.0 (10 June 2016). Electronic Database accessible at http://research.amnh. org/herpetology/amphibia/index. html. American Museum of Natural History, New York, USA.

Frost D. R., Grant T., Faivovich J., Bain R. H., Haas A., Haddad C. F. B., de Sá R. O., Channing A., Wilkinson M., Donnel- 
Ian S. C., Raxworthy C. J., Campbell J. A., Blotto B. L., Moler P. E., Drewes R. C., Nussbaum R. A., Lynch J. D., Green D. M., Wheeler W. C. 2006. The amphibian tree of life. Bulletin of the American Museum of Natural History 297: 1-370.

Gallardo J. M. 1961. La ubicación sistemática y distribución geográfica de Brachycephalidae Argentinos. 1a Reunión de Trabajos y Comunicaciones de Ciencias Naturales y Geografía del Litoral Argentino, del 27 al 30 de setiembre de 1960:205-212. Santa Fe, Argentina, Universidad Nacional del Litoral.

Grazziotin F.G.; Zaher, H.; Murphy, R.W.; Scrocchi, G.; Benavides, M.A.; Zhang, Y. P, Bonatto, S.L. 2012. Molecular phylogeny of the New World Dipsadidae (Serpentes: Colubroidea): a reappraisal. Cladistics 1: 1-23.

Harvey M. B., Gutberlet R. L. J. 1998. Lizards of the genus Tropidurus IIguania: Tropiduridae) from the Serrania de Huanchaca, Bolivia: new species, natural history and a key to the genus. Herpetologica 54 [4]: 493-520.

Harvey M. B., Ugueto G. N., Gutberlet Jr. R. L. 2012. Review of Teiid Morphology with a Revised Taxonomy y Phylogeny of the Teiidae (Lepidosauria: Squamata). Zootaxa 3459: 1-156.

Hayward K. J. 1963. Lista de los tipos de vertebrados conservados en el Instituto Miguel Lillo. Acta zoologica lilloana 19: 507-510.

Hollis J. L. 2006. Phylogenetics of the genus Chironius Fitzinger, 1826 (Serpentes, Colubridae] based on morphology. Herpetologica 62 (4): 435-453.

International Trust for Zoological Nomenclature. 1999. Código Internacional de Nomenclatura Zoológica. Cuarta Edición. Versión en español. 156 pp.

Köhler J., Koscinski D., Padial J. M., Chaparro J. C., Handford P. S., Lougheed C., De La Riva I.2010. Systematics of Andean gladiator frogs of the Hypsiboas pulchellus species group (Anura, Hylidae). Zoologica Scripta 39 (6): 572-590.

Kretzschmar S. 2006. Revisión histórica y redescripción de Leptotyphlops albipunctus [Serpentes: Leptotyphlopidae]. Cuadernos de Herpetología 19: 43-56.

Langstroth R.P. 2005. Adiciones probables y confirmadas para la saurofauna boliviana. Kempffiana 1 (1): 101-128.

Langone J. A., Lavilla E. 0. 2002. Comentarios nomenclatoriales sobre algunos taxa del grupo de Hyla pulchella (Anura:
Hylidae). Cuadernos de Herpetología 16 (1): 73-78.

Laurent R. F. 1977. Contribución al conocimiento del género Telmatobius Wiegmann [4a nota]. Acta zoologica lilloana 32: 189-206.

Laurent R. F. 1982. Las especies y "variedades" de Liolaemus descritas por J. Koslowsky. Neotrópica 28 (80): 87-96.

Laurent R.F. 1986. Descripciones de nuevos Iguanidae del género Liolaemus. Acta zoologica lilloana 38 (2): 87-105.

Laurent R. F., Terán E. M. 1981. Lista de los anfibios y reptiles de la provincia de Tucumán. Miscelánea. Fundación Miguel Lillo. Tucumán 71: 1-15.

Laurent R. F., Lavilla E. O. 1986. Redescipción de Telmatobius hauthali Koslowsky (Anura: Leptodactylidae) y descripción de una nueva especie del mismo género. Cuadernos de Herpetología 2 (4): $1-24$.

Lavilla E. 0. 1994 "1992". Tipos portadores de nombre y localidades tipo de anfibios de Argentina. Acta zoologica lilloana 42: 61-101.

Lavilla E. O., Barrionuevo J. S. 2005. El género Telmatobius en la República Argentina: una síntesis. In: Lavilla, E. O. y I. De la Riva eds. Estudios sobre las ranas andinas de los géneros Telmatobius y Batrachophrynus (Anura: Leptodactylidae). Monografías de Herpetología, 7:115-165.Valencia, Asociación Herpetológica Española.

Lavilla E. O., Kretzschmar S. 1998. La identificación de los tipos portadores de nombre y localidades tipo de Telmatobius barrioi (Leptodactylidae) y Gastrotheca christiani (Hylidae). Acta zoologica lilloana 44: 219-222.

Lema T. 1984. Sobre o gênero Elapomorphus Wiegmann, 1843 [Serpentes, Colubridae, Elapomorphinae). Iheringia ser. Zoologia 64: 53-86.

Lema T., D'Agostini F. M., Cappelari L. H. 2005. Nova espécie de Phalotris, redescrição de $P$. tricolor e osteologia craniana (Serpentes, Elapomorphinae). Iheringia, Série Zoologia 95: 65-78.

Lobo F., Espinoza R. E., Quinteros S. 2010. A critical review and systematic discussion of recent classification proposals for liolaemid lizards. Zootaxa 2549: 1-30

Lobo F., Laurent R. F. 1995. Un nouveau Liolaemus andin. (Tropiduridae). Revue française d’Aquariologie 22 (3-4): 107116.

McDiarmid, R. W. 1972. La posición sistemática de la rana Atelopus rubri- 
ventris Vellard. Physis 31 (82): 15-21.

Mott T., Vieites D. R. 2009. Molecular phylogenetics reveals extreme morphological homoplasy in Brazilian worm lizards challenging current taxonomy. Molecular Phylogenetics and Evolution 51 (2):190200.

Passos P., Aguayo R., Scrocchi G. 2009. Rediscovery of the rare Atractus bocki, with assessment of the taxonomic status of Atractus canedii (Serpentes: Colubridae: Dipsadinae). Journal of Herpetology 43: 710-715.

Pereyra E. A. 1985. Nuevo iguánido del género Phymaturus del Noroeste Argentino. Boletín Asociación Herpetológica Argentina 2 (4): 3-4.

Pereyra E. 1991. Phymaturus antofagastensis [Pereyra, 1985) (Tropiduridae-Liolaeminae). Ampliación descriptiva. Boletín de la Asociación Herpetológica Argentina 7 [2]: 24-27.

Poynton J. C., Broadley, D. G. 1985. Amphibia Zambesiaca 1. Scolecomorphidae, Pipidae, Microhylidae, Hemisidae, Arthroleptidae. Annals of the Natal Museum 26: 503-553.

Reig, O. A., Limeses, C. E. 1963. Un nuevo género de anuros ceratofrínidos del distrito chaqueño. Physis. Buenos Aires 24: 113-128.

Ribeiro S.; Nogueira C., Cintra C. E., Silva Jr. N. J., Zaher H. 2011. Description of a new pored Leposternon (Squamata,
Amphisbaenidae) from the Brazilian Cerrado. South American Journal of Herpetology 6 (3): 177-188.

Schiøtz A. 1999. Treefrogs of Africa. Frankfurt am Main, Germany. Chimaira Ed.

Uetz P., Freed, P., Jirí Hosek (eds.), The Reptile Database, http://www.reptile-database.org, accessed [24 April 2017].

Vaira M. 2002. Variación de la coloración en poblaciones argentinas de Melanophryniscus rubriventris (Vellard, 1947). Cuadernos de Herpetología 16 (2):151163.

Valetti J. A., Salas N. E., Martino A. L. 2009. A new polyploid species of Pleurodema (Anura: Leiuperidae) from Sierra de Comechingones, Córdoba, Argentina y redescription of Pleurodema kriegi (Muller, 1926). Zootaxa 2073: 1-21.

Vellard J. 1947. Leptodactylus laticeps Blgr. un raro batracio del chaco argentino. Acta zoologica lilloana IV: 463-491.

Wallach V., Williams K. L., Boundy J. 2014. Snakes of the World: A catalogue of living y extinct species. Taylor y Francis, CRC Press, 1237 pp.

Zaher H., Grazziotin, F. G., Cadle J. E., Murphy R. T. W., Moura-Leite J. C., Bonato S. L. 2009. Molecular phylogeny of advanced snakes (Serpentes, Caenophidia) with an emphasis on South American Xenodontines: a revised classification y descriptions of new taxa. Papéis Avulsos de Zoologia, São Paulo 49: 115-153. 